\title{
jpen
}

AUTARQUIA ASSOCIADA À UNIVERSIDADE DE SÃO PAULO

TEXTURIZAÇÃO EM SUPERFÍCIES DE TITÂNIO GRAU 2 IRRADIADAS COM LASER DE PULSOS ULTRACURTOS

Alessandro Francelino Nogueira

Dissertação apresentada como parte dos requisitos para obtenção do Grau de Mestre em Ciências na Área de Tecnologia Nuclear - Materiais

Orientador:

Prof. Dr. Wagner de Rossi 


\title{
INSTITUTO DE PESQUISAS ENERGÉTICAS E NUCLEARES
}

Autarquia associada à Universidade de São Paulo

\section{TEXTURIZAÇÃO EM SUPERFÍCIES DE TITÂNIO GRAU 2 IRRADIADAS COM LASER DE PULSOS ULTRACURTOS}

Alessandro Francelino Nogueira

\begin{abstract}
Dissertação apresentada como parte dos requisitos para obtenção do Grau de Mestre em Ciências na Área de Tecnologia Nuclear - Materiais

Orientador:

Prof. Dr. Wagner de Rossi
\end{abstract}

Versão Corrigida

Versão Original disponível no IPEN

São Paulo

2015 
Dedico à minha Nani, pelas horas de estudos dedicadas, pelas ausências necessárias e acima de tudo pela compreensão e amor. Aos meus pais pelos constantes incentivos durante toda minha trajetória pessoal e profissional. Aos meus familiares, amigos e à todos aqueles que sempre estiveram e estão próximos nos bons a maus momentos da vida. Ao Irineu e Lourdes Carta pelo exemplo de superação e por estarem tão presentes em nossas vidas. Ao meu filho João Victor que é uma dádiva de Deus em minha vida e de minha esposa. 


\section{AGRADECIMENTOS}

Agradeço por tudo que acontece em minha vida, a tudo aquilo que me acontece em todos os momentos. Agradeço pelos erros que cometi, pois são com eles que hoje aprendo. Agradeço a todas as minhas desilusões, pois são com elas que hoje vejo tudo de forma mais coerente. Agradeço acima de tudo pela vida que Deus me deu de presente.

Agradeço ao meu orientador Dr. Wagner de Rossi pela atenção, paciência e ótima orientação.

Ao CTMSP da Marinha do Brasil por permitir as ausências de expediente normal de trabalho para a dedicação da realização do mestrado.

Ao IPEN por oferecer toda a infraestrutura necessária para o desenvolvimento deste trabalho.

Ao Dr. Ricardo Elgul Samad e ao Dr. Nilson Dias Vieira Junior pela utilização da infraestrutura do laboratório e pela valiosa colaboração com o projeto.

Ao Dr. Marcus Paulo Raele pela colaboração na realização dos experimentos utilizando laser de nanossegundos.

Ao Dr. Nelson Batista de Lima pela colaboração na realização de análises de DRX na estrutura do CCTM-IPEN.

Ao Dr. Milton Sergio Fernandes de Lima pela colaboração na colagem das amostras no IEAv-CTA e pela contribuição ao trabalho. 


\section{TEXTURIZAÇÃO EM SUPERFÍCIES DE TITÂNIO GRAU 2 IRRADIADAS COM \\ LASER COM PULSOS ULTRACURTOS}

\section{Alessandro Francelino Nogueira}

\section{RESUMO}

A texturização por microusinagem a laser é uma importante alternativa para que se consiga melhorar a ligação de aderência entre materiais compósitos e o titânio, aplicados em componentes estruturais na indústria aeronáutica. A execução de texturização em chapas de titânio deve-se ao fato de que a técnica de junção preferida para muitos materiais compósitos é a ligação adesiva.

Neste trabalho foram realizadas texturizações em chapas de titânio utilizando laser com pulsos ultracurtos de largura temporal da ordem de femtossegundos. Tal processo resultou em mínima transferência de calor para o material, evitando assim deformação superficial da chapa de titânio bem como a formação de material ressolidificado na região ablacionada. Estes inconvenientes ocorreram na utilização do laser chaveado com pulsos de nanossegundos.

Foram executadas três tipos de texturizações utilizando laser com pulsos de femtossegundos, com variações nas distâncias entre as linhas usinadas. Pela análise das superfícies obtidas, detectou-se que a molhabilidade aumenta quando há o aumento da distância entre as linhas da texturização. Avançando nas análises, pela perfilometria óptica das superfícies texturizadas observou-se que há sensível aumento do volume disponível para penetração do adesivo estrutural quando são diminuídas as distâncias entre as linhas texturizadas. Nos ensaios de tração realizados observou-se que há o aumento da resistência ao cisalhamento da junta adesiva com a diminuição da distância entre as linhas texturizadas. 


\title{
TEXTURING IN TITANIUM GRADE 2 SURFACE IRRADIATED WITH ULTRASHORT PULSE LASER
}

\section{Alessandro Francelino Nogueira}

\begin{abstract}
The texturing laser micromachining is an important alternative to improve the bonding adhesion between composites and titanium, which are applied to structural components in the aerospace industry. The texturing running on titanium plates is due to the fact that the preferred joining technique for many composite materials is the adhesive bonding.

In this work, titanium plates were texturized using laser ultrashort pulses temporal widths of femtoseconds. This process resulted in minimal heat transfer to the material, avoiding deformation of the titanium plate surface as well as the formation of resolidified material in the ablated region. These drawbacks have occurred with the use of nanoseconds pulses.

Were performed three types of texturing using laser with femtosecond pulses, with variations in the distances between the machined lines. The analysis of the obtained surfaces found that the wettability increases when there is the increased distance between the texturing lines. Advancing in the analysis by optical profilometry of textured surfaces was observed that there is substantial increase in the volume available for penetration of structural adhesive when the distances between the textured lines are diminished. In tensile tests conducted it was observed that there is an increase in shear strength of the adhesive joint by reducing the distance between the textured lines.
\end{abstract}




\section{SUMÁRIO}

INTRODUCÃO Pagina

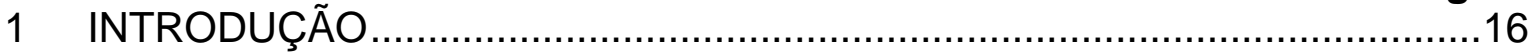

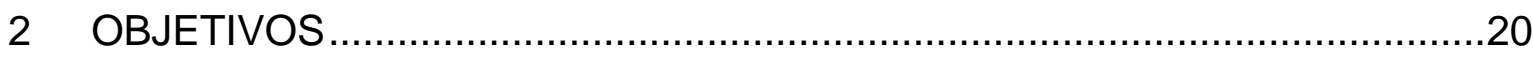

3 REVISÃO DA LITERATURA ………………………………………….....21

3.1 Microusinagem utilizando laser ...........................................................21

3.2 Laser com pulsos de nanossegundos..................................................2

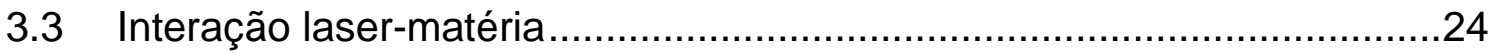

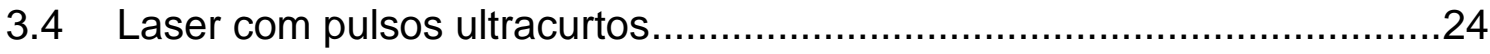

3.4.1 Irradiação de materiais com laser com pulsos ultracurtos …..............25

3.4.2 Escalas de tempo na irradiação com laser com pulsos ultracurtos ...29

3.5 A ablação por laser com pulsos ultracurtos ...........................................30

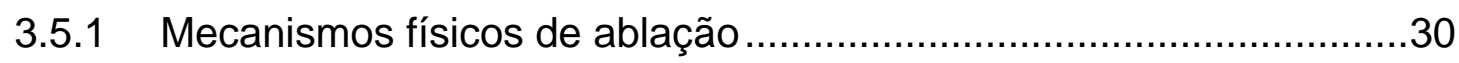

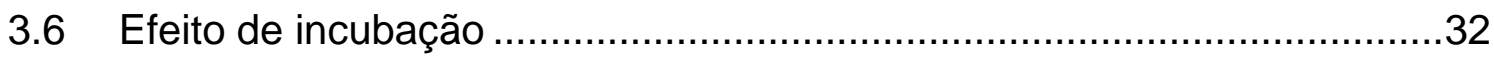

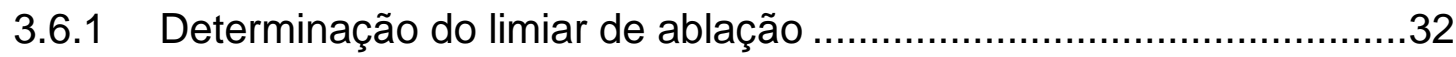

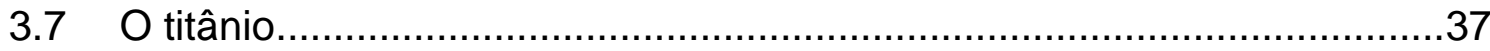

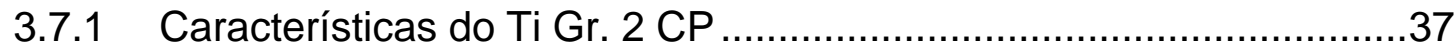

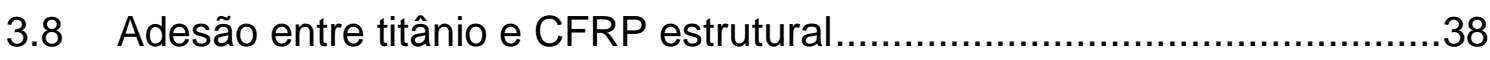

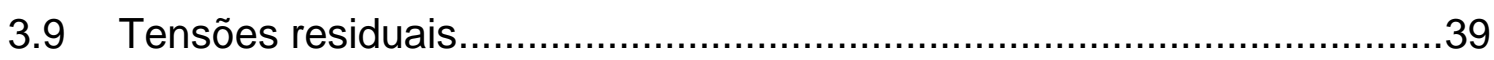

3.9.1 Tensões Residuais Macroscópicas (Tipo I) ....................................39

3.9.2 Tensões Residuais Microscópicas (Tipo II) ......................................39

3.9.3 Tensões Residuais Submicroscópicas (Tipo III) ……………….........39

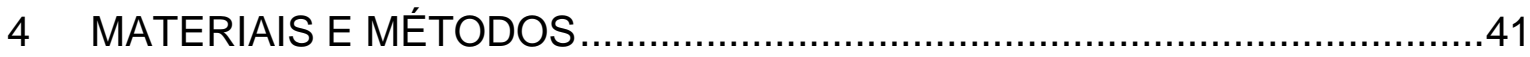

4.1 Laser com pulsos de nanossegundos ................................................... 41

4.2 Laser com pulsos ultracurtos e sistema de entrega do feixe ....................41

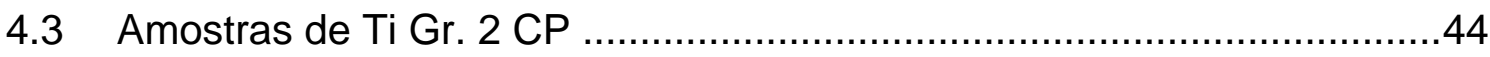

4.4 Texturização de chapas de Ti Gr. 2 CP com espessura de $0,1 \mathrm{~mm}$ utilizando laser com pulsos de nanossegundos .............................................44

4.5 Amostras para realização dos métodos Dano Zero e D-Scan...................45

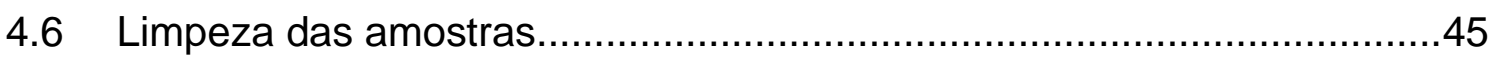

4.7 Determinação do limiar de ablação pelo método Dano Zero.....................45

4.8 Determinação do limiar de ablação pelo método D-Scan..........................48

4.9 Texturização de chapas de Ti Gr. 2 CP com espessura de $0,1 \mathrm{~mm}$

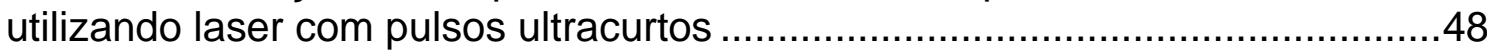

4.10 Texturização em amostras de $2 \mathrm{~mm}$ de espessura ..............................50

4.11 Microscopia eletrônica de varredura (MEV) .......................................50

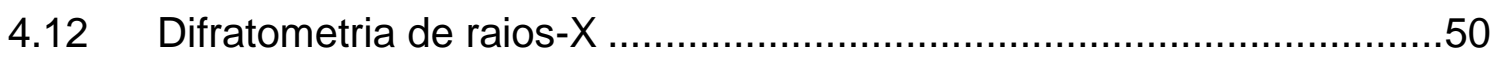

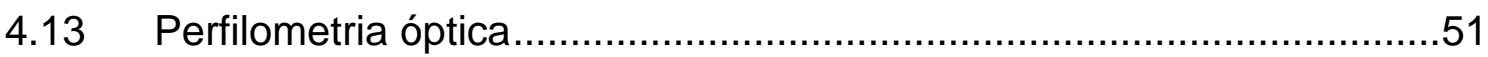




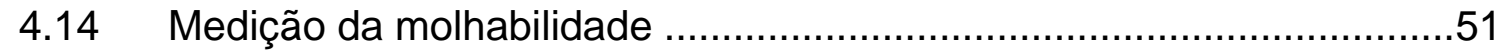

4.15 Junção por adesão das amostras de Ti Gr.2 CP e CFRP ....................52

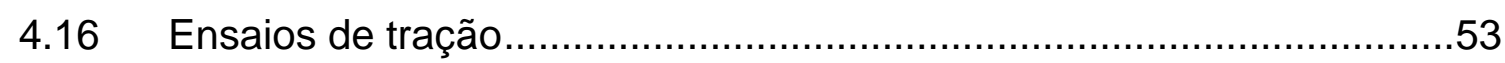

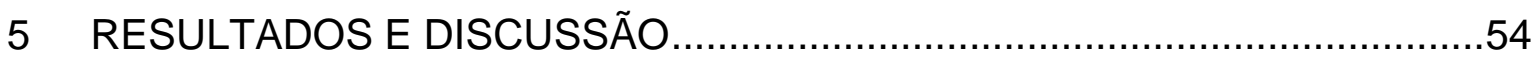

5.1 Texturização de chapas de Ti Gr. 2 CP com espessura de $0,1 \mathrm{~mm}$ utilizando laser com pulsos de nanossegundos .............................................54

5.2 Difratometria de raios-X (DRX) em amostra de $0,1 \mathrm{~mm}$ de espessura texturizada por laser com pulsos de nanossegundos........................................58

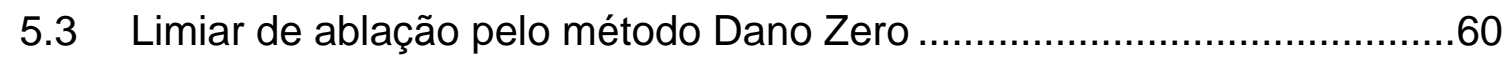

5.4 Limiar de ablação pelo método D-Scan ...............................................68

5.5 Texturização de chapas de Ti Gr. 2 CP com espessura de $0,1 \mathrm{~mm}$ utilizando laser com pulsos ultracurtos .........................................................

5.6 Texturização em amostras de $2 \mathrm{~mm}$ de espessura ................................80

5.7 Difratometria de raios-X (DRX) em amostras de $2,0 \mathrm{~mm}$ de espessura texturizadas com laser com pulsos ultracurtos ...................................................83

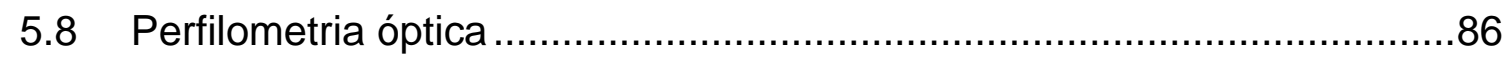

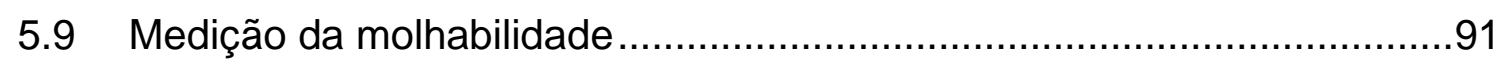

5.10 Junção por adesão das amostras de Ti Gr.2 CP e CFRP .....................95

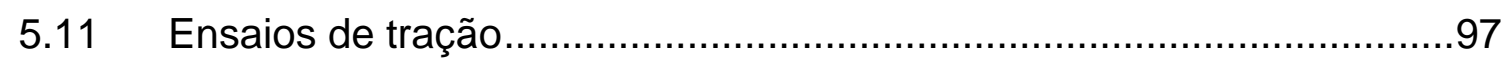

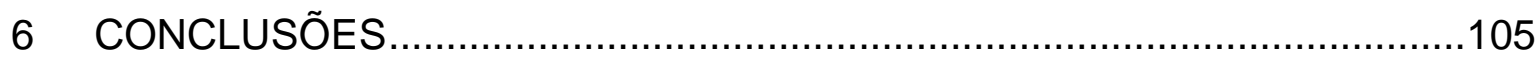

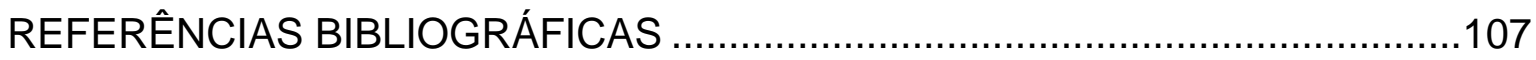




\section{LISTA DE TABELAS}

TABELA 1 - Proporcionalidade para o coeficiente de absorção (A) ......................24

TABELA 2 - Composição química para o Ti Gr. 2 CP .........................................4

TABELA 3 - Limites de tensão para o Ti Gr. 2 CP ………............................... 44

TABELA 4 - Parâmetros utilizados para texturização de amostras de Ti Gr. 2 por laser com pulsos de nanossegundos. .54

TABELA 5 - Diâmetro do foco calculado a partir dos dados do laser utilizado.....54 TABELA 6 - Valores de rugosidade $\mathrm{Ra}(\mu \mathrm{m})$ das amostras de Ti Gr. 2 CP para realização dos métodos Dano Zero e D-Scan

TABELA 7 - Fluências de energia por pulso para usinagem de matrizes para determinação do limiar de ablação (Dano Zero)

TABELA 8 - Valores medidos de $D^{2}\left(\mu m^{2}\right)$ pelo software ImageJ das imagens obtidas

TABELA 9 - Valores dos limiares de ablação do Ti Gr.2 CP para cada sobreposição de pulsos

TABELA 10 - Parâmetros para texturizações nas chapas de 0,1 mm utilizando laser com pulsos ultracurtos

TABELA 11 - Parâmetros para microusinagem de traços nas chapas de 0,1 mm

TABELA 12 - Parâmetros para texturizações nas chapas de 0,1 mm de espessura

TABELA 13 - Parâmetros para texturizações em amostras de 2 mm de espessura

TABELA 14 - Valores do perímetro e volume específicos para as três geometrias de texturização realizadas

TABELA 15 - Valores do perímetro e volume específicos para as três geometrias de texturização realizadas

TABELA 16 - Valores do ângulo de contato da gota para mensuração da molhabilidade

TABELA 17 - Áreas de colagem e Tensão de ruptura ao cisalhamento 101 TABELA 18 - Médias e desvios padrões dos resultados da tensão de ruptura ao cisalhamento 


\section{LISTA DE FIGURAS}

Página

FIGURA 1 - Imagens esquemáticas de dois regimes de aquecimento com pulsos

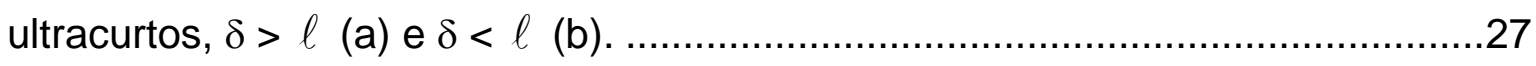

FIGURA 2 - Escala de tempo dos vários processos secundários.........................29 FIGURA 3 - Relação entre o diâmetro ao quadrado $D^{2}$ do dano formado em silício por um pulso laser com fluência $F_{0}$

FIGURA 4 - a) Esquema da técnica D-Scan; b) perfil gravado na superfície da amostra pelo movimento diagonal em posição através da cintura do feixe. 36 FIGURA 5 - Arranjo do laser e do sistema óptico de entrega do feixe e visualização. 43

FIGURA 6 - Mesa de trabalho com movimentação $X$, Y via CNC e $Z$ manual; e arranjo óptico do sistema de entrega do feixe e visualização. 43

FIGURA 7 - Geometria das texturizações em zig-zag executadas nas chapas de $0,1 \mathrm{~mm}$.

FIGURA 8 - llustração das matrizes usinadas para o método Dano Zero. Todos os seis pontos de cada linha contém o mesmo número $\mathrm{N}$ de pulsos sobrepostos. $\mathrm{N}$ varia para a coluna e a energia é a mesma para todos os pontos da matriz.....48 FIGURA 9 - llustração esquemática da gaussiana de um feixe laser (a) e o dano causado na superfície do material (b). .50

FIGURA 10 - Dimensões da norma ASTM D1002-1 e adotadas neste trabalho..52 FIGURA 11 - Imagem do ensaio de tração em conjunto de amostras coladas. ...53 FIGURA 12 - Imagens de chapa de 0,1 mm de espessura texturizada por laser com pulsos de nanossegundos. Rebarbas são observadas devido ao corte da chapa

FIGURA 13 - Imagem de MEV de chapa de 0,1 mm de espessura texturizada por laser com pulsos de nanossegundos. Aumento de 50x.

FIGURA 14 - Imagem de MEV de chapa de 0,1 mm de espessura texturizada por laser com pulsos de nanossegundos. Aumento de 30x.

FIGURA 15 - Imagem de MEV de chapa de 0,1 mm de espessura texturizada por laser com pulsos de nanossegundos. Aumento de 200x. 
FIGURA 16 - Imagem de MEV de chapa de 0,1 mm de espessura texturizada por laser com pulsos de nanossegundos. A texturização foi executada na direção vertical. Aumento de 600x.

FIGURA 17 - Imagem de MEV de chapa de 0,1 mm de espessura texturizada por laser com pulsos de nanossegundos (a). Gráfico da topografia da imagem (b)....58 FIGURA 18 - DRX de chapa de 0,1 mm de espessura texturizada por laser com pulsos de nanossegundos .59

FIGURA 19 - Imagem de MEV da matriz 08 para determinação do limiar de ablação (Dano Zero). As colunas mais externas à direita e à esquerda não fazem parte da matriz, são apenas guias para posicionamento das linhas onde não se tem fluência suficiente para fácil visualização dos danos. Aumento de 120x

FIGURA 20 - Imagem do software ImageJ para dois pontos da linha 8 da matriz 05. Aumento de 1.200x

FIGURA 21 - Gráfico $F_{0} \times D^{2}$ para somente 1 pulso (sem sobreposição) pelo método Dano Zero.

FIGURA 22 - Gráfico $F_{0} \times D^{2}$ para sobreposição de 1024 pulsos pelo método Dano Zero.

FIGURA 23 - Gráfico da fluência em função do número de pulsos sobrepostos $\left(F_{\text {th }} \times N\right)$ para o método Dano Zero (regime de baixa fluência). .66 FIGURA 24 - Gráfico da fluência em função do número de pulsos sobrepostos $\left(F_{\text {th }} \times N\right)$ para o método Dano Zero (regime de alta fluência). .66 FIGURA 25 - Imagem de MEV no software 3D-Viewer para análise topográfica da superfície texturizada da matriz 5 e uma sobreposição de 1024 pulsos. Aumento de $1200 x$.

FIGURA 26 - Imagem em MEV dos traços ablacionados na amostra de Ti Gr. 2 CP pelo método D-Scan. Aumento de 20x.

FIGURA 27 - Gráfico da fluência em função do número de pulsos sobrepostos para o método D-Scan (regime de baixa fluência).

FIGURA 28 - Gráfico da fluência em função do número de pulsos sobrepostos para o método D-Scan (regime de alta fluência).

FIGURA 29 - Imagem de MEV da texturização 1 na chapa de 0,1 mm de espessura. Texturização na direção vertical. Aumento de 300x (a) e aumento de $1.200 x(b)$. 
FIGURA 30 - Imagem de MEV da texturização 2 na chapa de 0,1 mm de espessura. Texturização na direção vertical. Aumento de 1.000x (a) e aumento de $1.800 \times(b)$.

FIGURA 31 - Imagem de MEV da texturização 4 na chapa de 0,1 mm de espessura. Texturização na direção vertical. Aumento de 800x (a) e aumento de $1.800 x(b)$ .72

FIGURA 32 - Texturização 1 na chapa de 0,1 mm de espessura vista de topo (a) e vista de perfil (b) .73

FIGURA 33 - Traços de 1 a 6 em chapa de 0,1 $\mathrm{mm}$ de espessura. .74 FIGURA 34 - Imagem de MEV dos traços de 1 a 6 em chapa de 0,1 mm de espessura. Aumento de 40x. 75

FIGURA 35 - Imagens de MEV dos traços 1, 2 e 3 (a) e dos traços 4, 5 e 6 (b). Aumento de 150x. .75

FIGURA 36 - Imagens de MEV dos traços 1 (a) 2 (b). Aumento de 600x. .76 FIGURA 37 - Imagens de MEV dos traços 3 (a) e 4 (b). Aumento de 600x. .76

FIGURA 38 - Imagens de MEV dos traços 5 (a) 6 (b). Aumento de 600x. .76 FIGURA 39 - Imagem de MEV das texturizações 01, 02 e 03 com geometrias zigzag cruzadas em chapa de 0,1 mm de espessura. Aumento de 40x. .78 FIGURA 40 - Imagem de MEV da texturização 01 com geometria zig-zag cruzada em chapa de 0,1 mm de espessura. Aumentos de 300x, 800x e 1.800x. .79 FIGURA 41 - Imagem de MEV da texturização 02 com geometria zig-zag cruzada em chapa de 0,1 mm de espessura. Aumentos de 150x, 800x e 1.200x. .79 FIGURA 42 - Imagem de MEV da texturização 03 com geometria zig-zag cruzada em chapa de 0,1 mm de espessura. Aumentos de 400x, 800x e 1.200x. FIGURA 43 - Imagens de MEV em três dimensões da texturização 01 através do software 3D-Image Viewer. .80

FIGURA 44 - Imagens de MEV em três dimensões da texturização 01 através do software 3D-Image Viewer.

FIGURA 45 - Geometria das texturizações em zig-zag executadas nas chapas de $2,0 \mathrm{~mm}$.

FIGURA 46 - Imagem de MEV da texturização 01 com passo $75 \mu \mathrm{m}$, energia 105 $\mu \mathrm{J}$ e velocidade $35 \mathrm{~mm} / \mathrm{min}$ em chapa de $2,0 \mathrm{~mm}$ de espessura. Aumentos de $40 x, 100 x$ e 200x. .82 
FIGURA 47 - Imagem de MEV da texturização 02 com passo $100 \mu \mathrm{m}$, energia 15 $\mu \mathrm{J}$ e velocidade $5 \mathrm{~mm} / \mathrm{min}$ em chapa de 2,0 mm de espessura. Aumentos de 30x, 100x e 200x

FIGURA 48 - Imagem de MEV da texturização 02 com passo $100 \mu \mathrm{m}$, energia $105 \mu \mathrm{J}$ e velocidade $35 \mathrm{~mm} / \mathrm{min}$ em chapa de 2,0 mm de espessura. Aumentos de 40x, 100x e 200x.

FIGURA 49 - Imagem de MEV da texturização 03 com passo $200 \mu \mathrm{m}$, energia 15 $\mu \mathrm{J}$ e velocidade $5 \mathrm{~mm} / \mathrm{min}$ em chapa de 2,0 mm de espessura. Aumentos de 30x, $100 x$ e $200 x$

FIGURA 50 - Imagem de MEV da texturização 03 com passo $200 \mu \mathrm{m}$, energia $105 \mu \mathrm{J}$ e velocidade $35 \mathrm{~mm} / \mathrm{min}$ em chapa de 2,0 mm de espessura. Aumentos de 40x, 100x e 200x. .83

FIGURA 51 - Difratograma de raios-X em amostra com a texturização 01. .84

FIGURA 52 - Difratograma de raios-X em amostra com a texturização 03. .84

FIGURA 53 - Difratograma de raios-X em amostra com a texturização 03. .85

FIGURA 54 - Perfilometria da amostra 3 da texturização 01. .86

FIGURA 55 - Perfilometria da amostra 3 da texturização 02. .87

FIGURA 56 - Perfilometria da amostra 3 da texturização 03. .87

FIGURA 57 - Detalhe das células unitárias da amostra 3 da texturização 03.....88 FIGURA 58 - Perfil da microusinagem para determinação do perímetro e volume específicos da texturização 03.

FIGURA 59 - Detalhe das linhas limitadoras das células unitárias no perfil da microusinagem da texturização 03.

FIGURA 60 - Linha para obtenção do perímetro específico da célula unitária da texturização 03 (a) e área específica da célula unitária para determinação do volume específico (b). .89

FIGURA 61 - Perfilometria da amostra 3 da texturização 01 sem texturização....91 FIGURA 62 - Imagem do perfil da gota para medição da molhabilidade pelo método da gota séssil na texturização 01 .

FIGURA 63 - Imagem do perfil da gota para medição da molhabilidade pelo método da gota séssil na texturização 02 . .92 FIGURA 64 - Imagem do perfil da gota para medição da molhabilidade pelo método da gota séssil na texturização 03 . 
FIGURA 65 - Imagem do perfil da gota para medição da molhabilidade pelo método da gota séssil em amostra sem texturização.

FIGURA 66 - Imagem do perfil da gota na texturização 03 no software Image J linhas representam as referências para determinação do ângulo de contato pelo método da gota séssil.

FIGURA 67 - Amostras de Ti Gr.2 CP sem textura coladas às amostras de CFRP-

a) Vista de topo; b) vista de perfil mostrando a adesão ineficiente. .96 FIGURA 68 - Amostras coladas a) Texturização 01 amostra 2; b) Texturização 02 amostra 3A; c) Texturização 03 amostra 2

FIGURA 69 - Imagem de MEV após ruptura por cisalhamento da amostra 3 da texturização 01 no Ti Gr. 2 CP. Aumento de 100x.

FIGURA 70 - Imagem de MEV após ruptura por cisalhamento da amostra 3 da texturização 01 no Ti Gr. 2 CP. Aumento de 600x. .98

FIGURA 71 - Imagem de MEV após ruptura por cisalhamento da amostra 3 da texturização 01 no Ti Gr. 2 CP. Aumento de 1000x. .98

FIGURA 72 - Imagem de MEV após ruptura por cisalhamento da amostra 1 da texturização 02 no Ti Gr. 2 CP. Aumento de 100x.

FIGURA 73 - Imagem de MEV após ruptura por cisalhamento da amostra 1 da texturização 02 no Ti Gr. 2 CP. Aumento de 300x. .99 FIGURA 74 - Imagem de MEV após ruptura por cisalhamento da amostra 1 da texturização 03 no Ti Gr. 2 CP. Aumento de 30x. 100

FIGURA 75 - Imagem de MEV após ruptura por cisalhamento da amostra 1 da texturização 03 no Ti Gr. 2 CP. Aumento de 200x. 100 FIGURA 76 - Imagem de MEV após ruptura por cisalhamento da amostra 1 da texturização 03 no Ti Gr. 2 CP. Aumento de 200x. 102 FIGURA 77 - Imagem de MEV de linha realizada no método D-Scan com fluência de energia por pulso e sobreposição similares às condições das texturizações. Aumento de 200x. 103 


\section{LISTA DE ABREVIATURAS, SIGLAS E SÍMBOLOS}

$\begin{array}{ll}\text { Ar } & \text { Gás inerte argônio } \\ \text { ASTM } & \text { "American Society for Testing and Materials" - Sociedade } \\ & \text { Americana para testes e materiais } \\ \text { CCC } & \text { Estrutura cristalina cúbica de corpo centrado } \\ \text { CCTM-IPEN } & \text { Centro de Ciência e Tecnologia de Materiais do Instituto de } \\ & \text { Pesquisas Energéticas e Nucleares } \\ \text { CEA } & \text { Centro Experimental Aramar } \\ \text { CNC } & \text { Controle Numérico Computadorizado } \\ \text { CLA-IPEN } & \text { Centro de Lasers e Aplicações do Instituto de Pesquisas } \\ \text { CFRP } & \text { Energéticas e Nucleares } \\ \text { CTMSP } & \text { "Carbon fiber-reinforced polymer" - Polímero reforçado com fibra } \\ \text { D-Scan } & \text { Centro Tecnológico da Marinha em São Paulo } \\ \text { DRX } & \text { Diagonal Scan } \\ \text { fs } & \text { Difratometria de raios-x } \\ \text { HC } & \text { Femtossegundo(s) } \\ \text { IEAv-CTA } & \text { Estrutura cristalina hexagonal compacta } \\ \text { IPEN } & \text { Instituto de Estudos Avançados do Centro Técnico Aeroespacial } \\ \text { LABMAT } & \text { Instituto de Pesquisas Energéticas e Nucleares } \\ \text { Laboratório de Materiais Nucleares do Centro Experimental } & \text { Aramar do Centro Tecnológico da Marinha em São Paulo } \\ \text { pm } & \text { Micrometro } \\ \text { MDT } & \text { Modelo de duas temperaturas } \\ \text { MEV } & \text { Microscópio eletrônico de varredura } \\ \text { mm } & \text { Milímetro } \\ \text { Nd:YAG } & \text { "Neodymium-doped yttrium aluminium garnet" } \\ \text { nm } & \text { Nanômetro } \\ & \text { Nanossegundo(s) } \\ \text { "Powder Diffraction File" - Fichas de difração do pó }\end{array}$


Ti Gr. 2 CP Titânio grau 2 comercialmente puro

$\mathrm{Yb}$

Itérbio

ZTA

Zona termicamente afetada 


\section{INTRODUÇÃo}

A microusinagem tem aplicações voltadas para diversos segmentos industriais, tais como a indústria aeroespacial e aeronáutica, equipamentos médicos, microeletrônica, automotiva, além de utilização em micromotores, circuitos microfluídicos, micro sistemas eletro mecânicos, dispositivos médicos, ferramentas eletrônicas, filtros de partículas, micromoldes e microválvulas, entre outros. Contudo, o crescimento irreversível das aplicações exige ainda um grande desenvolvimento e pesquisas científicas [1].

A substituição de fios de cobre por fibras ópticas para controle e monitoramento de sistemas de aeronaves é cada vez mais empregada, devido às reduções de peso e da sua intrínseca confiabilidade. Desta forma, há a necessidade de elaboração de orientações de fibras ópticas em polímeros reforçados com fibra de carbono (CFRP). No entanto, deve-se efetuar a ligação destes materiais com os elementos estruturais embarcados, principalmente em ligas de titânio (Ti) [2]. Assim, texturizações com laser são uma importante alternativa para que se consiga melhorar a ligação de aderência entre o CFRP e o titânio. Devido à elevada resistência específica do titânio, são empregadas chapas de pequenas espessuras como partes de elementos estruturais, sendo então de preponderante importância que os processos de microusinagem para confecção das texturizações sejam controlados e impeçam danos ao titânio.

A execução de texturização nas chapas de titânio grau 2 comercialmente puro (Ti Gr. $2 \mathrm{CP}$ ) deve-se ao fato de que a técnica de junção preferida para o CFRP é a ligação adesiva. Atualmente, a junção por adesão de CFRP em titânio é um problema que ainda não foi totalmente resolvido e é alvo de vários estudos. Foi evidenciado neste trabalho que a adesão do CFRP ao Ti Gr. 2 CP sem texturização não foi bem sucedida, visto que a junta não apresentou tenacidade suficiente e decorridas 24 horas após o processo de colagem as partes se desprenderam espontaneamente.

Pesquisas anteriores mostraram que a resistência pode ser significativamente melhorada por tratamento de superfície dos aderentes antes da colagem. No entanto, muitos dos tratamentos de superfície bem sucedidos envolvem o uso de produtos químicos perigosos, que devem ser eliminados como 
parte de uma diretiva da União Europeia, o que abre caminho para métodos respeitadores do ambiente e menos tóxicos [3].

Como resultado, a natureza da superfície influencia a estabilidade da junta colada. Quando exposto a condições com ambiente quente e úmido, a interface adesivo polimérico-polímero é muito mais estável que a interface adesivo polimérico-metal [3]. Por isto a necessidade de se efetuar um tratamento na superfície do titânio, de forma a promover o aumento da rugosidade da superfície, o que acarreta uma redução na molhabilidade e um aumento na energia de superfície, proporcionando uma maior eficiência na adesão [4].

Um importante fator que influencia a precisão na microusinagem a laser é a zona termicamente afetada (ZTA), que se estende além da região de interação do pulso laser e é responsável por uma transformação de fase alterando as propriedades do material colateralmente [5]. O efeito colateral termodinâmico é intrínseco ao processo de ablação quando são utilizados pulsos mais longos que dezenas de picossegundos, sendo este o caso de lasers comuns utilizados para produzir texturas que têm largura temporal da ordem de dezenas de nanossegundos. Contudo este fator pode ser minimizado depositando-se a energia de forma rápida, através de pulsos ultracurtos (dezenas de femtossegundos), ablacionando assim o material antes que ocorra a difusão do calor e afete a vizinhança da região de interação [5; 6].

A técnica de amplificação de pulsos com varredura de frequência, ou "Chirped Pulse Amplification", foi desenvolvida por Strickland e Mourou [7], e em consequência Keller [8] utilizou lasers de estado sólido bombeados por diodo permitindo o uso de pulsos ultracurtos com energias da ordem de micro e milijoules ( $\mu \mathrm{J}$ e $\mathrm{mJ}$ ), podendo esses lasers produzir pulsos de femtossegundos e intensidades da ordem de $10^{13}$ a $10^{14} \mathrm{~W} / \mathrm{cm}^{2}$ [1].. Atualmente os principais tipos de laser ultracurtos utilizados para microusinagem são o Ti:Safira e o Itérbio:Fibra (Yb:Fibra). Os sistemas de Ti:Safira são capazes de produzir pulsos com poucas dezenas de femtossegundos, centrados em $800 \mathrm{~nm}$, com energias da ordem de $\mathrm{mJ}$, e taxas de repetição acima de poucos $\mathrm{kHz}$, enquanto que os lasers baseados em Yb:Fibra geram pulsos centrados em $1030 \mathrm{~nm}$ com duração de centenas de femtossegundos e energia limitada no intervalo de poucos $\mu \mathrm{J}$, operando com taxas de repetição no intervalo de $\mathrm{MHz}$. Esta maior taxa de repetição permite, contudo maiores velocidades de microusinagem por este tipo de laser $[1 ; 9]$. 
Uma das principais características destes pulsos, quando são usados para a microusinagem, é a pequena ZTA, devido à dinâmica particular de absorção e ablação gerada por esses pulsos ultracurtos e ultraintensos [10]. O processo de interação da radiação com a matéria envolve muitos fenômenos que ocorrem em diferentes escalas de tempo, desde femtossegundos até nanossegundos [10]. Os pulsos ultracurtos permitiram uma interação determinística com um limiar de ablação bem definido, porém, o limiar de ablação não depende apenas das características do pulso laser e do tipo de material ablacionado [11]. A absorção do pulso também depende da presença de defeitos na estrutura cristalina desses materiais [11]. A pré-irradiação por um pulso laser num material, mesmo que abaixo do limiar de dano, pode criar defeitos na rede cristalina [11]. Esse processo é chamado de efeito de incubação e é responsável pela diminuição do limiar de dano em materiais pré-irradiados [11].

O pulso laser de femtossegundos apresenta uma largura temporal muito mais curta que o tempo de interação elétron-fonon, e por este motivo, uma grande quantidade de material pode ser ablacionada antes que a maior parte da energia do feixe de luz seja transferida para a rede cristalina e aqueça o material.

A utilização de lasers com o intuito de texturizar superfícies de ligas de titânio para aderência de CFRP estrutural aeronáutico até então utilizada baseiase em lasers chaveados de Nd:YAG (Neodymium-doped yttrium aluminium garnet) com pulsos de largura temporal de algumas dezenas de nanossegundos. Neste caso, contudo, o calor produzido pela interação com os pulsos laser causa uma deformação muito grande quando da utilização de chapas muito finas, além de que a região texturizada não proporciona a aderência desejada em virtude do material ressolidificado não proporcionar uma rugosidade adequada. Assim, surge a necessidade de se obter tal textura sem a produção colateral de calor, o que pode ser conseguido com a utilização de laser com pulsos ultracurtos como o disponível nos laboratórios do CLA-IPEN.

O processo de texturização superficial de materiais exige a sobreposição de pulsos para que a quantidade de material necessária seja removida. Assim o limiar de ablação e o parâmetro de incubação são parâmetros importantes para a microusinagem e devem ser previamente conhecidos. Nesse contexto, este trabalho teve seu foco na realização de experimentos impondo 
alterações nas variáveis fluência, taxa de repetição e parâmetros de incubação pela sobreposição de pulsos.

Para obter a condição de mínima transferência de calor para o material, parâmetros adequados de processo precisam ser utilizados. Assim, a fluência deve estar acima do limiar de ablação para o material. Portanto, o início do trabalho concentrou-se na obtenção dos regimes de baixa e de alta fluência, para posteriormente microusinagem da texturização com parâmetros de processo adequados ao material. Para a medida do limiar de ablação e o parâmetro de incubação, duas técnicas experimentais foram utilizadas. Primeiramente, uma técnica bem conhecida para medir o limiar de ablação, de pulsos únicos e sobrepostos, chamada Técnica do Dano Zero introduzida por Liu [12]. A segunda técnica foi a Diagonal Scan (D-Scan), introduzida por Samad e Vieira [13] e caracteriza-se pela simplicidade prática e analítica comparativamente com a primeira.

Os experimentos foram desenvolvidos no Laboratório de Lasers de Altíssima Intensidade do Centro de Lasers e Aplicações do Instituto de Pesquisas Energéticas e Nucleares (CLA-IPEN), com a utilização de pulsos laser de femtossegundos. 


\section{OBJETIVOS}

Este trabalho teve como objetivo a produção de texturização a laser em chapas de titânio Gr. 2 CP de $0,1 \mathrm{~mm}$ de espessura com características adequadas à adesão com CFRP estrutural que são utilizados na proteção de componentes eletrônicos aeronáuticos.

Para a obtenção deste objetivo foram estabelecidas as seguintes metas:

i. Produzir texturas em chapas de $0,1 \mathrm{~mm}$ de espessura utilizando laser chaveado com pulsos de nanossegundos.

ii. Produzir texturas em chapas de $0,1 \mathrm{~mm}$ de espessura utilizando laser com pulsos ultracurtos.

iii. Medir a resistência ao cisalhamento da junta adesiva entre o titânio e o CFRP para as diferentes condições de texturização e fazer uma avaliação qualitativa e quantitativa dos resultados. 


\section{REVISÃO DA LITERATURA}

\subsection{Microusinagem utilizando laser}

A microusinagem a laser tem como característica a remoção de uma parcela muito pequena de material, que pode ser mantida controlada, de um substrato por meio da absorção da energia laser. Com isto, ocorre a ablação do material da superfície na forma de uma transformação de fase termodinâmica sólido-líquido-gás, sólido-gás ou e até mesmo sem aquecimento do material, ou seja, por repulsão eletrostática de íons induzida pelo laser [9].

$O$ processo de ablação e o controle dos diferentes regimes de microusinagem dependem enormemente da maneira como a energia é depositada pelo laser e absorvida pelo material [9]. O acabamento final, além do controle dimensional, estão intimamente relacionados com os diferentes regimes de interação. As proporções da ZTA estão associadas à quantidade da energia depositada no material, além do plasma formado na superfície do material, o que influencia colateralmente o substrato usinado [9].

O acabamento é afetado pela ejeção do material fundido durante a microusinagem, devido às rebarbas e regiões disformes [9]. Assim, espera-se um acabamento melhor para regimes de interação que promovam a sublimação do material fundido de modo que não haja a formação de rebarbas nas regiões adjacentes.

Os principais parâmetros de controle do laser que afetam diretamente 0 processo de ablação são comprimento de onda, densidade espacial de potência (intensidade), fluência de energia (energia por unidade de área do feixe laser), distribuição temporal de potência do laser (largura temporal do pulso), estratégia de microusinagem que determina a deposição da energia laser, além da atmosfera na região ablacionada [9]. Diferentes larguras temporais podem ser utilizadas no caso dos lasers pulsados, assim diferentes dinâmicas de ablação são possíveis. Desta forma, o processo de absorção pode ser separado em duas formas de ablação distintas, a executada por laser com pulsos de nanossegundos, e outra por laser com pulsos ultracurtos [9]. 


\subsection{Laser com pulsos de nanossegundos}

No processo de interação com pulsos de nanossegundos, ou seja, quando o tempo de interação é maior que algumas dezenas de picossegundos, o processo de dano ou ablação, para o caso dos metais, envolve o aquecimento dos elétrons na banda de condução pela radiação incidente, acarretando assim na transferência dessa energia para a rede [14]. Transferência esta que ocorre num processo de quase equilíbrio entre a temperatura dos elétrons e da rede, durante o tempo de interação do pulso laser com o material [14]. Se a difusão do calor via corrente eletrônica ou fônons na rede cristalina não for suficiente para dissipar o calor absorvido, a ablação ocorre devido à transformação de fase do material e simples evaporação, e havendo energia suficiente, o material é sublimado [14; 15].

Sob o ponto de vista da conservação da energia do sistema, qualquer variação na energia interna $U$ de um volume $V$, deve ocorrer devido à absorção da luz do laser ou pela difusão da energia para fora desse volume ( $\mathrm{j}$ sendo o fluxo de energia e $S$ a fonte de calor). Assim, a variação pode ser descrita conforme a Equação 1 [16]:

$$
\frac{\partial U}{\partial t}=-\nabla(j \cdot V)+S \cdot V
$$

Pode-se relacionar esta variação na energia interna no tempo à mudança de temperatura $T$ através da capacidade térmica $C_{i}$ do material por unidade de volume, pela Equação 2 [16].

$$
\frac{\partial \mathrm{U}}{\partial \mathrm{t}}=\mathrm{C}_{\mathrm{i}} \cdot \mathrm{V} \cdot \frac{\partial \mathrm{T}}{\partial \mathrm{t}}
$$

E, assim a fonte de calor $S$ pode ser expressa na forma como apresentado na Equação 3 [16]:

$S=I(z, t) \cdot[1-R(t)] \cdot A(z, t)$ 
onde $\mathrm{R}$ é a refletividade da superfície, $\mathrm{A}$ é a absorção pelo material e I é a intensidade do laser em função da posição no eixo $z$ na direção do eixo de propagação, e do tempo t.

$\mathrm{Na}$ maioria dos casos, a perda de energia será por difusão térmica, conforme Equação 4 [16].

$\mathbf{j}=-\mathrm{k} . \nabla \mathrm{T}$

sendo que $\mathrm{k}$ é a condutividade térmica. Desta forma a Equação 1 pode ser reescrita na forma da Equação 5 [16].

$\mathrm{C}_{\mathrm{i}} \cdot \frac{\partial \mathrm{T}}{\partial \mathrm{t}}=\nabla(\mathrm{k} \cdot \nabla \mathrm{T})+\mathrm{S}$

A Equação 5 é conhecida como equação parabólica do calor. A dependência da temperatura com os parâmetros físicos $C_{i}$ e $k$, além dos parâmetros ópticos $R$ e A, fazem com que a Equação 5 seja não linear, sendo então sua solução analítica obtida somente em alguns casos [16].

Analisando de forma qualitativa o transporte do calor, de modo a explicitar as escalas de tempo e espaço envolvidas neste processo com pulsos de nanossegundos, pode-se supor constantes os valores $C_{i}$ e de $k$, e assim, resultando da Equação 5 que a onda de calor após a absorção do laser se propagará pela relação [16]:

$\mathrm{l}_{\mathrm{D}} \approx \sqrt{2 \cdot \mathrm{D} . \mathrm{t}}$

onde $I_{D}$ é o comprimento de difusão, e $D=k / C_{i}$ é a difusividade térmica do material irradiado. Para metais, o comprimento de difusão é maior que a profundidade de penetração óptica $\delta(\delta=1 / \alpha$, onde $\alpha$ é o coeficiente de absorção óptica do material), acarretando que a ZTA será maior que a região englobada pelo foco do feixe na superfície do material, prejudicando assim o controle de forma precisa da região usinada [16]. 


\subsection{Interação laser-matéria}

Conforme o formalismo de Drude ${ }^{1}$, a energia absorvida por metais procede através do intermédio dos elétrons livres, que transmitem, através de colisões, esta energia para a rede cristalina [16].

No entanto, nem toda a energia emitida pelo laser é absorvida pelo material, sendo que uma parte dela é refletida. Desta forma, temos a definição de coeficiente de reflexão $(R)$, que é a porcentagem de luz que é refletida pelo material. Analogamente, o coeficiente de absorção (A) é a porcentagem de luz que é absorvida pelo material, ou seja, $A=1-R$.

Assim, o quanto um material pode absorver energia depende de vários fatores. Como influências diretas no coeficiente de absorção, tem-se temperatura, comprimento de onda utilizado e condições da superfície [17]. A relação desta influência para os metais está apresentada na TAB. 1.

TABELA 1 - Proporcionalidade para o coeficiente de absorção (A)

\section{Parâmetro}

Coeficiente de absorção (A)

Aumento da temperatura do material

Aumenta

Aumento do comprimento de onda

Diminui

Aumento da rugosidade

Aumenta

\subsection{Laser com pulsos ultracurtos}

São designados ultracurtos os pulsos com largura temporal menor ou igual ao tempo de relaxação elétron-fônon (dezenas de picossegundos). Assim, a rápida deposição de energia determinada pela aplicação de laser com pulsos ultracurtos resulta em alta concentração espacial de energia no interior do material, e, como consequência a redução da ZTA e a presença de zona fundida [18].

Os processos de absorção eletrônica e aquecimento da rede devem ser analisados separadamente, pois o pulso laser transfere uma parcela de sua energia para os elétrons, e somente após o término da relaxação elétron-fônon ocorrem efeitos termodinâmicos que promovem a ejeção de grande quantidade

\footnotetext{
${ }^{1}$ Paul Karl Ludwig Drude (1863 - 1906), físico alemão especialista em óptica.
} 
de material. Dependendo das condições, a taxa de relaxação elétron-fônon pode ser tão alta que promove um aquecimento abrupto do material, ocasionando que antes que ocorra a passagem do estado sólido para o estado líquido, o material ultrapassa em milhares de Kelvin a temperatura de ebulição. A consequência direta deste fenômeno acarreta em uma explosão de fase, promovendo a ablação térmica do material [18].

\subsubsection{Irradiação de materiais com laser com pulsos ultracurtos}

A irradiação de um material com pulsos ultracurtos causa um forte desequilíbrio entre as temperaturas dos elétrons e da rede [19]. No início, a radiação laser é absorvida por elétrons livres dentro de uma camada muito superficial. A excitação destes elétrons leva a uma ionização da superfície com consequente ejeção de material por efeito Coulomb [19]. Antes da ionização, contudo, os elétrons excitados adquirem temperaturas extremamente altas. Assim, antes da transferência do calor para a rede, existe um desequilíbrio de temperatura muito alto, no qual os elétrons excitados apresentam temperaturas de milhares de graus e a rede permanece à temperatura ambiente. Esta situação, chamada de modelo de duas temperaturas (MDT), permanece durante um tempo inferior ao tempo necessário à transferência de calor elétron-íon, que é geralmente da ordem de picossegundo. Como o pulso laser incidente tem uma duração muito inferior a este tempo, todo o processo de ejeção acontece antes que o calor seja transferido para a rede [19]. Assim, o material é ejetado e o processo de microusinagem ocorre sem que o material base seja termicamente afetado [19].

Em qualquer caso, a absorção da radiação é seguida por um rápido relaxamento de energia dentro do subsistema eletrônico, seguido de transferência de energia por difusão térmica para a rede devido ao acoplamento do par elétronfônon. A evolução espacial e temporal das temperaturas dos elétrons e da rede ( $T_{e}$ e $T_{i}$, respectivamente) em uma fina camada de superfície com subsequente expansão do material, que é a base do MDT proposto por [20], é descrita por [21]:

$$
C_{e} \frac{\partial T_{e}}{\partial t}=-\frac{\partial Q(x)}{\partial x}-\gamma\left(T_{e}-T_{i}\right)+S-P_{e} \frac{\partial u}{\partial x}
$$


$C_{i} \frac{\partial T_{i}}{\partial t}=\gamma\left(T_{e}-T_{i}\right)$

onde $\mathrm{C}_{e}$ e $\mathrm{C}_{i}$ são as capacidades de calor do elétron e da rede, respectivamente, x é a direção perpendicular para a superfície designada, o parâmetro $\gamma$ caracteriza a interação elétron-rede, $\mathrm{Q}(\mathrm{x})=-\mathrm{k}_{\mathrm{e}}\left(\mathrm{T}_{\mathrm{e}}\right) \partial \mathrm{T}_{\mathrm{e}} / \partial \mathrm{x}$ é o fluxo de calor, $\mathrm{k}_{\mathrm{e}}$ é $\mathrm{a}$ condutividade térmica do elétron, $S=I(t) A \cdot \alpha \exp (-\alpha x)$ é o termo de fonte da energia laser, A é o coeficiente de absorção da superfície (índice que caracteriza a capacidade de absorção de radiação) da superfície, a é o coeficiente de absorção do material, e I(t) é a intensidade do pulso laser.

Se a duração do pulso laser é maior que o tempo de aquecimento da rede $\left(\tau_{\mathrm{i}}=\mathrm{C}_{\mathrm{i}} / \gamma\right.$, que é da ordem de $\tau_{\mathrm{i}} \approx 0,01$ a $\left.1 \mathrm{~ns}\right)$, o equilíbrio térmico entre 0 subsistema de elétrons e o meio material se dá durante o pulso laser. Neste caso, os elétrons e a rede podem ser caracterizados por uma temperatura comum $\mathrm{T}=\mathrm{T}_{\mathrm{e}}=\mathrm{T}_{\mathrm{i}}$,e a Equação 7 e Equação 8 ficam reduzidas à bem conhecida equação de difusão de calor unidimensional (Equação 9), que descreve o aquecimento por laser com pulsos de nanossegundos. Soluções da Equação 9 podem ser encontradas, por exemplo, em [16].

$$
C_{i} \frac{\partial T}{\partial t}=\frac{\partial}{\partial x} k_{e} \frac{\partial T}{\partial x}+I(t) A \alpha \exp (-\alpha x)
$$

Para pulsos laser de femtossegundos, a condução de calor e a transferência de energia para a rede durante o pulso podem ser negligenciadas em uma primeira aproximação. Neste caso simplificado, a taxa de ablação e o limiar de ablação só dependem da profundidade de penetração óptica $\delta$. Porém, $a$ interação de troca de energia entre elétrons e o meio e a difusão de calor têm consequências importantes, até mesmo para a ablação com pulsos ultracurtos [21].

A profundidade de penetração óptica é definida como por $\delta=1 / \alpha$ e 0 comprimento de difusão térmica de elétrons é dado por $\ell=\sqrt{D \cdot \tau_{a}}$. A duração do processo de ablação, $\tau_{a}$, é determinado pelo tempo necessário para a transferência de energia dos elétrons para a rede cristalina. 
Quando a capacidade de calor, a condutividade térmica e a difusão térmica do elétron são tratadas como constantes, pode-se encontrar a distribuição de temperatura de equilíbrio para os elétrons e para a rede, após o relaxamento térmico, através da Equação 10 [21].

$$
T \approx \frac{F_{a}}{C_{i}}\left(\frac{1}{\ell^{2}-\delta^{2}}\right) \cdot\left[\ell \exp \left(\frac{-x}{\ell}\right)-\delta \exp \left(\frac{-x}{\delta}\right)\right]
$$

onde $F_{\mathrm{a}}$ é a fluência do pulso laser, ou seja, a densidade espacial de energia, e $\ell$ é o comprimento de difusão térmica no meio.

Dois casos podem ser distinguidos: quando a profundidade de penetração óptica é superior ao comprimento de difusão térmica, $\delta>\ell$, e viceversa, $\ell>\delta$. Para estes casos, para as temperaturas de equilíbrio podem ser obtidas a Equação 11 e a Equação 12, respectivamente. A FIG. 1 apresenta um esquema para estes dois casos. [21].

$$
\begin{array}{ll}
T \approx \frac{F_{a}}{C_{i} \delta} \exp \left(\frac{-x}{\delta}\right) & (\delta>\ell) \\
T \approx \frac{F_{a}}{C_{i} \ell} \exp \left(\frac{-x}{\ell}\right) & (\delta<\ell)
\end{array}
$$
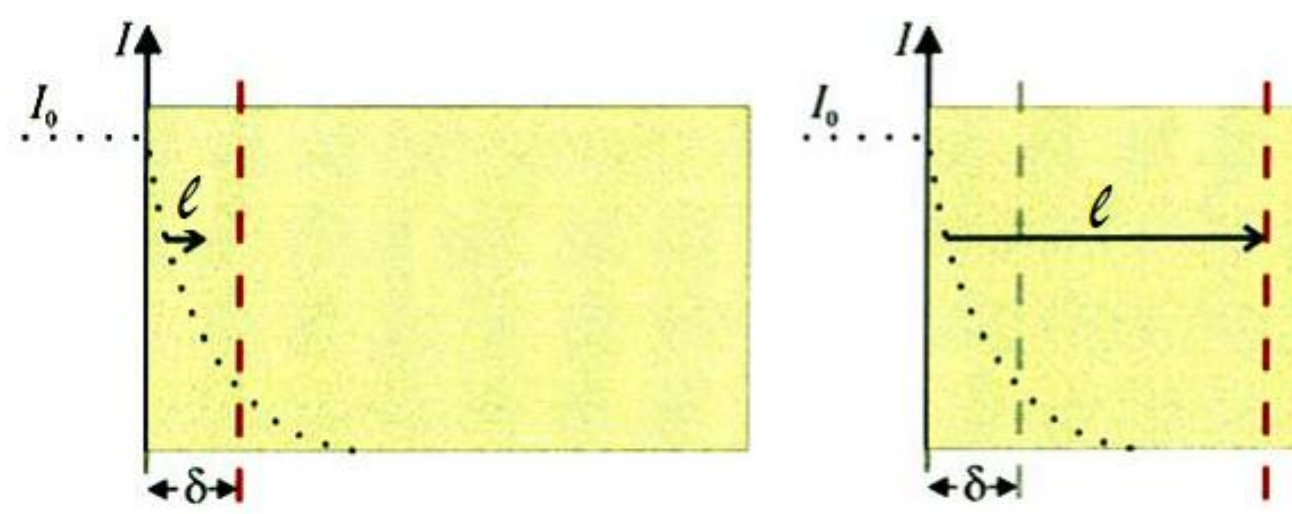

FIGURA 1 - Imagens esquemáticas de dois regimes de aquecimento com pulsos ultracurtos, $\delta>\ell$ (a) e $\delta<\ell$ (b).

Fonte - [21]. 
Neste modelo simplificado de ablação, algo significativo acontece quando a energia da rede $C_{i} / T_{i}$ (por unidade de volume) excede um certo valor de limiar. Este valor de limiar pode ser calculado, em uma primeira aproximação, como o calor de evaporação $\rho . \Omega$, onde $\rho$ é a densidade e $\Omega$ é o calor específico de evaporação por unidade de massa.

A condição para ablação significativa, $C_{i} / T_{i} \geq \rho . \Omega$, pode ser conforme mostrado na Equação 13 e na Equação 14 [21].

$$
\begin{aligned}
& F_{a} \geq F_{t h}^{\delta} \exp \left(\frac{x}{\delta}\right), F_{t h}^{\delta} \approx \rho . \Omega . \delta \quad(\delta>\ell) \\
& F_{a} \geq F_{t h}^{\ell} \exp \left(\frac{x}{\ell}\right), F_{t h}^{\ell} \approx \rho . \Omega . \ell \quad(\delta<\ell)
\end{aligned}
$$

onde, $F_{t h}^{\delta}$ e $F_{t h}^{\ell}$, são os limiares de ablação para as correspondentes fluências laser absorvidas. As profundidades da ablação $L$ podem ser obtidas a partir da Equação 13 e Equação 14 para as condições onde $\delta>\ell$ e $\delta<\ell$, respectivamente, obtendo-se desta forma a Equação 15 e a Equação 16 [21].

$$
\begin{array}{ll}
L \approx \delta \ln \left(\frac{F_{a}}{F_{t h}^{\delta}}\right) & (\delta>\ell) \\
L \approx \ell \ln \left(\frac{F_{a}}{F_{t h}^{\ell}}\right) & (\delta<\ell)
\end{array}
$$

Isto significa que são obtidas duas relações em escala logarítmicas no MDT. Com relação à Equação 15 e Equação 16, estas duas relações logarítmicas podem ser atribuídas à profundidade de penetração óptica e à condução de calor eletrônica, respectivamente [21]. 


\subsubsection{Escalas de tempo na irradiação com laser com pulsos ultracurtos}

O primeiro passo em qualquer modificação estrutural de um material por meio de radiação laser é a deposição de uma certa quantidade de energia do laser. A energia total do laser e a distribuição de energia espacial e temporal determinam que tipo de modificação final será obtida [22].

O processo primário de interação laser-sólido é a excitação de elétrons de seus estados de equilíbrio para alguns estados excitados por absorção de fótons. A largura temporal do pulso de laser determina o tempo para depósito de energia para estes estados. Outros mecanismos de excitação são possíveis, como absorção de dois fótons ou transições eletrônicas multifótons de ordem superior [22]. Para uma dada fluência do laser a duração do pulso mais curto favorece processos de excitação multifótons, porque a probabilidade de absorção não linear aumenta fortemente com a intensidade do laser. A excitação eletrônica primária está associada com uma polarização coerente do material em um tempo muito curto [22].

A excitação eletrônica inicial é seguida por uma complexa sequência de processos secundários, que eventualmente acarretam na modificação estrutural final do material. As escalas de tempo desta cadeia de eventos podem ser grosseiramente classificadas como mostrado na FIG. 2 [22].

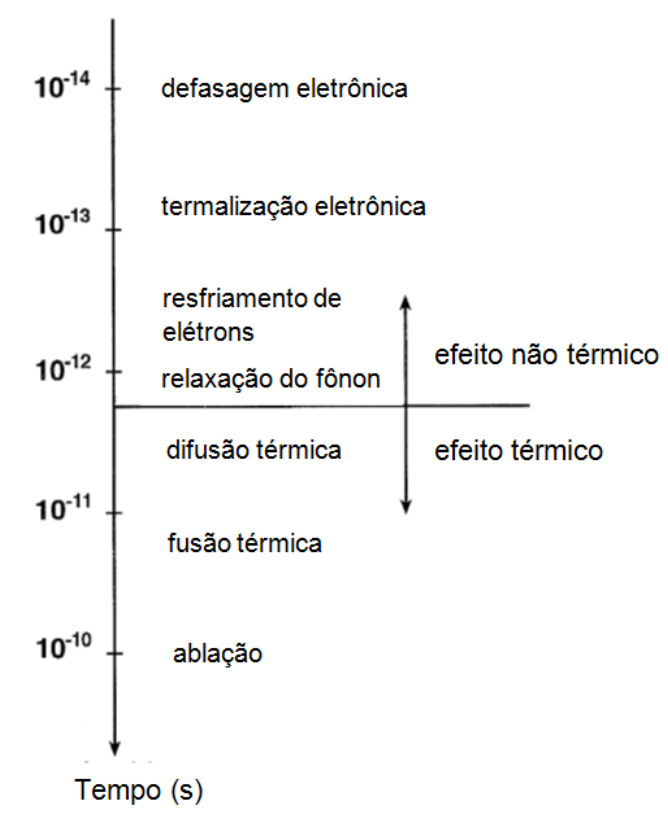

FIGURA 2 - Escala de tempo dos vários processos secundários.

Fonte - [22]. 


\subsection{A ablação por laser com pulsos ultracurtos}

Para ablação de sólidos utilizando laser com pulsos ultracurtos, são empregadas energias na faixa de dezenas a centenas de micro Joules, largura temporal de pulso em torno de 100 fs e raio de foco de $20 \mu \mathrm{m}$, gerando intensidades no intervalo de $10^{12}$ a $10^{14} \mathrm{~W} / \mathrm{cm}^{2}[1]$.

Segundo [1], quando um pulso ultracurto colide com um sólido, o fato da sua duração ser mais curta que o período vibracional dos íons da rede significa que a maior parte da energia do pulso será transferida para os elétrons do material, aquecendo-os sem que haja tempo para aquecer a rede. A maior parte da energia térmica eletrônica será levada com o material ablacionado, e a pequena porção restante será adicionada à energia diretamente acoplada nos íons, aquecendo a rede, com a possibilidade de criar uma pequena ZTA. O controle das condições de irradiação pode reduzir esta ZTA a quase zero [1].

\subsubsection{Mecanismos físicos de ablação}

O processo de ejeção tem uma alta probabilidade de ocorrência em uma camada superficial de $100 \mathrm{~nm}$ pelos elétrons que adquiriram alguns $\mathrm{eV}$ de energia cinética. A emissão destes elétrons deixa uma carga em desequilíbrio na superfície, o que pode produzir uma explosão pelo efeito Coulomb devido à repulsão dos íons positivos gerados na rede após a ejeção dos elétrons [10].

Se a energia e intensidade do pulso são suficientemente altas, a densidade de elétrons livres atinge um valor crítico, que é cerca de $10^{21} \mathrm{~cm}^{-3}[23$; 24], e, em seguida, os elétrons transferem sua energia aos íons circundantes. Esse relaxamento aquece rapidamente a estrutura vizinha acima da sua temperatura de vaporização, criando uma fase instável que sofre uma expansão adiabática violenta, fenômeno este conhecido como explosão de fase [25; 26]

Para metais, são os elétrons livres da banda de condução os responsáveis pela transferência de energia. Para outros materiais, o pulso resulta na excitação dos elétrons da banda de valência pela ionização de multifótons [27; 28] ou tunelamento induzido pelo campo do laser [29; 30]. Uma vez que os elétrons livres estão presentes, a metalização ocorre e o aquecimento dos elétrons evolui deterministicamente quase da mesma maneira em todos os materiais [30; 31]. 
Dependendo da energia do pulso, dois regimes de ablação podem ser identificados: de baixa e de alta fluência. Estes regimes são definidos pelo mecanismo de ablação dominante, sendo que no regime de baixa fluência predomina a ejeção pelo efeito Coulomb [10], enquanto a explosão de fase prevalece no regime de ablação de alta fluência. No entanto, em metais, a ejeção pelo efeito Coulomb é de difícil ocorrência, visto que nas intensidades utilizadas na microusinagem, a acumulação de carga na superfície é eficazmente extinta pela mobilidade eletrônica, suprimindo a explosão íons positivos [32]. O campo elétrico necessário para promover a acumulação de carga positiva em metais $\left(\sim 10^{10} \mathrm{~V} / \mathrm{m}\right.$ ) demanda intensidades de energia em torno de $10^{18} \mathrm{~W} / \mathrm{cm}^{2}$, empurrando o limiar de ejeção pelo efeito Coulomb acima do regime de explosão de fase [33]. Nos metais, os regimes de baixa e alta fluência ocorrem quando a ZTA é menor ou maior que o comprimento óptico de interação dentro do metal (Lei de Beer), respectivamente [33]. O limiar dos regimes pode ser previsto utilizando o MDT que descreve a aquecimento eletrônico, difusão e aquecimento da estrutura [34; 35].

Para todas as classes de materiais, a principal diferença entre os dois regimes de ablação é que na alta fluência haverá fusão na região de interação, e o material remanescente pode resfriar para uma fase amorfa ou policristalina, cujas características físicas (mecânicas, ópticas, etc.) podem diferir dos materiais de base. Além disso, a ZTA será maior no regime de alta fluência [36].

Uma vez que o processo de ablação por pulsos ultracurtos depende principalmente de como os elétrons respondem ao campo de excitação do laser e não das propriedades termodinâmicas que surgem como consequência da estrutura atômica, o limiar de ablação não mostra uma dependência da raiz quadrada da duração do pulso, como em processos de ablação térmica. Adicionalmente, a ablação por pulsos ultracurtos tem um caráter não seletivo, e o único parâmetro que tem que ser conhecido para ablacionar um material é a sua fluência de limiar de ablação, $F_{\text {th }}$ [27]. Como regra geral, uma vez que em nãometais uma porção da energia do pulso é utilizada para criar elétrons livres, estes materiais apresentam geralmente limiares de ablação mais elevados que os metais para as mesmas condições do laser. Além disso, um único material pode apresentar dois valores de limiar de ablação, um para baixa e outro para alta 
fluência, e que devem ser conhecidos e levados em consideração na microusinagem do material [1].

\subsection{Efeito de incubação}

Quando um pulso laser incide sobre uma região previamente irradiada por outro pulso laser, este encontrará o material com condições estruturais diferentes daquela encontrada pelo pulso inicial. Isto ocorre porque, mesmo que a densidade de energia F esteja abaixo do limiar de ablação (sem ocorrência visível de dano), uma mudança na distribuição eletrônica do material irradiado acontece por conta dos campos elétricos extremamente altos, que são característicos de um pulso laser ultracurto. Este dano imperceptível cria níveis intermediários de energia, entre a banda de condução e a de valência, que facilitam a absorção multifotônica e diminuem o limar de ablação. Isto ocorre até que a concentração destes danos, ou defeitos na rede cristalina, atinjam uma concentração limite e este efeito seja saturado [1]. Assim, o limiar de ablação $F_{t h}$, diminui com 0 acúmulo de pulsos sobrepostos até que haja uma saturação de defeitos e $F_{\text {th }}$ se mantenha constante a partir de certo número $\mathrm{N}$ de pulsos [1].

A relação entre o limiar de ablação $F_{\text {th }}$ e o número $N$ de pulsos sobrepostos é dada pela Equação 17.

$$
F_{t h(N)}=F_{t h(1)} N^{S-1}
$$

onde $F_{\text {th(N) }}$ é o limiar de dano para $N$ pulsos, $F_{\text {th(1) }}$ é o limiar de dano para um pulso, e S é o parâmetro de incubação. Usando um gráfico do limiar de dano em função do número de pulsos é possível encontrar o valor se $\mathrm{S}$ através do ajuste dos dados com a curva da Equação 17.

\subsubsection{Determinação do limiar de ablação}

A determinação do limiar de ablação de um dado material por pulsos ultracurtos geralmente é feito usando o método de Dano Zero, introduzido por Liu em 1982 [12]. 
Esta técnica está baseada no fato de que a dimensão do dano provocado no material esta diretamente ligada à fluência do pulso incidente $F_{a}, e$ considera-se a dimensão do dano como o diâmetro medido da região afetada [1].

A distribuição de fluência radial no foco do feixe com distribuição Gaussiana é determinada pela Equação 18.

$$
F(r)=\frac{E_{\text {meas }}}{\pi w_{0}^{2}} e^{\frac{-2 r^{2}}{w_{0}^{2}}}=F_{\text {meas }} e^{\frac{-2 r^{2}}{w_{0}^{2}}}
$$

onde $E_{\text {meas }}$ é a energia medida, $r$ a coordenada radial, $w_{0}$ o raio médio medido a $1 / e^{2}$ da intensidade máxima e $F_{\text {meas }}$ é a fluência da energia medida. Assim, a suposição é que, se o material não é danificado a uma distância $r$ do centro do feixe, então, o valor correspondente da fluência $F(r)$ iguala-se ao valor de limiar $F_{\text {th. }}$.

Assim, a interação do feixe com a superfície da amostra resulta em um dano, cujo diâmetro $D^{2}$ e o diâmetro do feixe no foco $\phi$ obedecem a uma relação logarítmica com a fluência do pulso laser. Desta maneira, a Equação 18 pode ser reescrita na forma da Equação 19.

$$
F_{0}=F_{t h} \exp \left(\frac{D^{2}}{2 w_{0}}\right)
$$

Em seguida, os diâmetros das crateras ablacionadas, D, são medidos e os quadrados dos valores são representados como uma função da fluência do pulso, F. Os dados são então encontrados pela Equação 20:

$$
D^{2}=2 \cdot w^{2} \cdot \ln \left(\frac{F}{F_{t h}}\right)
$$

onde $\mathrm{w}_{0}$ é o raio do feixe na superfície da amostra e $F_{\text {th }}$ é o limiar de fluência de ablação, em que o diâmetro da cratera ablacionada é zero. Para executar esta medida, os parâmetros de propagação do feixe devem ser conhecidos para 
calcular seu diâmetro e fluência na superfície da amostra, além de que muitas medições devem ser feitas.

Desta forma, são utilizados dados experimentais para se traçar o gráfico da fluência $\mathrm{F}$ em função de $D^{2}$. Uma projeção numérica permite então a obtenção da fluência de limiar para a ocorrência de dano; ou seja, a fluência $F_{\text {th }}$ para a qual o diâmetro $D$ seja igual a zero.

A medida precisa de $F_{\text {th }}$ é extremamente importante para microusinagem com pulsos ultracurtos, pois somente a utilização de fluências próximas a $F_{\text {th }}$ irá garantir um processo sem acúmulo de calor na região afetada. Fluências muito acima de $F_{\text {th }}$ levam à ocorrência de outros fenômenos que resultam em transferência de calor para a rede e limitam a precisão do processo de microusinagem [1]. Diz-se então que a microusinagem ocorre no regime de alta fluência. O gráfico da FIG. 3 mostra a relação experimental entre a fluência F e o diâmetro do dano ao quadrado, obtida como exemplo para o caso do silício monocristalino [9].

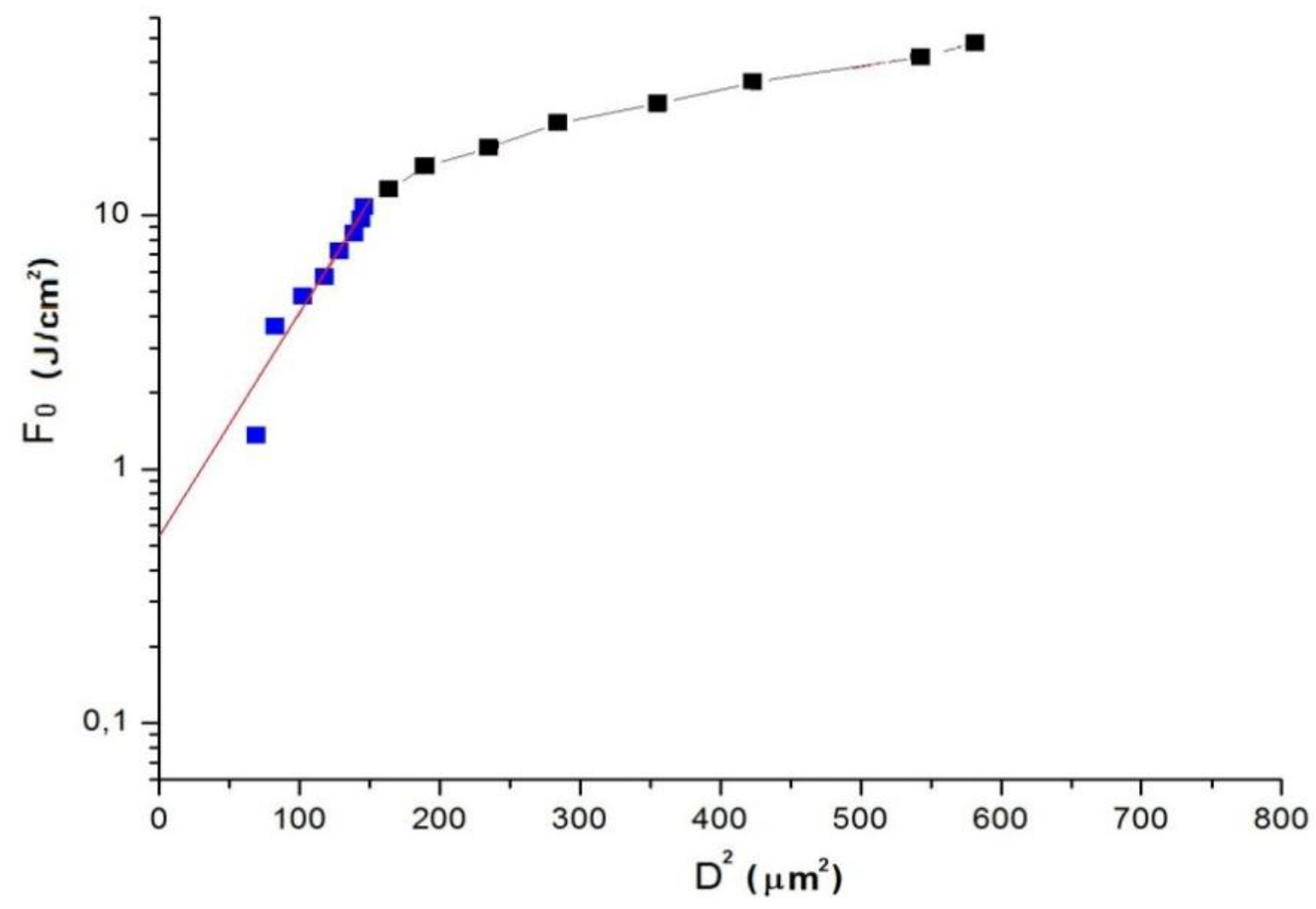

FIGURA 3 - Relação entre o diâmetro ao quadrado $D^{2}$ do dano formado em silício por um pulso laser com fluência $F_{0}$.

Fonte - [9]. 
No regime de alta fluência ocorre uma variação abrupta do diâmetro do dano em função da fluência $F$ utilizada. Isto ocorre porque a partir deste valor de densidade de energia, o acúmulo de calor na região afetada começa a ser significante e a profundidade de penetração térmica é muito maior que a profundidade de penetração óptica. Neste caso, a temperatura local sobe tão rapidamente, e a valores muito acima da temperatura de evaporação, que o material sofre uma transformação de fase instável, conhecida como explosão de fase, e uma grande quantidade de material é ejetada por ablação [1].

Para fluências abaixo do valor correspondente ao valor de inflexão da reta, o acumulo de calor é mínimo, e a ejeção de material pode ser considerada não térmica. A projeção da reta para o eixo de $\mathrm{F}$ determina a fluência mínima $F_{\text {th }}$ para a qual o diâmetro do dano se aproxima de zero. $F_{\text {th }}$ é, portanto, considerada a fluência de limar [1].

A parte do gráfico onde a ocorrência de fenômenos térmicos é muito pequena é conhecida como região de baixa fluência, a outra parte é a de alta fluência. A região de alta fluência oferece maior eficiência de remoção de material, porém com efeitos térmicos significantes, como fusão (e ressolidificação), ocorrência de rebarbas, zona afetada pelo calor, além de uma menor precisão dimensional. A região de baixa fluência, por outro lado, apresenta uma baixa eficiência de ablação, porém sem os efeitos térmicos adversos e com maior precisão dimensional [1].

Experimentalmente, este método é bastante trabalhoso, pois requer o conhecimento exato dos parâmetros do feixe e necessita de sua estabilização, além de um bom sistema de posicionamento da amostra para manter o tamanho da cintura do feixe constante na superfície da amostra para todas as medições, uma vez que ao longo do tempo está propenso a ser afetado por instabilidades do laser. Além disso, muitas vezes o uso de um microscópio eletrônico ou de força atômica é necessário para determinar o diâmetro da cratera próximas ao limiar de fluência, em que o tamanho dos danos é próximo de zero e é difícil de ser medido. Adicionalmente, uma grande quantidade de medições são necessárias para que possa ser traçado o gráfico.

Há alguns anos foi introduzida no laboratório de lasers de altíssima intensidade do CLA-IPEN a técnica D-Scan, apresentada em [13], sendo esta 
uma alternativa de método simples para medir o limiar de ablação por pulsos ultracurtos. O método consiste em percorrer uma amostra longitudinalmente e transversalmente, nas direções z e y conforme mostra a FIG. 4(a), através da cintura do feixe focado, a partir de uma posição antes da cintura. Desta forma, um perfil simétrico com dois lóbulos, como o mostrado na FIG. 4(b), será gravado na superfície da amostra. Se o perfil gravado não apresenta dois lóbulos, o procedimento tem de ser repetido com uma energia de pulso maior ou com uma lente com foco menor [13].

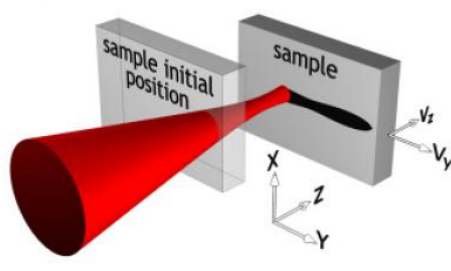

(a)

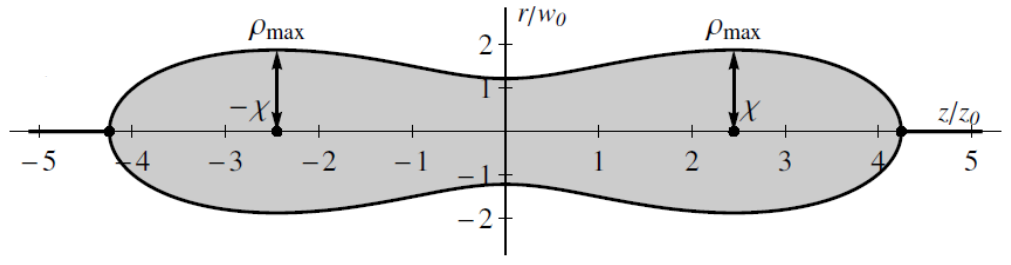

(b)

FIGURA 4 - a) Esquema da técnica D-Scan; b) perfil gravado na superfície da amostra pelo movimento diagonal em posição através da cintura do feixe.

Assim, o limiar de fluência de ablação para a amostra é determinado pela Equação 21.

$$
F_{t h}=\frac{1}{e \cdot \pi} \frac{E_{0}}{\rho_{\max }^{2}} \cong 0.117 \frac{E_{0}}{\rho_{\max }^{2}}
$$

onde $E_{0}$ é a energia de pulso e $\rho_{\text {MAx }}$ é a metade da dimensão transversal do perfil gravado.

A determinação do limiar de ablação envolve saber a energia de pulso e a medição da dimensão transversal máxima do perfil (tipicamente algumas dezenas de micra), que pode ser feita com um microscópio óptico, e através da Equação 21 [13].

Em comparação com a técnica de Dano Zero, o método D-Scan é mais fácil de ser experimentalmente realizado, uma vez que exige apenas uma varredura que pode ser feita em poucos segundos e uma simples medição geométrica, em substituição a necessidade de uma série de medições que pode 
demandar um tempo relativamente longo, além do conhecimento do diâmetro do feixe laser na superfície da amostra.

\subsection{0 titânio}

O titânio é um dos elementos da Tabela Periódica, descrito pelo reverendo inglês William Gregor em 1791. Seu número atômico é 22, seu peso atômico é 47,9 , apresenta uma densidade de $4,51 \mathrm{~g} / \mathrm{cm}^{3}$ (60\% menor que o ferro) e seu ponto de fusão está na ordem de $1668 \stackrel{\circ}{\circ}$. No ano de 1795 o químico alemão Martin Klaproth encontrou o titânio presente no minério rutílio $\left(\mathrm{TiO}_{2}\right)$, que até então era desconhecido e, desta forma então surgiu o nome titânio [38].

Por ser um metal muito reativo, o titânio historicamente era de difícil obtenção na forma pura a partir do minério rutílio. $O$ processo de refino foi desenvolvido pelo metalurgista alemão Wihelm Kroll, por isto é considerado o pai da indústria do titânio. O início das aplicações industriais do titânio deu-se na década de 50, com o desenvolvimento da indústria aeronáutica e espacial, onde o titânio passou a ser utilizado fortemente em substituição ao alumínio onde há temperaturas elevadas [39]. Atualmente o titânio tem seu emprego na biomedicina devido que algumas de suas ligas têm biocompatibilidade e, devido à resistência à maior parte dos ácidos minerais e cloretos tem larga aplicação na indústria petroquímica, de papel de celulose, aeronáutica, aeroespacial e até na construção de reatores de nucleares [39]. Contudo, um grande inconveniente do titânio é a enorme afinidade com o oxigênio, sendo assim é de extrema necessidade o uso de atmosferas protetoras com gases inertes quando no trabalho a quente, de modo a inibir a formação de óxidos [38].

\subsubsection{Características do Ti Gr. 2 CP}

O Ti Gr. 2 CP apresenta duas fases bem distintas, sendo que a temperatura ambiente apresenta uma estrutura hexagonal compacta $(\mathrm{HC})$, cuja denominação é alfa ( $\alpha$ ). Em uma temperatura próxima a $882 \stackrel{\circ}{\circ}$ o Ti Gr. 2 CP sofre uma transformação alotrópica, que resulta em uma estrutura cúbica de corpo centrado (CCC), denominada beta $(\beta)$. Procedendo-se o resfriamento sua estrutura retorna para HC. Como trata-se de titânio puro, com poucos elementos em sua composição, não temos uma faixa significativa de transição para tal transformação de fase [40]. 
O Ti Gr. 2 CP possui níveis satisfatórios de resistência mecânica, tenacidade e soldabilidade, sendo apropriado também para aplicações criogênicas por não apresentarem transformação dúctil-frágil que é típico de estruturas cristalinas do tipo CCC. Além disto, são utilizadas quando há a necessidade de resistência à fadiga em temperaturas na faixa de $600{ }^{\circ} \mathrm{C}$ a $800{ }^{\circ} \mathrm{C}$ [39].

\subsection{Adesão entre titânio e CFRP estrutural}

Para produzir uma junta adesiva resistente e durável entre materiais dissimilares, um tratamento de superfície eficiente é necessário. Certas técnicas de colagem fornecem adequada força estática, mas têm pouca durabilidade quando exposto a ambientes úmidos e quentes, enquanto outras são suscetíveis a sofrerem descolamento na presença de combustíveis, óleos e limpeza com solventes comumente encontrados em aplicações de aeronaves [3]. Além disso, a natureza do tratamento de superfície antes da ligação é uma das principais influências no controle destes efeitos. Um tratamento superficial eficiente aumenta a aderência entre as superfícies devido a vários aspectos, tais como aumento da tensão superficial, aumento da rugosidade ou alteração química da superfície [3]. Aumentando a rugosidade da superfície, ocorre um aumento na sua área de superfície, o que permite que o adesivo flua em torno das irregularidades na superfície para formar uma adesão mecânica [3]. A alteração química da superfície pode provocar a formação de uma ligação química, por exemplo, entre as moléculas poliméricas na matriz de polímeros do CFRP e a camada de óxido de metal na outra superfície aderente [3; 4].

O principal objetivo do tratamento superficial é aumentar superfície de contato, de forma a propiciar uma maior área da junta adesiva. A molhabilidade é a propriedade de um líquido de aderir, ou molhar uma superfície, ou ainda de ser absorvido por essa superfície. A molhabilidade da superfície é um fator importante para o desempenho do adesivo, visto que os tratamentos de superfície diminuem o ângulo de contato da água, aumentam a tensão superficial e como resultado promovem um aumento na resistência da junta colada [4]. 


\subsection{Tensões residuais}

Tensões residuais podem ser definidas como tensões existentes em um material, mesmo sem a ação de forças externas sobre o mesmo. Dependendo da magnitude, orientação e da distribuição, tais tensões têm influências boas e ruins no material [41].

As tensões residuais podem ser impostas ao material pelo próprio processo de beneficiamento, como laminação, trefilação, extrusão e tratamentos térmicos. Contudo, em função de processos de fabricação, tais como microusinagem, devido ao aporte térmico inerente ao processo, ocorre a alteração no estado das tensões residuais e acarreta uma redistribuição de tais tensões [42].

As tensões residuais podem ser classificadas em tensões residuais macroscópicas (tipo I), microscópicas (tipo II) e submicroscópicas (tipo III).

\subsubsection{Tensões Residuais Macroscópicas (Tipo I)}

As tensões residuais macroscópicas são aquelas que se desenvolvem em grandes proporções volumétricas em relação ao tamanho de grão do material. Normalmente, se apresentam em peças deformadas plasticamente e submetidas a gradientes térmicos, sendo as tensões residuais com relativa uniformidade para muitos grãos da superfície da peça [41].

\subsubsection{Tensões Residuais Microscópicas (Tipo II)}

As tensões residuais microscópicas ocorrem em escalas da ordem do tamanho de grão do material. Tais tensões ocorrem durante a deformação elastoplástica de um material policristalino com grãos aleatoriamente orientados, devido ao escoamento promovido no material. Assim, a resistência ao escoamento e ao encruamento de um material depende da orientação cristalográfica [41].

\subsubsection{Tensões Residuais Submicroscópicas (Tipo III)}

As tensões residuais submicroscópicas são aquelas que existem em escalas da ordem de distâncias interatômicas, ou seja, em pequenas frações do tamanho de um grão. Essencialmente, ocorrem em processos que como 
resultado produzem a presença de descontinuidades e outros defeitos cristalinos, tais como vazios, impurezas e falhas de empilhamento [41]. 


\section{MATERIAIS E MÉTODOS}

\subsection{Laser com pulsos de nanossegundos}

Foi utilizado um sistema instalado no Laboratório de Aplicações Lasers em Ciências Nucleares no CLA-IPEN, que consiste de um laser pulsado e chaveado de Nd:YAG, marca Quantel e modelo Briliant, com energia máxima por pulso de $350 \mathrm{~mJ}$, comprimento de onda de $1064 \mathrm{~nm}$ e largura temporal do pulso laser de 5 ns. O feixe é direcionado para a região onde é feita a microusinagem, com lentes para ajuste do foco na amostra a ser usinada. O sistema de movimentação para a execução das usinagens consiste em uma mesa com precisão micrométrica e movimento coordenado dos eixos $\mathrm{X}$ e $\mathrm{Y}$ automatizado por computador.

\subsection{Laser com pulsos ultracurtos e sistema de entrega do feixe}

Os experimentos utilizaram um sistema estável, que proporcionou uma confiável repetibilidade da energia dos pulsos. O sistema consiste em um laser de Ti:Safira de femtossegundo amplificado pelo método de amplificação por varredura de frequência (Femtopower Compact Pro CE-Phase HP/HR da marca Femtolasers) que gera continuamente pulsos de 25 fs (FWHM) centrados em 775 $\mathrm{nm}$ com $40 \mathrm{~nm}$ de largura de banda (FWHM), taxa de repetição máxima de $4 \mathrm{kHz}$ e energias máxima por pulso de $750 \mu \mathrm{J}$.

O feixe foi gerado no laboratório de lasers de altíssima intensidade no CLA-IPEN, percorrendo aproximadamente $30 \mathrm{~m}$ conforme ilustra a FIG. 5 até o sistema de guiamento de feixe existente no laboratório de aplicações industriais do CLA-IPEN. Nesse sistema, o feixe, polarizado linearmente, foi centrado em uma íris de $18 \mathrm{~mm}$ de diâmetro. Após passar por um obturador pneumático controlável, o feixe teve seu diâmetro reduzido em três vezes por um expansor invertido para que pudesse ser compatível com uma óptica de $6 \mathrm{~mm}$ de diâmetro livre. Para o controle preciso da energia na amostra, foi usada uma placa de meia onda para girar a polarização seguida de um polarizador Glan-Thompson para atenuar as componentes perpendiculares ao polarizador.

A parte do feixe que é atenuada pelo polarizador é desprezada. Os pulsos então sofrem quatro reflexões consecutivas em dois espelhos (Chirped 
Mirror) que compensam parte da dispersão positiva adquirida durante a propagação pelo ar e pelos componentes ópticos. Foi ainda realizada a précompensação de dispersão através dos prismas de difração na saída do amplificador, pois os espelhos de correção não foram suficientes para compensar toda a dispersão positiva.

Um pulso laser ultracurto é composto por um largo espectro de frequências com uma forma complicada. A velocidade de grupo é a velocidade com que este envelope de frequências se propaga em um meio. A dispersão da velocidade de grupo é o fenômeno em que a velocidade de grupo da luz em um meio transparente depende do comprimento de onda, ou da frequência óptica [43]. Dispersão positiva, ou dispersão normal, significa que a velocidade de grupo decresce com o aumento da frequência óptica (ou com a diminuição do comprimento de onda). Este fenômeno acontece quando a intensidade do pulso laser é muito alta e fenômenos de segunda ordem se tornam significativos. Esta dispersão leva a uma diminuição da largura de banda do pulso e a um consequente alargamento temporal do pulso [44].

Após algumas reflexões em espelhos de guiamento, o feixe foi focalizado na amostra de titânio [9; 45]. Nos métodos Dano Zero e D-Scan foram utilizadas lentes com comprimento focal de $38 \mathrm{~mm}$ e $75 \mathrm{~mm}$ respectivamente. Também foi utilizada uma segunda objetiva da marca Mitutoyo do tipo "long working distance" com abertura numérica de 0,42 e distância de trabalho de 20 $\mathrm{mm}$ e comprimento focal $4 \mathrm{~mm}$ para o método do Dano Zero.

O sistema de movimentação para a execução das usinagens consiste em uma mesa com movimento coordenado dos eixos $\mathrm{X}$ e $\mathrm{Y}$ via comando Controle Numérico Computadorizado (CNC), enquanto que o movimento no $Z$ é manual através de um micrômetro. Para todos os eixos os movimentos têm precisão micrométrica. Na FIG. 6 é ilustrado o sistema de movimentação para realização do processo de microusinagem.

Para a utilização do sistema, é necessária a realização do desenho da amostra no software AutoCad e com o auxílio do software MasterCam é gerado o programa CNC da geometria requerida para cada caso. 


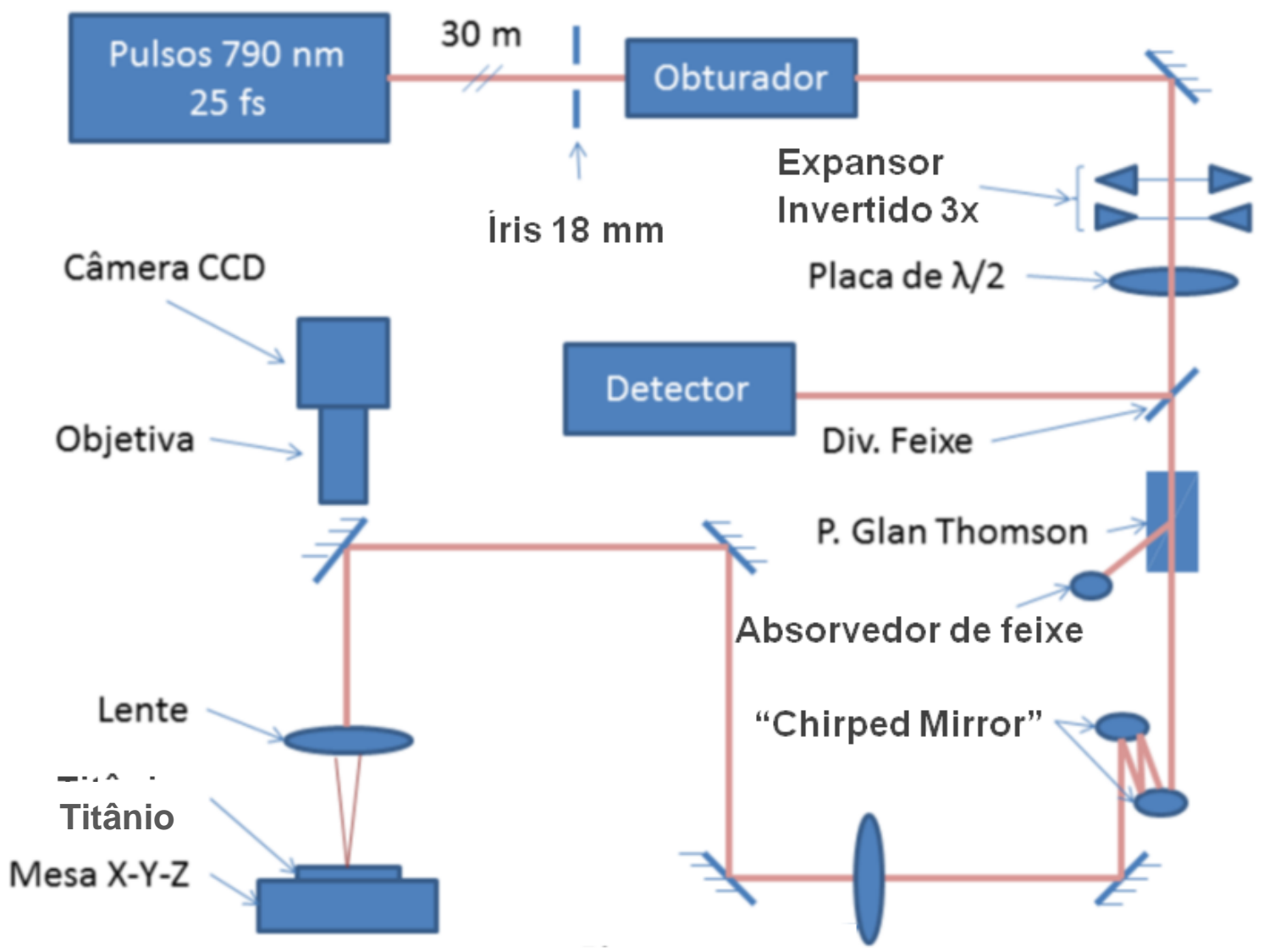

FIGURA 5 - Arranjo do laser e do sistema óptico de entrega do feixe e visualização.

Fonte- [9].

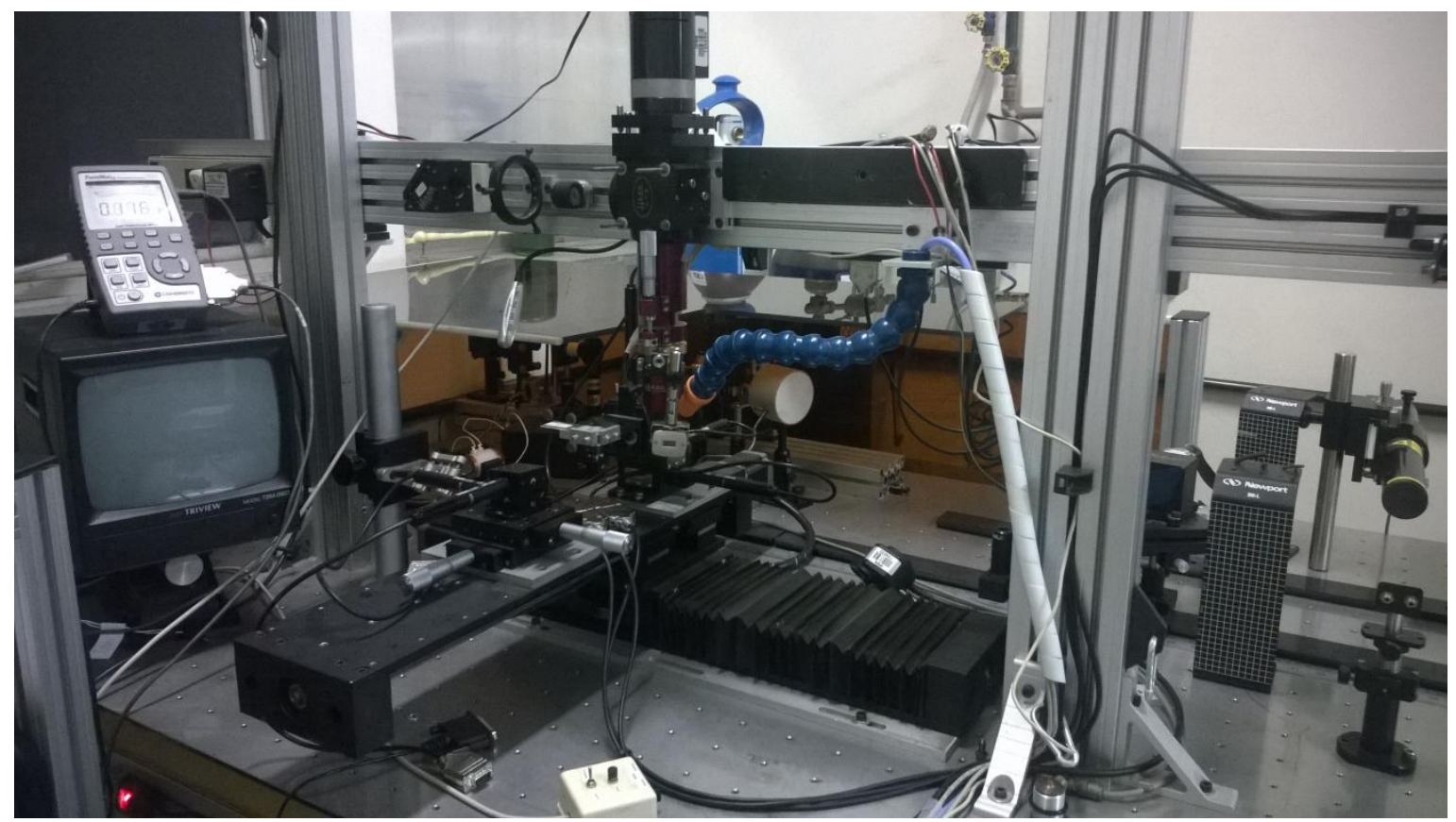

FIGURA 6 - Mesa de trabalho com movimentação X, Y via CNC e Z manual; e arranjo óptico do sistema de entrega do feixe e visualização. 


\subsection{Amostras de Ti Gr. 2 CP}

Na TAB. 2 é apresentada a composição química do Ti Gr. 2 CP.

TABELA 2 - Composição química para o Ti Gr. 2 CP

\begin{tabular}{ccccccc}
\hline Elementos & $\mathrm{C}$ & $\mathrm{H}$ & $\mathrm{O}$ & $\mathrm{N}$ & $\mathrm{Fe}$ & Outros \\
\hline Teor em peso $(\%)$ & 0,10 & 0,015 & 0,25 & 0,03 & 0,30 & 0,30 \\
\hline
\end{tabular}

Fonte - [46]

A TAB. 3 apresenta os valores de referência para o comportamento mecânico do Ti Gr. 2 CP.

TABELA 3 - Limites de tensão para o Ti Gr. 2 CP

\begin{tabular}{ccc}
\hline $\begin{array}{c}\text { Resistência à tração } \\
(\mathrm{MPa})\end{array}$ & $\begin{array}{c}\text { Limite de } \\
\text { escoamento }(\mathrm{MPa})\end{array}$ & $\begin{array}{c}\text { Alongamento } \\
\text { mínimo (\%) }\end{array}$ \\
\hline 343 & $275-410$ & 20 \\
\hline
\end{tabular}

Fonte $-[46]$

\subsection{Texturização de chapas de Ti Gr. 2 CP com espessura de $0,1 \mathrm{~mm}$ utilizando laser com pulsos de nanossegundos}

Inicialmente foram texturizadas chapas de $\mathrm{Ti}$ com espessura de 0,1 $\mathrm{mm}$ utilizando laser com pulsos de nanossegundos. O material utilizado foi uma chapa laminada de Ti Gr. 2 CP com rugosidade superficial média (Ra) de 0,15 \pm $0,02 \mu \mathrm{m}$; para medição da rugosidade foi utilizado um rugosímetro apalpador com ponta de diamante da marca Hommel, modelo Tester T600. A geometria de texturização está indicada na FIG. 7.

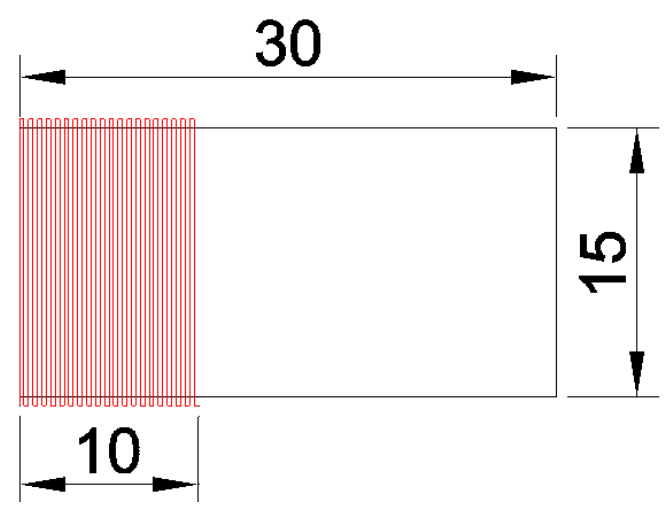

FIGURA 7 - Geometria das texturizações em zig-zag executadas nas chapas de $0,1 \mathrm{~mm}$. 


\subsection{Amostras para realização dos métodos Dano Zero e D-Scan}

O ponto de partida para a microusinagem controlada com laser de femtossegundos é a determinação do limiar de ablação. Para isto foram realizados dois métodos, já mencionados anteriormente, que são os métodos do Dano Zero e o D-Scan.

Para tal, inicialmente foram preparadas 4 amostras no Laboratório de Materiais Nucleares do Centro Experimental Aramar do Centro Tecnológico da Marinha em São Paulo (LABMAT-CEA-CTMSP). As amostras de Ti Gr. 2 CP com espessura 2,0 mm e dimensões $10,0 \mathrm{~mm} \times 15,0 \mathrm{~mm}$ passaram por processo de embutimento utilizando embutidora Simplimet 1000 marca Buehler; processo de polimento utilizando lixas SiC Gr. 400, 600, 1200 e $2400 \mu \mathrm{m} 3$ pastas diamantadas 9, 6 e $3 \mu \mathrm{m}$, politrizes Minimet 1000 e Ecomet 3, ambas da marca Buehler; e determinação de rugosidade por rugosímetro Perthometer M1 marca Mahr e padrão de rugosidade Mitutoyo.

\subsection{Limpeza das amostras}

A fim de padronizar a qualidade superficial das amostras, antes de todas as etapas de microusinagem, foi realizado procedimento de limpeza partindo-se de uma pré-limpeza com desengraxante/desoxidante leve marca Avesta modelo Cleaner, posteriormente uma limpeza secundária com água e detergente em ultrassom por 5 minutos e por fim uma limpeza com álcool isopropílico e secagem com papel para limpeza de superfícies ópticas para eliminação de qualquer resíduo. Antes da realização das análises em MEV o procedimento de limpeza descrito acima foi repetido.

\subsection{Determinação do limiar de ablação pelo método Dano Zero}

A ideia inicial foi a de se obter uma texturização formada por um conjunto de pontos cuja geometria, de cada ponto, fosse a de um furo cego com profundidade e paredes rugosas o suficiente para propiciar uma boa aderência. A formação de paredes rugosas implica na obtenção de um processo no qual não haja a produção de calor com consequente fusão e ressolidificação de material. A grande profundidade do furo implica em uma alta densidade de energia depositada, enquanto que a não produção de calor requer o oposto, ou seja, uma 
baixa densidade de energia (baixa fluência). Uma solução para este problema seria a de obter um furo profundo através da sobreposição de muitos pulsos com baixa fluência [47]. Esta estratégia, contudo, deve levar em conta o efeito de incubação, que reduz a região de baixa fluência com o aumento no número de pulsos sobrepostos. Assim, é preciso conhecer a relação entre o limiar de ablação e o número $\mathrm{N}$ de pulsos sobrepostos para garantir um processo sem ZTA. Mais ainda, é preciso que se encontre uma solução que garanta esta condição e ao mesmo tempo leve a um furo relativamente profundo.

A produção de furos cegos com informação de limiar de ablação em função do número $\mathrm{N}$ de pulsos pode ser obtida através do método de Dano Zero, conforme a metodologia descrita na sequência.

Inicialmente foi feita a estimativa da fluência. Considerando-se o modelo de propagação de um feixe gaussiano, foi calculado o valor teórico do diâmetro do feixe na superfície da amostra pela Equação 22 [47].

$$
\phi=4 \cdot M^{2} \cdot \lambda \cdot f /\left(\pi \cdot \phi_{0}\right)
$$

onde $\phi$ é o diâmetro do feixe no foco, $\mathrm{M}^{2}$ é o fator de qualidade do feixe, $\lambda$ é o comprimento de onda do laser, f é o comprimento focal da lente e $\phi_{0}$ é o diâmetro do feixe na entrada da lente.

Visando o melhor posicionamento possível, o ajuste da distância focal foi realizado inicialmente utilizando uma energia de $60 \mu \mathrm{J}$ e taxa de repetição 4 $\mathrm{kHz}$, para que fosse possível visualizar a formação de plasma no ar. A superfície da amostra foi então posicionada manualmente próxima ao ponto luminoso, visível através de uma câmera ccd, sendo este ajuste feito por meio de um micrômetro. Para refinamento do posicionamento, a energia dos pulsos foi diminuída para $15 \mu \mathrm{J}$ e a taxa de repetição baixada para $5 \mathrm{~Hz}$. Nestas condições, foram realizadas seguidas irradiações sobrepostas de 5 pulsos em diferentes posições ao longo do eixo x (espaçadas em $50 \mu \mathrm{m}$ ) e variando-se a altura através do eixo eixo z (com deslocamentos de $20 \mu \mathrm{m}$ ) para cima e para baixo.

Como cada marcação corresponde a uma posição focal diferente em torno da posição ajustada manualmente, foi possível encontrar através de um microscópio, a menor marcação que corresponde à irradiação com o diâmetro o 
mais próximo possível de $\phi$ (cintura do feixe). Este plano focal é então usado no procedimento para irradiações. Esse procedimento para encontrar as marcações pela cintura do feixe na amostra foi utilizado em todas as vezes que houve alguma variação na posição da superfície da amostra devido aos suportes utilizados.

Foram usinadas 09 matrizes variando-se os parâmetros energia e número de pulsos sobrepostos. Para tal, foram elaborados programas em linguagem $\mathrm{CNC}$, com controle do número de pulsos sobrepostos em cada ponto ablacionado, além das coordenadas em x e y. Em todos os casos foi utilizado o gás inerte argônio (Ar) com pureza superior a 99,999\% para proteção da atmosfera dos pontos ablacionados. Nas matrizes, cada linha contém uma repetição dos pontos ablacionados com a mesma sobreposição. O cálculo da fluência foi realizado conforme a Equação 23.

$F_{0}=\frac{E}{A_{f}}$

onde $F_{0}$ é a fluência, $E$ a energia do feixe e $A_{f}$ é a área do feixe no foco. Os valores da energia são obtidos através da medição do feixe, enquanto que a área é obtida através do conhecimento do diâmetro do feixe no foco. Através da Equação 22 foi calculado o diâmetro teórico do feixe laser focalizado sobre a amostra, resultando no valor de $24 \mu \mathrm{m}$.

A FIG. 8 ilustra a estratégia adotada para microusinagem das matrizes. Nas matrizes de 01 a 05 foram usinadas 8 linhas e 6 colunas, enquanto que nas matrizes de 06 a 09 foram usinadas 8 linhas e 5 colunas.

Através do Microscópio Eletrônico de Varredura (MEV) foram capturadas as imagens de cada ponto ablacionado. Utilizando o software ImageJ foram medidos os diâmetros dos danos ablacionados, para que desta forma pudessem ser traçados os gráficos $F_{0} \times D^{2}$, utilizando o software Origin 8 . 


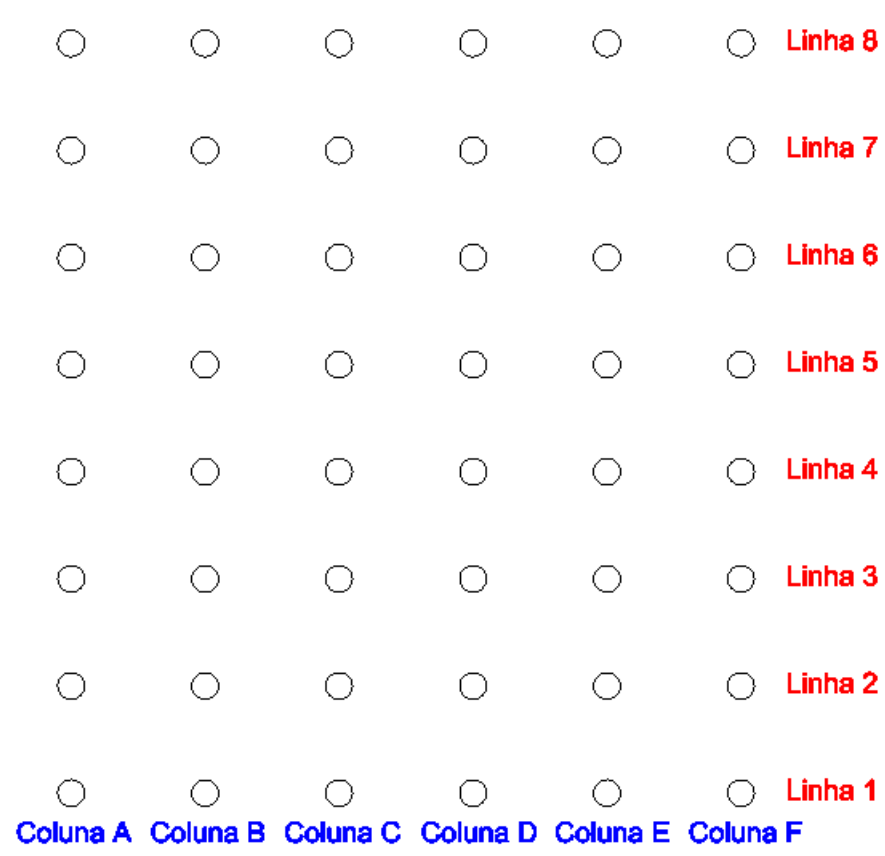

FIGURA 8 - llustração das matrizes usinadas para o método Dano Zero. Todos os seis pontos de cada linha contém o mesmo número $\mathrm{N}$ de pulsos sobrepostos. $\mathrm{N}$ varia para a coluna e a energia é a mesma para todos os pontos da matriz.

\subsection{Determinação do limiar de ablação pelo método D-Scan}

O método D-Scan foi realizado no Laboratório de lasers de altíssima intensidade do CLA-IPEN em uma amostra de mesmas características da utilizada para determinação do limiar de ablação pelo método do Dano Zero. No método foram feitos 28 traços, com frequências de $100 \mathrm{~Hz}, 500 \mathrm{~Hz}$ e $4.000 \mathrm{~Hz}$, energias variando de $67,2 \mu \mathrm{J}$ até $71,2 \mu \mathrm{J}$, sobreposição de 0,24 até $7.950,50$ pulsos. Foi utilizado o gás inerte argônio (Ar) com pureza superior a 99,999\% para proteção da atmosfera das regiões ablacionadas.

Através do MEV foram capturadas as imagens de cada perfil ablacionado. Com o auxílio do software ImageJ foi medida a metade da dimensão transversal de cada um dos 28 perfis gravados, para que desta forma pudesse ser traçados o gráfico $\mathrm{F}_{\text {th }} \times \mathrm{N}$, utilizando o software Origin 8 .

\subsection{Texturização de chapas de Ti Gr. 2 CP com espessura de 0,1 mm utilizando laser com pulsos ultracurtos}

$\mathrm{Na}$ etapa seguinte, por meio do laser com pulsos ultracurtos foram usinadas texturizações com as mesmas geometrias realizadas por laser com pulsos de nanossegundos, conforme FIG. 7. Tais geometrias foram obtidas por 
meio de programa CNC, gerado pelo software MasterCam. As amostras utilizadas foram as mesmas que as utilizadas para o caso anterior.

O objetivo nesta etapa foi o de se obter uma textura composta de pontos do tipo furos cegos, conhecidos como "dimples", espaçados uns dos outros. No sistema utilizado, a sincronização entre o pulso laser e o posicionamento espacial sobre a peça processada só é possível com uma parada de movimento para cada ponto. Isto, obviamente, leva a um tempo de microusinagem extremamente alto, inviabilizando o processo. Assim, a opção foi a de controlar o espaçamento entre os pontos através da relação adequada entre a velocidade de varredura do feixe sobre a amostra e a taxa de repetição dos pulsos laser.

Com este procedimento, contudo, não foi possível o acúmulo controlado de pulsos em uma mesma posição. Assim, a única maneira de se obter variação no diâmetro e profundidade dos pulsos é através da variação da energia de cada pulso.

Para determinação da velocidade com que o feixe deveria percorrer a amostra, foi utilizada a Equação 24.

$$
V=\frac{D}{t}=D \cdot f=\frac{D}{N} \cdot f
$$

onde $D$ é o diâmetro do feixe laser no foco sobre a superfície ablacionada, t é o tempo, f é a taxa de repetição do laser e $\mathrm{N}$ é o número de pulsos sobrepostos.

A sobreposição de pulsos $\mathrm{N}$ pode ser explicada como sendo o número de vezes que o feixe laser incide na mesma posição na superfície da amostra. Para isto, o diâmetro $\mathrm{D}$ considerado é aquele dado pela definição de diâmetro de um feixe laser gaussiano (cujo raio médio $\omega_{0}$ é medido a $1 / \mathrm{e}^{2}$ da intensidade máxima). Aqui também considera-se que toda energia está uniformemente distribuída na área definida por $\mathrm{D}$. Desta forma, a sobreposição $\mathrm{N}$ indicada não deve ser confundida com a sobreposição dos perfis de intensidade (gaussianas) de cada pulso laser. 


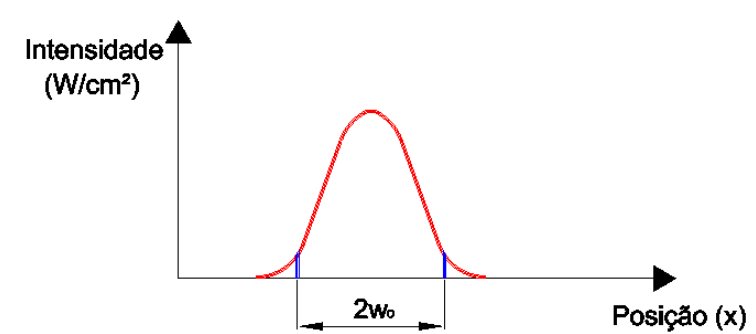

(a)

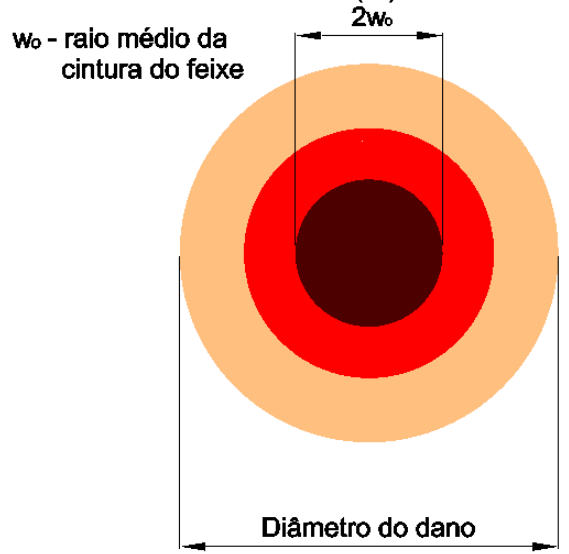

(b)

FIGURA 9 - llustração esquemática da gaussiana de um feixe laser (a) e o dano causado na superfície do material (b).

\subsection{Texturização em amostras de $2 \mathrm{~mm}$ de espessura}

$\mathrm{Na}$ sequência dos experimentos foram texturizadas amostras com 2 $\mathrm{mm}$ de espessura. O material utilizado foi uma chapa laminada de Ti Gr. 2 CP com rugosidade superficial média $(\mathrm{Ra})$ de 2,88 $\pm 0,08 \mu \mathrm{m}$; para medição da rugosidade foi utilizado um rugosímetro apalpador com ponta de diamante da marca Hommel e modelo Tester T500.

\subsection{Microscopia eletrônica de varredura (MEV)}

As análises de MEV foram realizadas no CLA-IPEN. Trata-se de um microscópio de bancada modelo TM3000 marca Hitachi, com análise em três dimensões (3D) e que possui também Espectrometria de Energia Dispersiva (EDS).

Para tratamento das imagens em 3D o equipamento disponibiliza 0 software 3D-Image Viewer.

\subsection{Difratometria de raios- $X$}

A difratometria de raios- $x(\mathrm{DRX})$ foi realizada no Centro de Ciência e Tecnologia de Materiais (CCTM-IPEN), utilizando o difratômetro de raios-x marca 
Rigaku modelo Multiflex a 40 kV e 20 mA usando radiação de Cu-ka $(\lambda=1,54184$ $\AA ̊ 冂)$. Foram selecionadas a amostra 3 da texturização $01\left(F_{0}=23,2 \mathrm{~J} / \mathrm{cm}^{2}\right)$ e a amostra 3 da texturização $03\left(F_{0}=3,3 \mathrm{~J} / \mathrm{cm}^{2}\right)$ realizadas com o laser com pulsos ultracurtos para realização das análises, além da texturização realizada pelo laser com pulsos de nanossegundos.

\subsection{Perfilometria óptica}

As análises de perfilometria óptica foram realizadas no CLA-IPEN, no perfilômetro ZeGage Zemetric marca Zygo com duas lentes ópticas objetivas, uma com magnificação de 20 vezes e outra de 50 vezes.

Através das imagens obtidas na perfilometria foram determinados os perímetros médios e os volumes médios para cada célula unitária resultante das texturizações. A determinação destes valores foi possível através da análise do perfil da microusinagem realizada, que é gerado pelo software do perfilômetro. Tal perfil foi analisado no software ImageJ, sendo possível assim a mensuração dos valores supracitados que são uma média de perfis de 5 células unitárias para cada texturização.

\subsection{Medição da molhabilidade}

Foram medidos os valores de molhabilidade na superfície das 03 condições de texturização usinadas e ainda na amostra sem texturização. A medição da molhabilidade foi realizada pelo método do ângulo de contato da gota séssil, conforme a norma da American Society for Testing and Materials ASTM D 5725-99 [48].

Utilizando uma pipeta com controle de volume micrométrico da marca HTL modelo LM10 foi possível adicionar uma gota de 0,500 $\mu \mathrm{L} \pm 0,018 \mu \mathrm{L}$ de água sobre a superfície para então obter a imagem do perfil da referida gota sobre a superfície da amostra.

Para captação das imagens foi utilizado um arranjo produzido no CLAIPEN que consiste em um conjunto óptico com uma câmera CMOS marca Thorlabs modelo DCC1545C de resolução $1280 \times 1024$ pixels, acoplada a um sistema de zoom com magnificação variável de até 12 vezes.

A captação da imagem das gotas ocorreu após 2 segundos o contato com a superfície das amostras. As imagens obtidas foram então exportadas para 
o software ImageJ, no qual foram medidos os ângulos de contato. Os resultados apresentados são uma média de 5 repetições consecutivas para cada amostra.

\subsection{Junção por adesão das amostras de Ti Gr.2 CP e CFRP}

A colagem foi realizada no Instituto de Estudos Avançados do Centro Técnico Aeroespacial IEAv-CTA. Foi utilizado o adesivo estrutural DP-460 ScotchWeld marca 3M, cujo tempo de cura é de 24 horas.

Antes da colagem as amostras foram limpas em ultrassom com detergente e após secagem foi aplicado o adesivo estrutural, sendo mantido em temperatura controlada durante todo o procedimento até a cura completa. Como referência para a colagem foram utilizadas as normas ASTM D1002-01 [50] e ASTM D5868-01 [51], porém com as dimensões das amostras reduzidas. Devido à escassez de material para confecção das amostras, as dimensões foram reduzidas, contudo a área de colagem manteve-se dentro da faixa recomendada pelas normas.

O quadro da FIG. 10 apresenta as dimensões recomendadas pela referida norma bem como as dimensões adotadas neste trabalho.

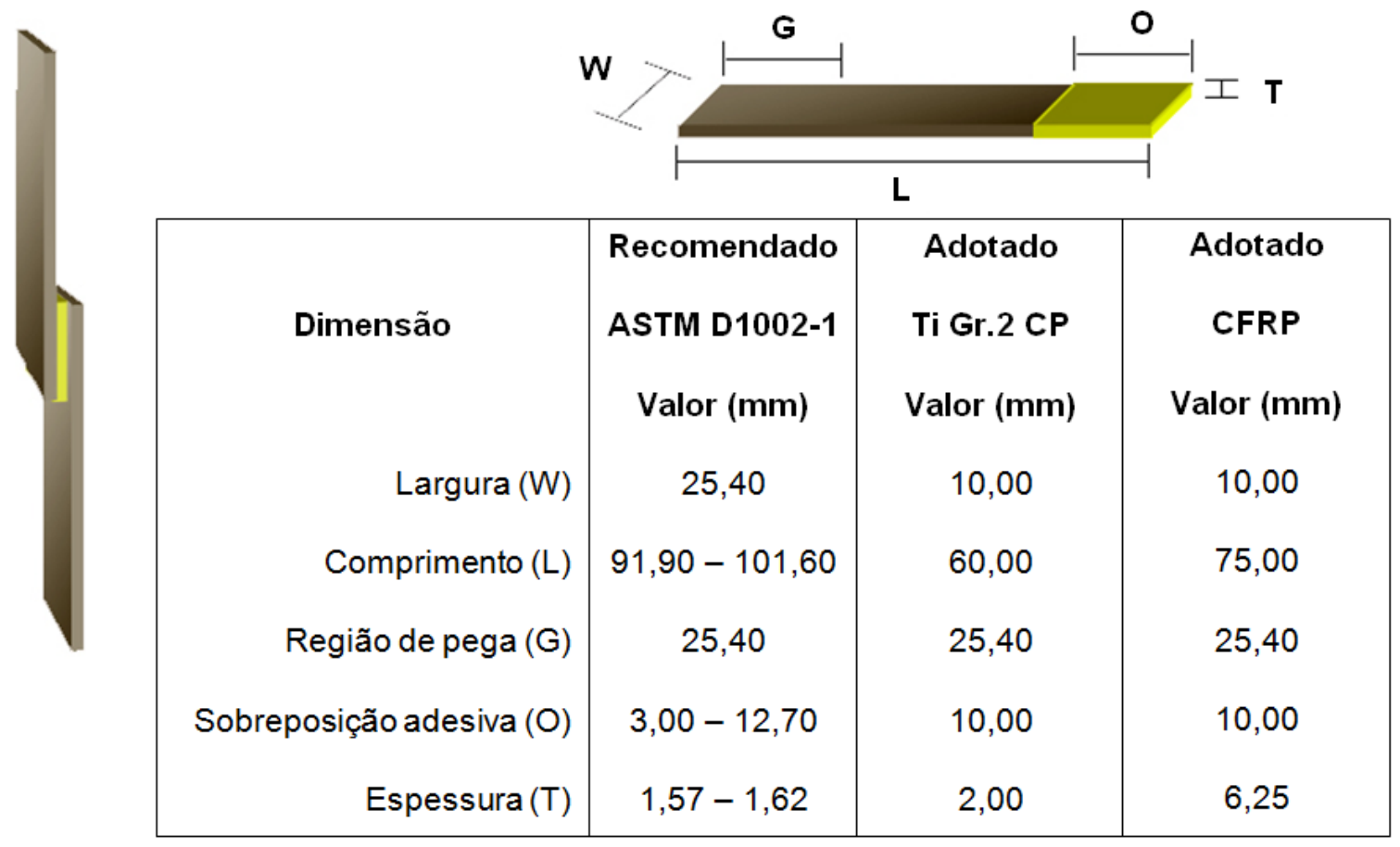

FIGURA 10 - Dimensões da norma ASTM D1002-1 e adotadas neste trabalho. 
A norma ASTM D1002-01 [50] trata de junção por adesão metal-metal, enquanto que a ASTM D5868-01 [51] sobre junção por adesão entre CFRP-CFRP e metal-CFRP, porém as dimensões das amostras são as mesmas para ambos os casos.

Além das junções em todas as amostras de Ti Gr.2 CP texturizadas às amostras de CFRP, foram realizadas também as junções de três amostras de Ti Gr.2 CP sem texturização às amostras de CFRP.

\subsection{Ensaios de tração}

Após realizadas as junções por adesão das amostras de Ti Gr. 2 CP ao CFRP, foram realizados os ensaios para a determinação do limite de ruptura por cisalhamento da região colada.

Os ensaios de tração foram realizados no Centro Tecnológico da Marinha em São Paulo (CTMSP), utilizando uma máquina de tração universal marca Instron, modelo 5500R de capacidade $15.000 \mathrm{kgf}$, com uma célula de carga de $15.000 \mathrm{kgf}$ e gerenciada pelo software Bluehill 2. A FIG. 11 mostra a realização do ensaio de tração em um dos conjuntos de amostras coladas.

As áreas de colagem para determinação de tensão de ruptura ao cisalhamento foram determinadas utilizando-se um paquímetro digital de $150 \mathrm{~mm}$ com resolução 0,01 $\mathrm{mm}$ marca Tesa.

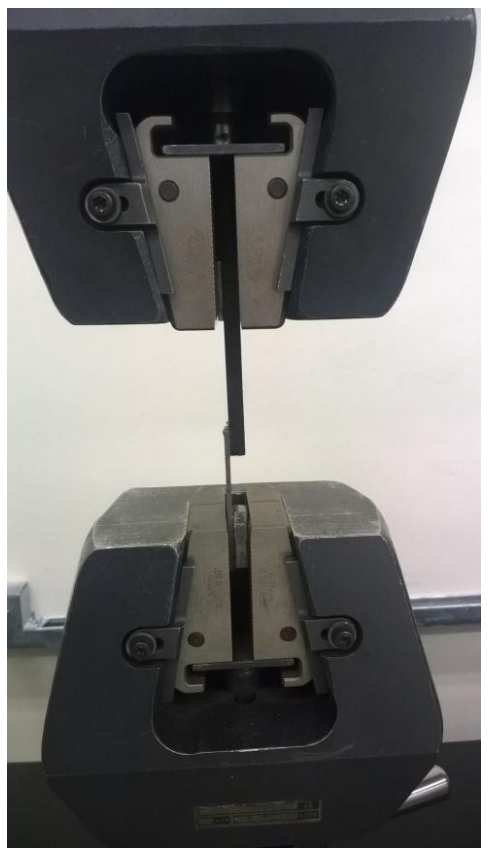

FIGURA 11 - Imagem do ensaio de tração em conjunto de amostras coladas. 


\section{RESULTADOS E DISCUSSÃO}

\subsection{Texturização de chapas de Ti Gr. 2 CP com espessura de 0,1 mm utilizando laser com pulsos de nanossegundos}

As texturizações foram realizadas nas amostras conforme geometria mostrada na FIG. 7. Esta geometria foi obtida diretamente pela introdução de parâmetros no software de comando do sistema de movimentação da mesa.

Na TAB. 4 são apresentados os parâmetros utilizados na texturização utilizando o laser com pulsos de nanossegundos.

TABELA 4 - Parâmetros utilizados para texturização de amostras de Ti Gr. 2 por laser com pulsos de nanossegundos.

\begin{tabular}{ccccc}
\hline Parâmetros & $\begin{array}{c}\text { Energia por } \\
\text { pulso }(\mathrm{mJ})\end{array}$ & $\begin{array}{c}\text { Taxa de } \\
\text { Repetição } \\
(\mathrm{Hz})\end{array}$ & $\begin{array}{c}\text { Velocidade de } \\
\text { microusinagem } \\
(\mathrm{mm} / \mathrm{s})\end{array}$ & $\begin{array}{c}\text { Passo* } \\
(\mu \mathrm{m})\end{array}$ \\
\hline Valor & $15,20 \pm 0,11$ & 20 & 0,96 & 450 \\
\hline
\end{tabular}

* - Distância entre as linhas de texturização

O diâmetro do foco foi calculado através da Equação 22 a partir dos dados do laser utilizado, conforme apresentado na TAB. 5

TABELA 5 - Diâmetro do foco calculado a partir dos dados do laser utilizado

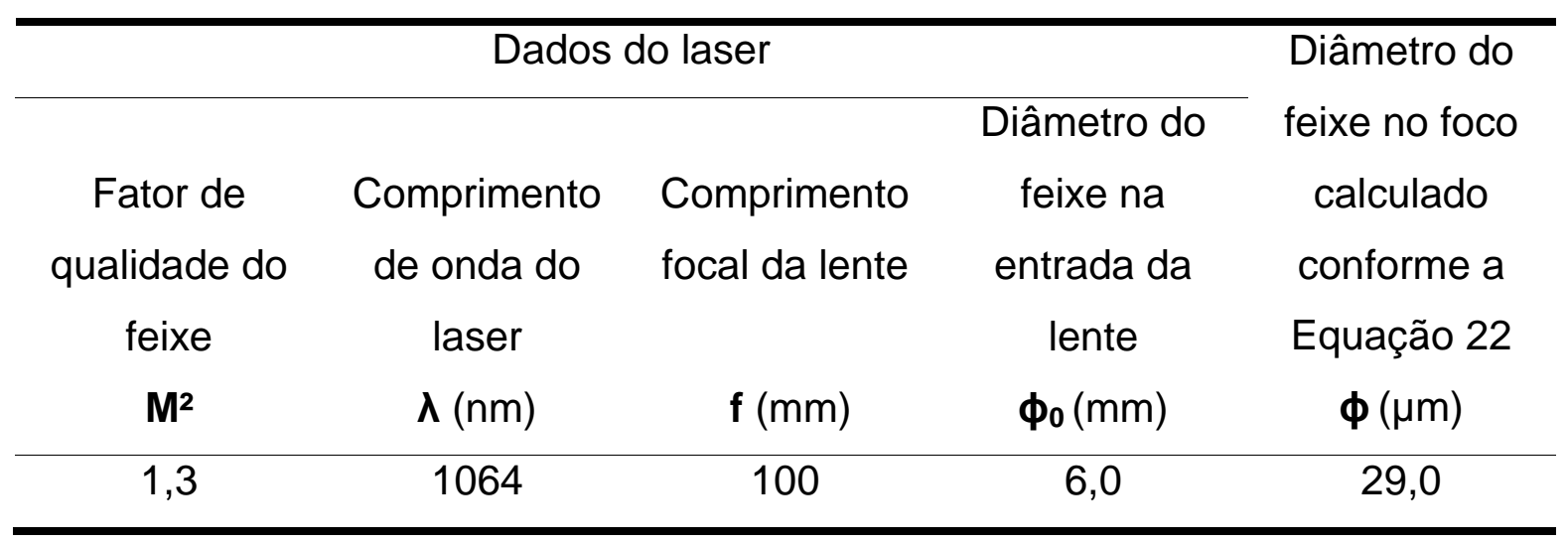

A partir da energia por pulso e do diâmetro do feixe no foco, foi possível calcular a fluência por pulso, conforme a Equação 23, que resultou no valor de 2.303,03 J/cm² $\pm 16,65 \mathrm{~J} / \mathrm{cm}^{2}$, e uma intensidade de $461 \mathrm{GW} / \mathrm{cm}^{2}$. A partir da Equação 24, foi possível calcular a sobreposição, resultando no valor de 0,6 
pulsos, ou seja, não houve sobreposição visto que a distância entre os pulsos é de $48 \mu \mathrm{m}$ (valor este obtido pela relação diâmetro do feixe no foco e o valor 0,6, ou seja, $\left.\phi_{\text {foco }} / 0,6\right)$.

A FIG. 12 mostra a chapa de 0,1 $\mathrm{mm}$ de espessura após microusinagem da texturização.

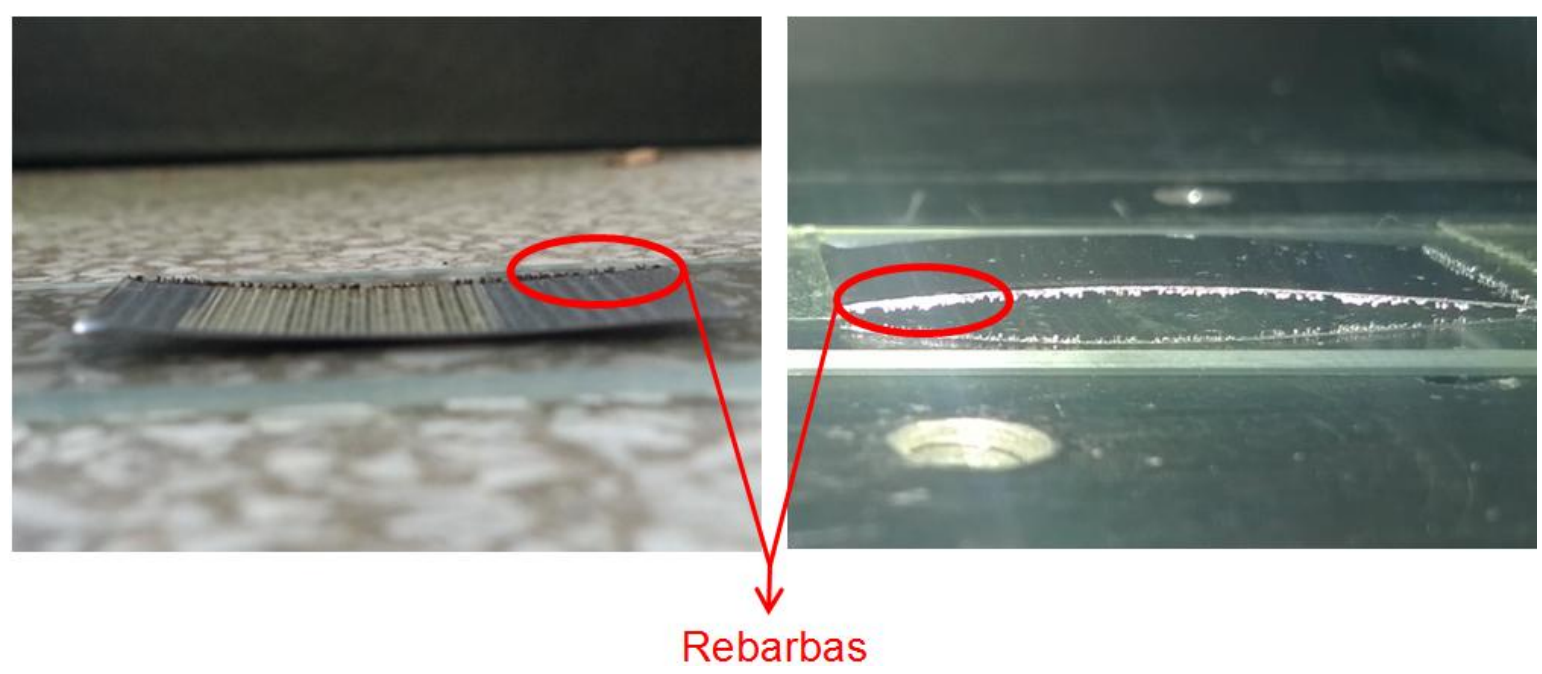

FIGURA 12 - Imagens de chapa de 0,1 mm de espessura texturizada por laser com pulsos de nanossegundos. Rebarbas são observadas devido ao corte da chapa.

Pode-se notar que houve uma grande deformação da chapa, acarretando no empenamento, fator este que é extremamente prejudicial para adesão do CFRP.

São apresentadas as imagens de MEV da superfície texturizada da FIG. 13 até a FIG. 16, onde com aumentos progressivos pode-se notar a presença de material ressolidificado. 


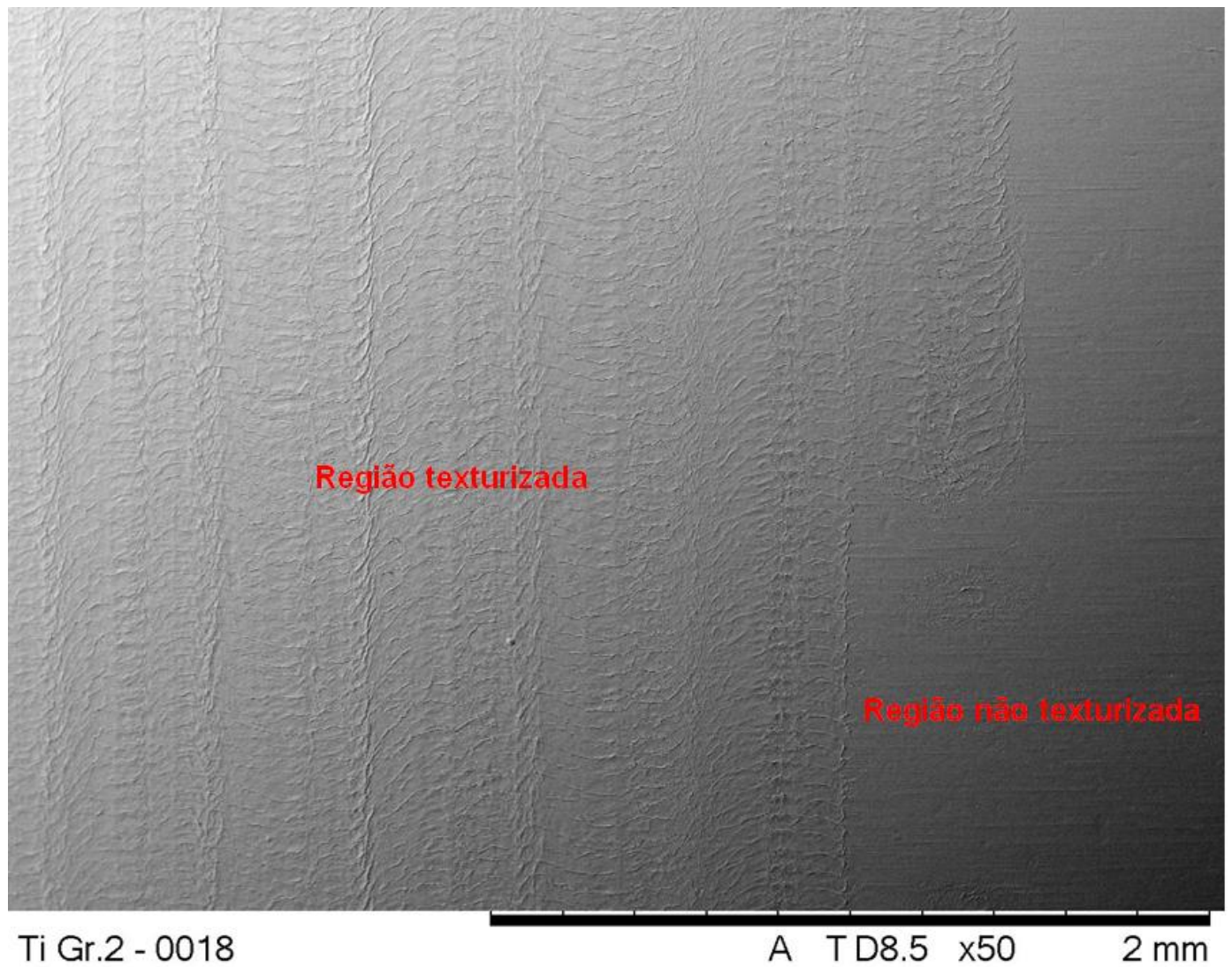

FIGURA 13 - Imagem de MEV de chapa de 0,1 $\mathrm{mm}$ de espessura texturizada por laser com pulsos de nanossegundos. Aumento de 50x.

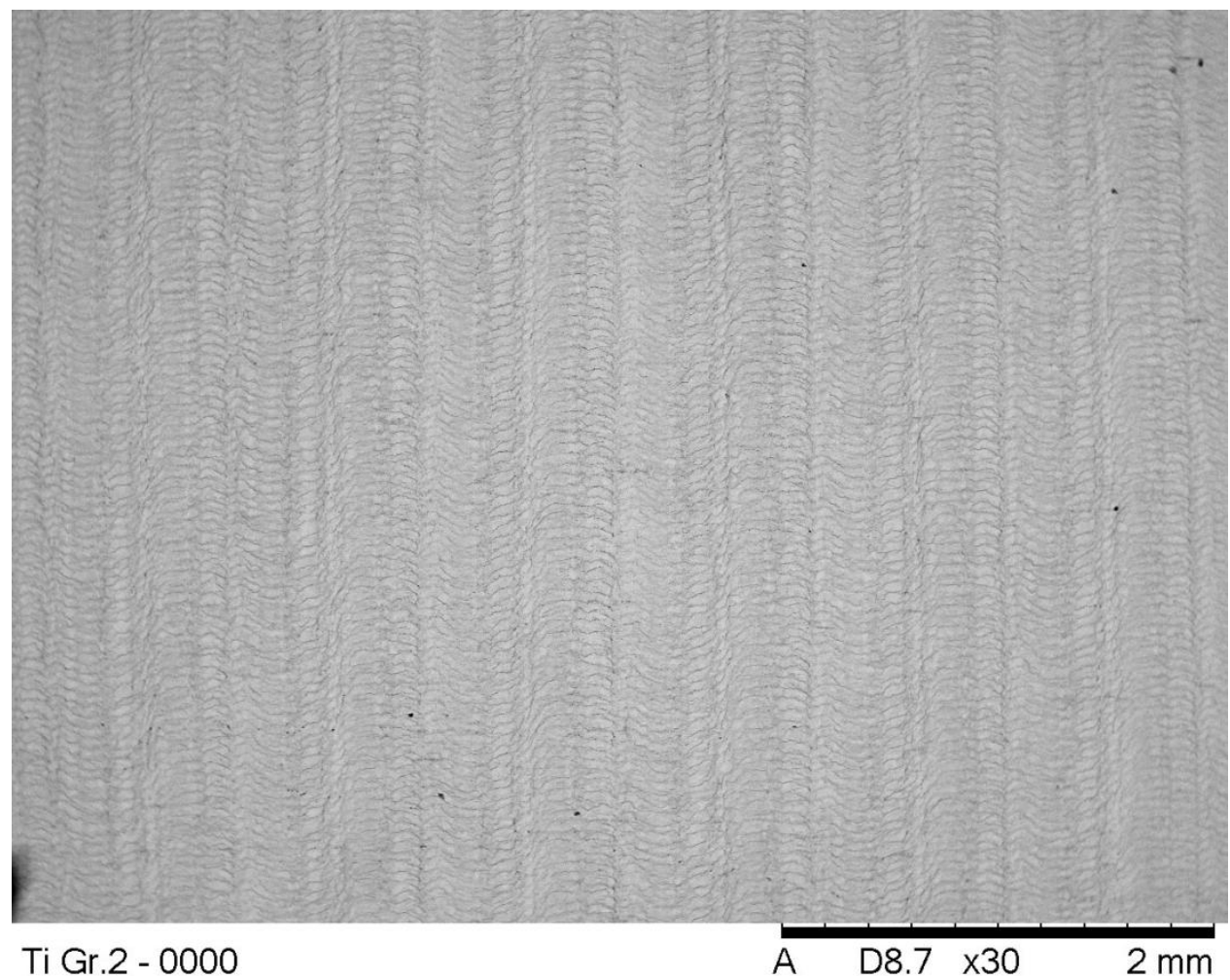

FIGURA 14 - Imagem de MEV de chapa de 0,1 $\mathrm{mm}$ de espessura texturizada por laser com pulsos de nanossegundos. Aumento de 30x. 


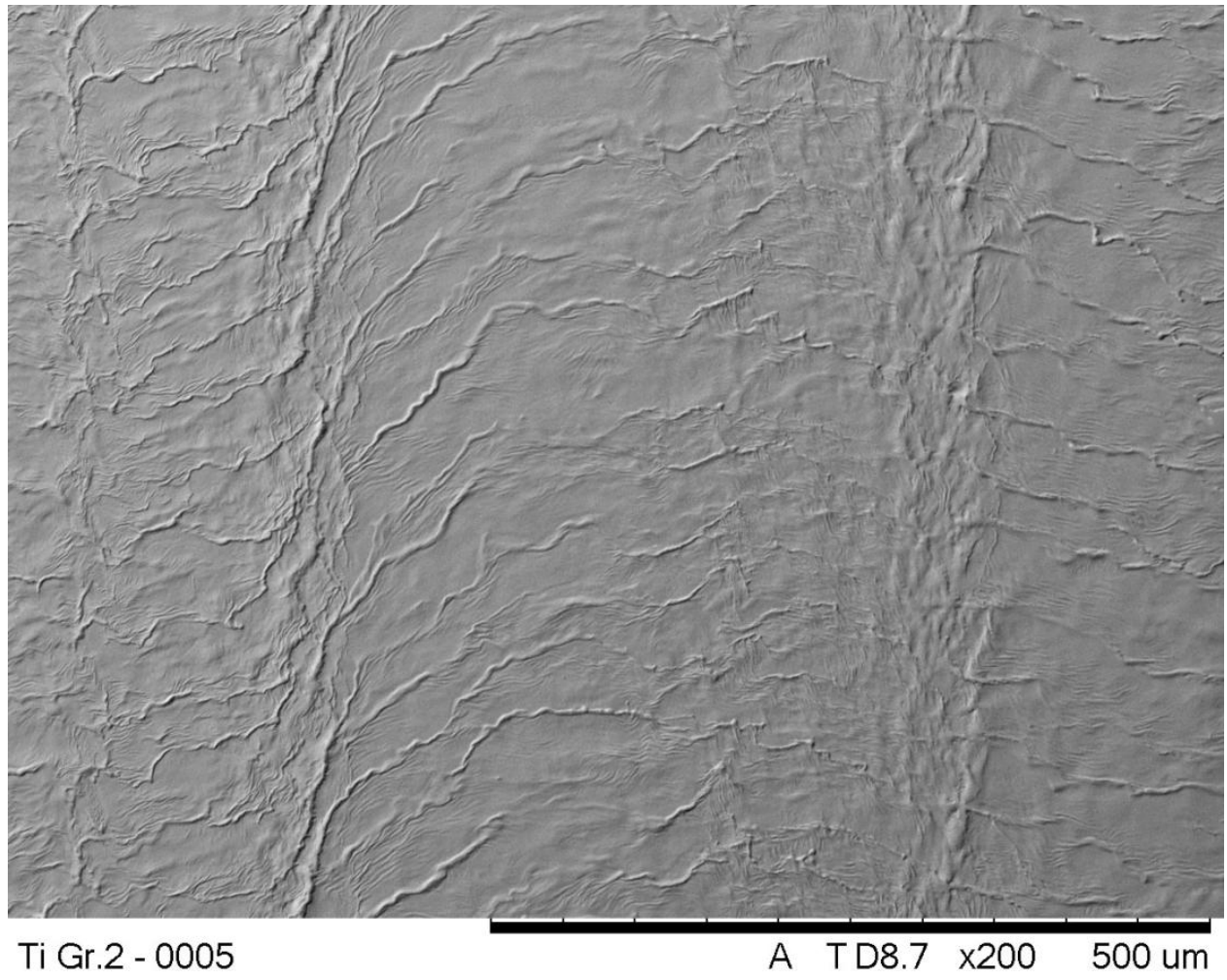

FIGURA 15 - Imagem de MEV de chapa de 0,1 $\mathrm{mm}$ de espessura texturizada por laser com pulsos de nanossegundos. Aumento de 200x.

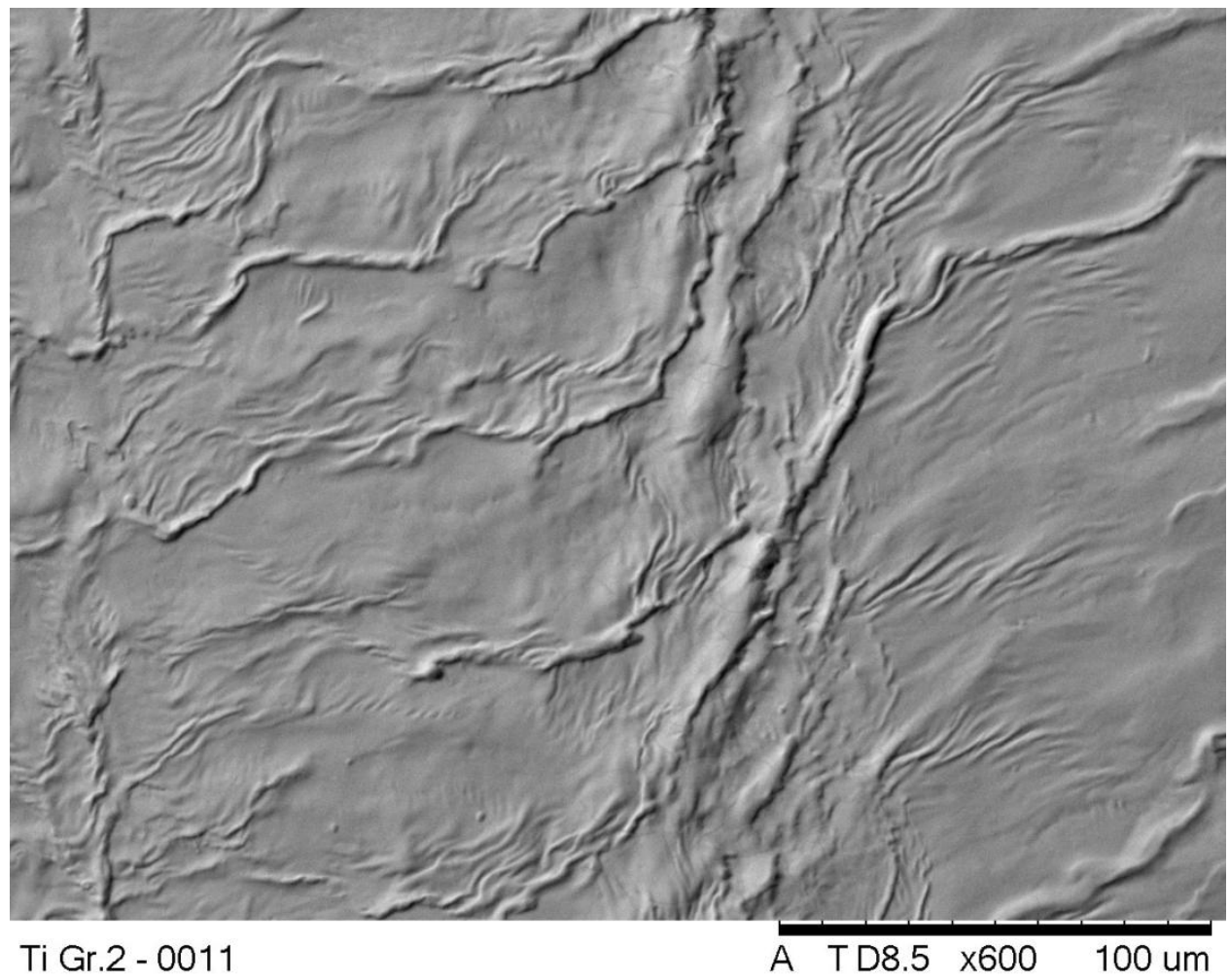

FIGURA 16 - Imagem de MEV de chapa de 0,1 $\mathrm{mm}$ de espessura texturizada por laser com pulsos de nanossegundos. A texturização foi executada na direção vertical. Aumento de 600x. 
Mesmo a distância entre os pulsos sendo $48 \mu \mathrm{m}$ não se observa os pulsos individuais. Nota-se uma textura quase contínua na qual não se percebe a posição da real incidência dos pulsos individuais. Isto deve-se ao fato de que as dimensões dos danos causados ultrapassaram a distância entre os pulsos.

Na FIG. 17 são apresentadas imagens obtidas no MEV com o auxílio do software 3D-Viewer, sendo possível constatar que a profundidade ablacionada na texturização é ínfima $(1,7 \mu \mathrm{m})$, o que para a adesão também é prejudicial, devido à pequena área de contato para a junta adesiva. Pode-se notar ainda pela mesma figura o empenamento da superfície.

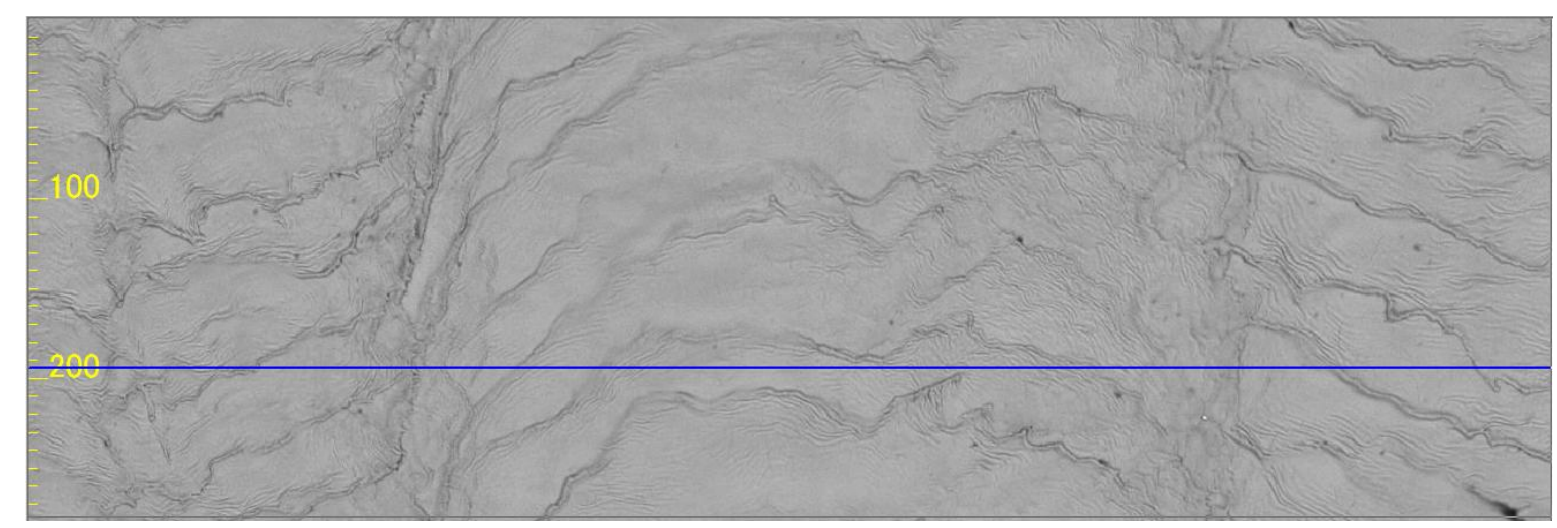

(a)

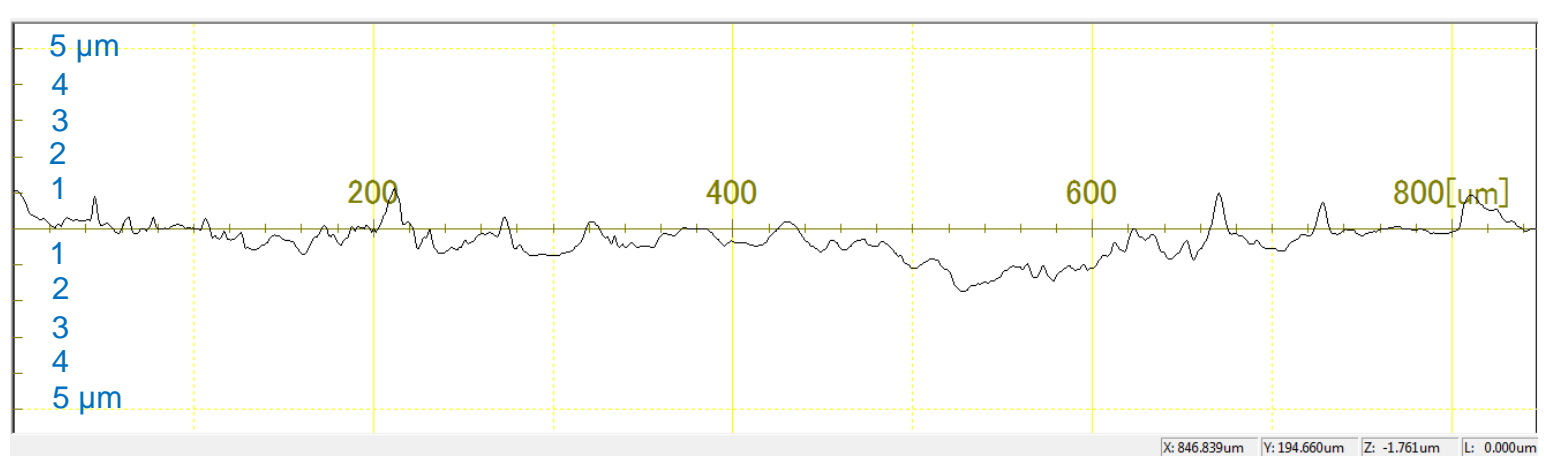

(b)

FIGURA 17 - Imagem de MEV de chapa de 0,1 mm de espessura texturizada por laser com pulsos de nanossegundos (a). Gráfico da topografia da imagem (b).

5.2 Difratometria de raios-X (DRX) em amostra de $0,1 \mathrm{~mm}$ de espessura texturizada por laser com pulsos de nanossegundos

Na FIG. 18 estão os difratogramas de raios-x da amostra texturizada por laser de nanossegundos. 


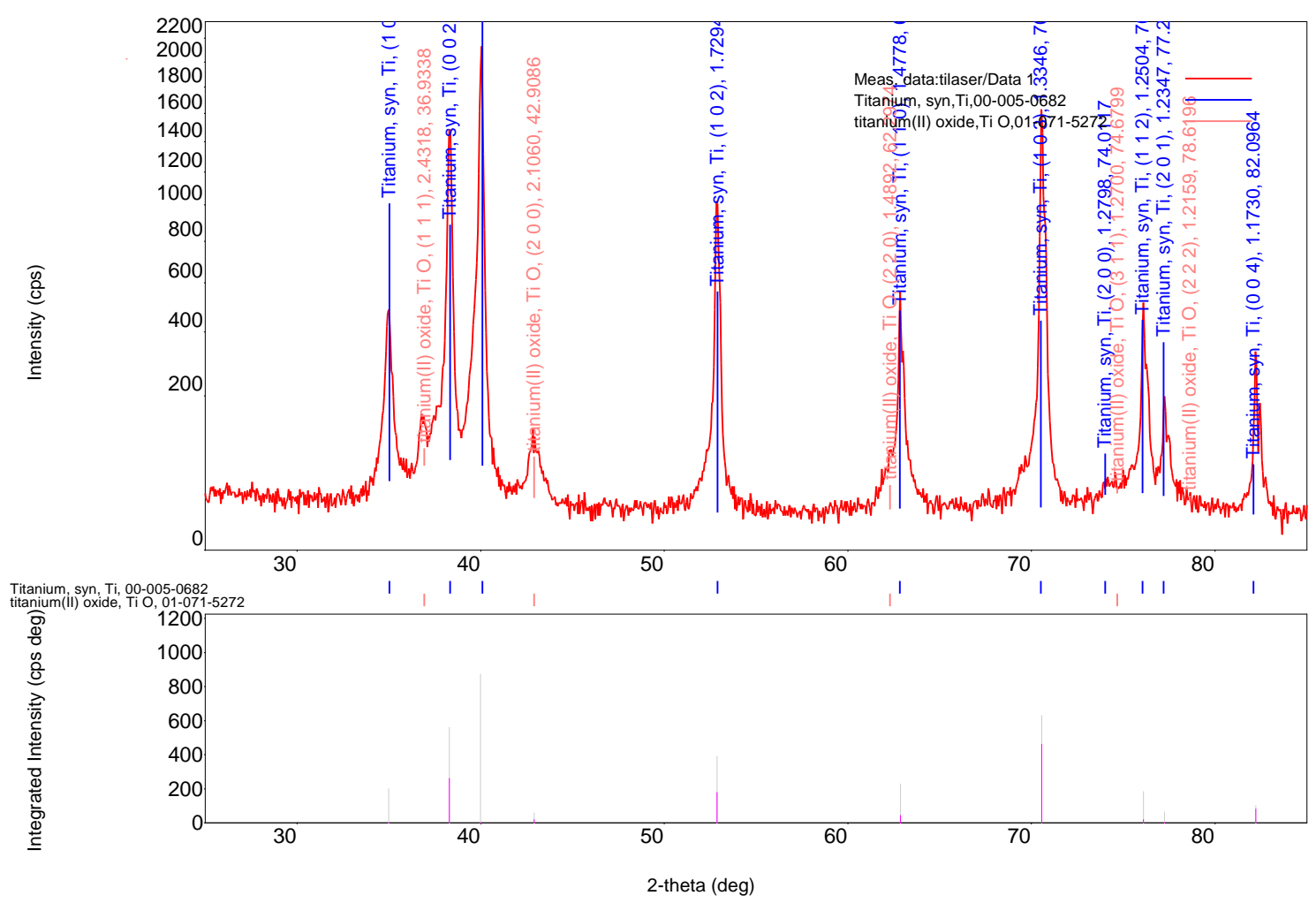

FIGURA 18 - DRX de chapa de $0,1 \mathrm{~mm}$ de espessura texturizada por laser com pulsos de nanossegundos

Pela análise dos difratogramas, é possível atestar que há somente a presença de fase a (Powder Diffraction File - PDF 05-0682), ou seja, não foi detectada fase $\beta$ retida. A técnica utilizada tem sensibilidade para detectar em uma camada de até 1 (um) $\mu \mathrm{m}$. Portanto, se houver a presença de fase $\beta$, ela estaria em uma camada menor que 1 (um) $\mu \mathrm{m}$. Sendo assim, o processo de ablação não proporcionou ao titânio que houvesse a presença de fase $\beta$ após o resfriamento, visto que está presente somente a estrutura cristalina HC. Foi detectada também a presença de óxido de titânio TiO (Powder Diffraction File PDF 71-5272).

No caso de lasers chaveados com pulsos de largura temporal da ordem de nanossegundos, a alta energia do laser é absorvida por uma camada absorvente que cobre a superfície do metal. O material absorvente vaporiza e forma o plasma, sendo que o plasma continua a absorver fortemente a energia do laser até que o final da deposição de energia. O plasma expande rapidamente, criando uma pressão elevada de superfície, que se propaga no interior do material, como uma onda de choque [49]. Isto, aliado ao fato da ocorrência de 
região com muito material ressolidificado, que tem como característica uma superfície mais lisa, ou seja, de rugosidade baixa, a adesão pode ficar prejudicada. Mesmo não tendo sido realizadas análises para verificação da existência de tensões residuais, pode-se perceber que macroscopicamente houve deformações acentuadas na amostra, com considerável empenamento muito possivelmente devido ao aporte térmico do processo.

Desta forma, a partir desta etapa, os trabalhos concentraram-se na realização de texturizações utilizando somente o laser com pulsos ultracurtos. Antes, contudo, foram determinados os limiares de ablação pelos métodos Dano Zero e D-Scan, que são condições preponderantes para o conhecimento dos regimes de baixa e alta fluência para o Ti Gr. 2 CP.

\subsection{Limiar de ablação pelo método Dano Zero}

Para determinação do limiar de ablação pelo método Dano Zero foram utilizadas as amostras embutidas em resina e polidas, cujas superfícies tinham os valores de rugosidade $\mathrm{Ra}(\mu \mathrm{m})$ conforme apresentados na TAB. 6. Os valores apresentados na referida tabela têm uma incerteza de medição de 0,01 $\mu \mathrm{m}$.

TABELA 6 - Valores de rugosidade $\mathrm{Ra}(\mu \mathrm{m})$ das amostras de Ti Gr. 2 CP para realização dos métodos Dano Zero e D-Scan

\begin{tabular}{ccccc}
\hline Medidas & Amostra 1 & Amostra 2 & Amostra 3 & Amostra 4 \\
\hline 1 & 0,06 & 0,07 & 0,09 & 0,05 \\
2 & 0,04 & 0,06 & 0,09 & 0,09 \\
3 & 0,04 & 0,09 & 0,04 & 0,05 \\
Média & $\mathbf{0 , 0 5}$ & $\mathbf{0 , 0 7}$ & $\mathbf{0 , 0 7}$ & $\mathbf{0 , 0 6}$ \\
Desvio Padrão & $\mathbf{0 , 0 1}$ & $\mathbf{0 , 0 1}$ & $\mathbf{0 , 0 3}$ & $\mathbf{0 , 0 2}$ \\
\hline
\end{tabular}

Foram usinadas 9 matrizes com sobreposições de pulsos variáveis ( $\mathrm{N}=1, \mathrm{~N}=4, \mathrm{~N}=16, \mathrm{~N}=32, \mathrm{~N}=64, \mathrm{~N}=128, \mathrm{~N}=512$ e $\mathrm{N}=1024$ ) e taxas de repetição variando de $1 \mathrm{~Hz}$ (para $\mathrm{N}=1$ até $\mathrm{N}=32$ ) e $33 \mathrm{~Hz}$ (para $\mathrm{N}=64$ até $\mathrm{N}=1024$ ). Na TAB. 7 estão apresentados os valores de fluência de energia por pulso utilizados para microusinagem das matrizes e na FIG. 19 está ilustrada a imagem obtida no MEV da matriz ablacionada 08. A vazão de argônio para a usinagem de todas as matrizes foi de $8,0 \mathrm{l} / \mathrm{min}$. 
TABELA 7 - Fluências de energia por pulso para usinagem de matrizes para determinação do limiar de ablação (Dano Zero)

\begin{tabular}{ccc}
\hline Matriz & $\begin{array}{c}\text { Energia por pulso } \\
(\mu \mathrm{J})\end{array}$ & $\begin{array}{c}\text { Fluência } \\
\left(\mathrm{J} / \mathrm{cm}^{2}\right)\end{array}$ \\
\hline 1 & 0,5 & $0,11 \pm 0,04$ \\
2 & 1,0 & $0,22 \pm 0,04$ \\
3 & 2,0 & $0,44 \pm 0,04$ \\
4 & 3,0 & $0,66 \pm 0,04$ \\
5 & 4,0 & $0,88 \pm 0,04$ \\
6 & 5,0 & $1,11 \pm 0,04$ \\
7 & 7,0 & $1,55 \pm 0,04$ \\
8 & 10,0 & $2,21 \pm 0,04$ \\
9 & 15,0 & $3,32 \pm 0,04$ \\
\hline
\end{tabular}

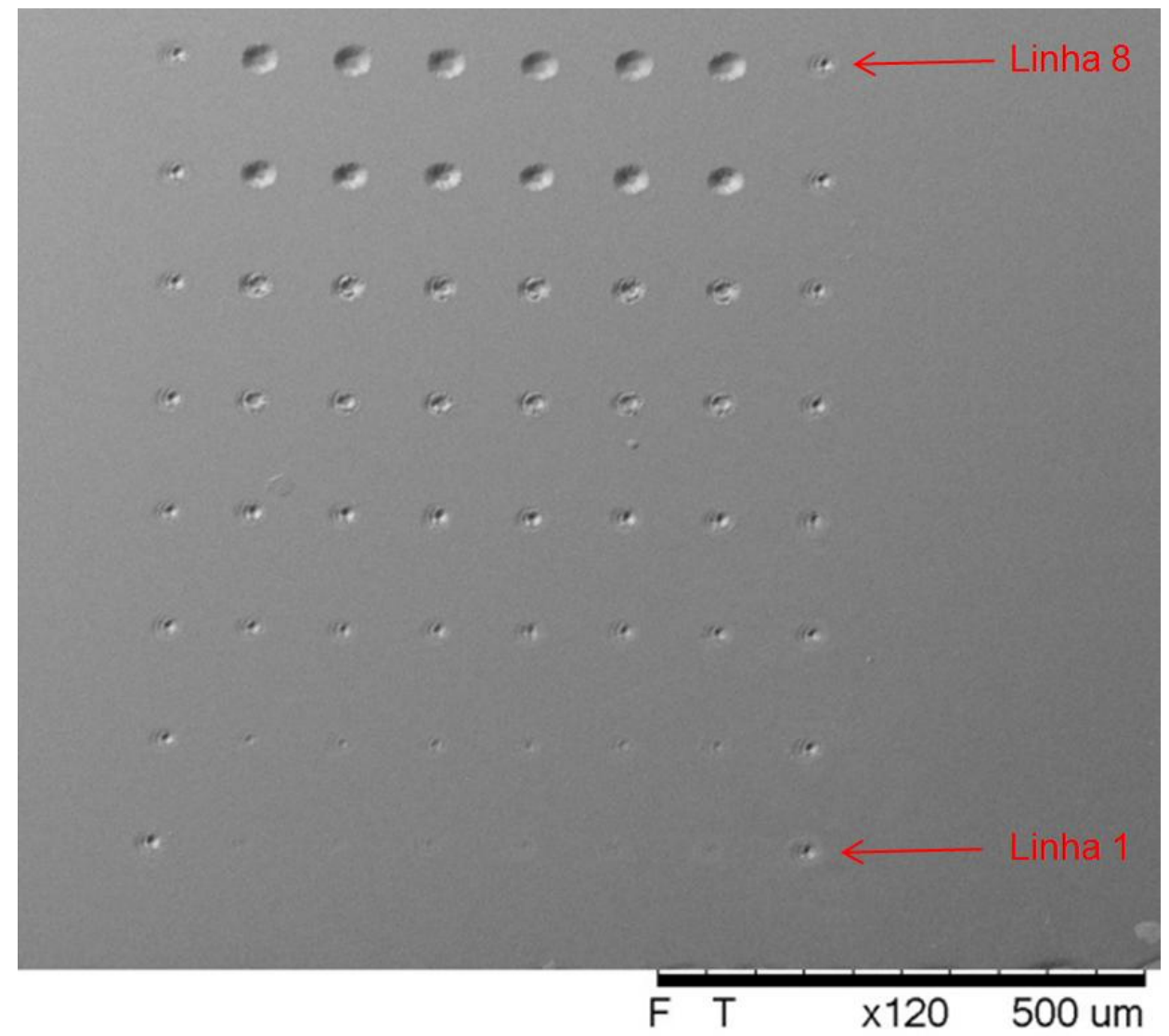

FIGURA 19 - Imagem de MEV da matriz 08 para determinação do limiar de ablação (Dano Zero). As colunas mais externas à direita e à esquerda não fazem parte da matriz, são apenas guias para posicionamento das linhas onde não se tem fluência suficiente para fácil visualização dos danos. Aumento de 120x.

Após a microusinagem de todas as matrizes, foram medidos os diâmetros dos danos ablacionados, através do software ImageJ, conforme 
mostrado na FIG. 20 e os resultados que estão apresentados na TAB. 8, são uma média dos valores encontrados.

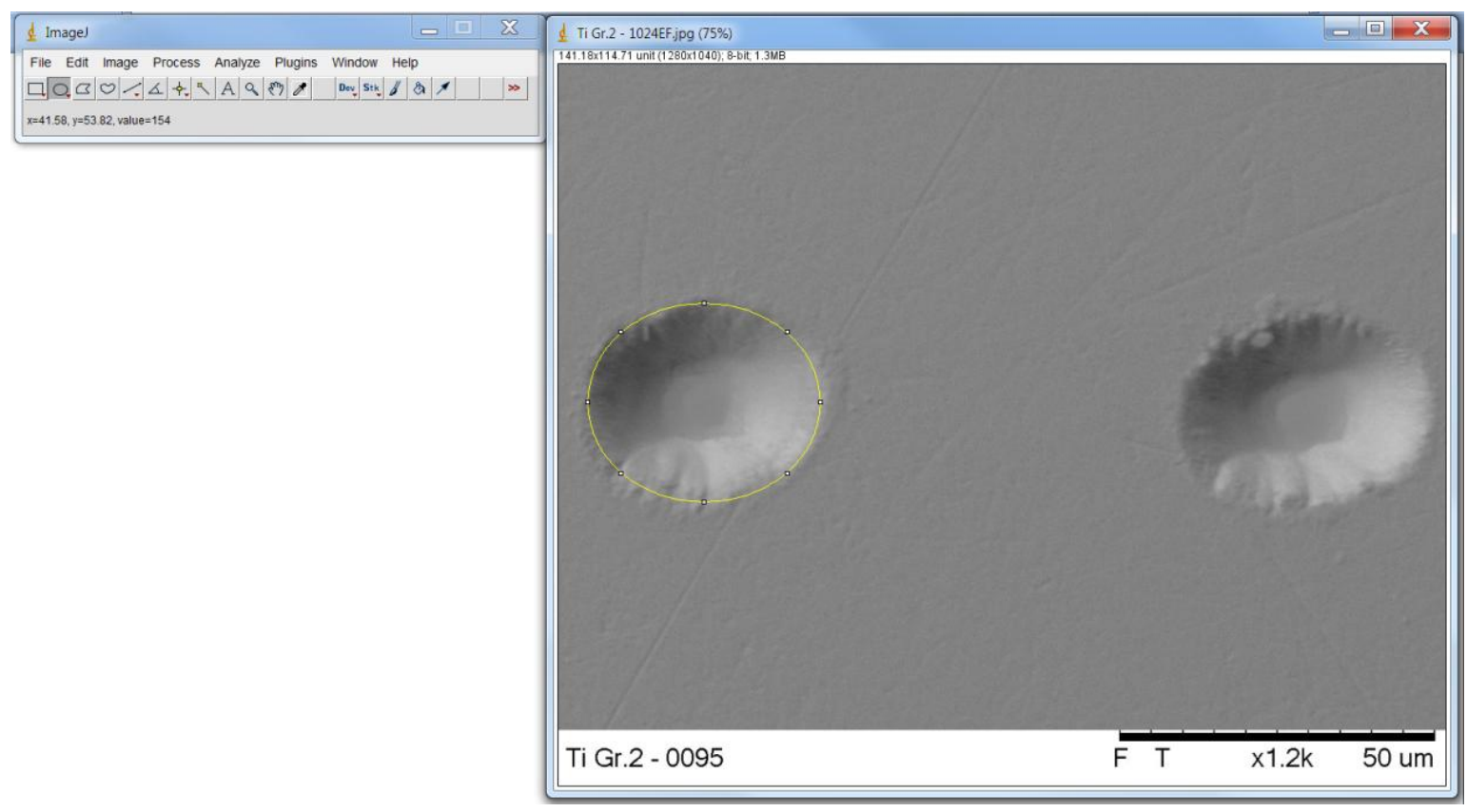

FIGURA 20 - Imagem do software ImageJ para dois pontos da linha 8 da matriz 05. Aumento de 1.200x.

TABELA 8 - Valores medidos de $D^{2}\left(\mu m^{2}\right)$ pelo software ImageJ das imagens obtidas

\begin{tabular}{|c|c|c|c|c|c|c|c|c|c|}
\hline \multirow{2}{*}{$\begin{array}{c}\mathbf{F}_{\mathbf{0}} \\
\left(\mathrm{J} / \mathrm{cm}^{2}\right)\end{array}$} & \multirow{2}{*}{$\begin{array}{l}\mathbf{F}_{\mathbf{0} \text {-corr }} \\
\left(\mathrm{J} / \mathrm{cm}^{2}\right)\end{array}$} & \multicolumn{8}{|c|}{$D^{2}\left(\mu m^{2}\right)$} \\
\hline & & N1 & N4 & N16 & N32 & N64 & N128 & N512 & N1024 \\
\hline 0,11 & 0,16 & 66,87 & 91,18 & 116,93 & 166,80 & 218,60 & 271,62 & 336,60 & 370,53 \\
\hline 0,22 & 0,32 & 106,40 & 124,32 & 223,65 & 256,61 & 331,82 & 397,70 & 437,26 & 530,80 \\
\hline 0,44 & 0,64 & 141,49 & 167,06 & 294,32 & 380,35 & 444,02 & 507,94 & 573,16 & 656,77 \\
\hline 0,66 & 0,96 & 176,16 & 223,05 & 485,76 & 703,71 & 712,09 & 736,85 & 773,26 & 879,42 \\
\hline 0,88 & 1,28 & 251,98 & 301,75 & 693,37 & 822,54 & 892,28 & 874,44 & 911,32 & 999,32 \\
\hline 1,11 & 1,62 & 296,01 & 398,00 & 757,26 & 901,40 & 982,20 & 1033,78 & 1105,29 & 1133,78 \\
\hline 1,55 & 2,26 & 315,13 & 490,36 & 790,29 & 919,12 & 1022,15 & 1064,98 & 1127,62 & 1224,79 \\
\hline 2,21 & 3,23 & 372,33 & 551,39 & 819,73 & 1027,42 & 1171,24 & 1206,64 & 1269,08 & 1471,81 \\
\hline 3,32 & 4,85 & 426,46 & 572,26 & 1053,98 & 1185,63 & 1298,52 & 1349,98 & 1453,59 & 1561,36 \\
\hline
\end{tabular}

A fluência calculada utiliza a área do foco, que leva uma grande incerteza no valor do diâmetro do feixe. Assim, os gráficos de $\mathrm{Fo}(\mathrm{N}=1) \times \mathrm{D}^{2}$ foram utilizados para o cálculo do valor médio de $w_{0}$ conforme a Equação 19. Isto resultou em uma modificação no valor médio do diâmetro do feixe no foco de 
$24 \mu \mathrm{m}$ para $16,4 \mu \mathrm{m}$. Com o novo valor do diâmetro do feixe no foco, foram corrigidos os valores das fluências ( $F_{0 \text {-corr }}$ ) e os dados da TAB. 8 foram utilizados e através do software OriginPro 8 traçados para cada sobreposição.

É sabido, contudo, que estas curvas incluem dois comportamentos distintos: uma região de baixa fluência, sem efeitos térmicos (ou muito pouco para o caso de metais), e uma região de alta fluência, onde a maior parte do material é expelido na forma de líquido. Assim, as curvas foram divididas nestas duas partes, resultando em dois limiares distintos para baixa e alta fluências. Na FIG. 21 e na FIG. 22 são apresentados os gráficos para somente um pulso e para 1024 pulsos sobrepostos, respectivamente.

Os gráficos da FIG. 21 e FIG. 22 mostram duas retas distintas com um ponto de inflexão. A primeira, com danos e fluência menores corresponde a uma ablação sem efeito térmico (baixa fluência); a ablação Coulombiana é o efeito predominante e não se nota resquício de material fundido. A partir do ponto de inflexão, a eficiência na remoção de material aumenta. Isto acontece porque o efeito térmico é pronunciado e passa a ser o processo predominante para a ejeção de material (alta fluência). O diâmetro e a profundidade do dano aumentam rapidamente.

A partir dos gráficos obtidos, através da extrapolação das retas são obtidos os valores dos limiares de ablação do Ti Gr. 2 CP para cada sobreposição de pulsos pelo método Dano Zero. Os valores estão apresentados na TAB. 9. Como pode ser constatado, os valores dos limiares de ablação são reduzidos à medida que é aumentada a sobreposição de pulsos, devido ao efeito de incubação. 


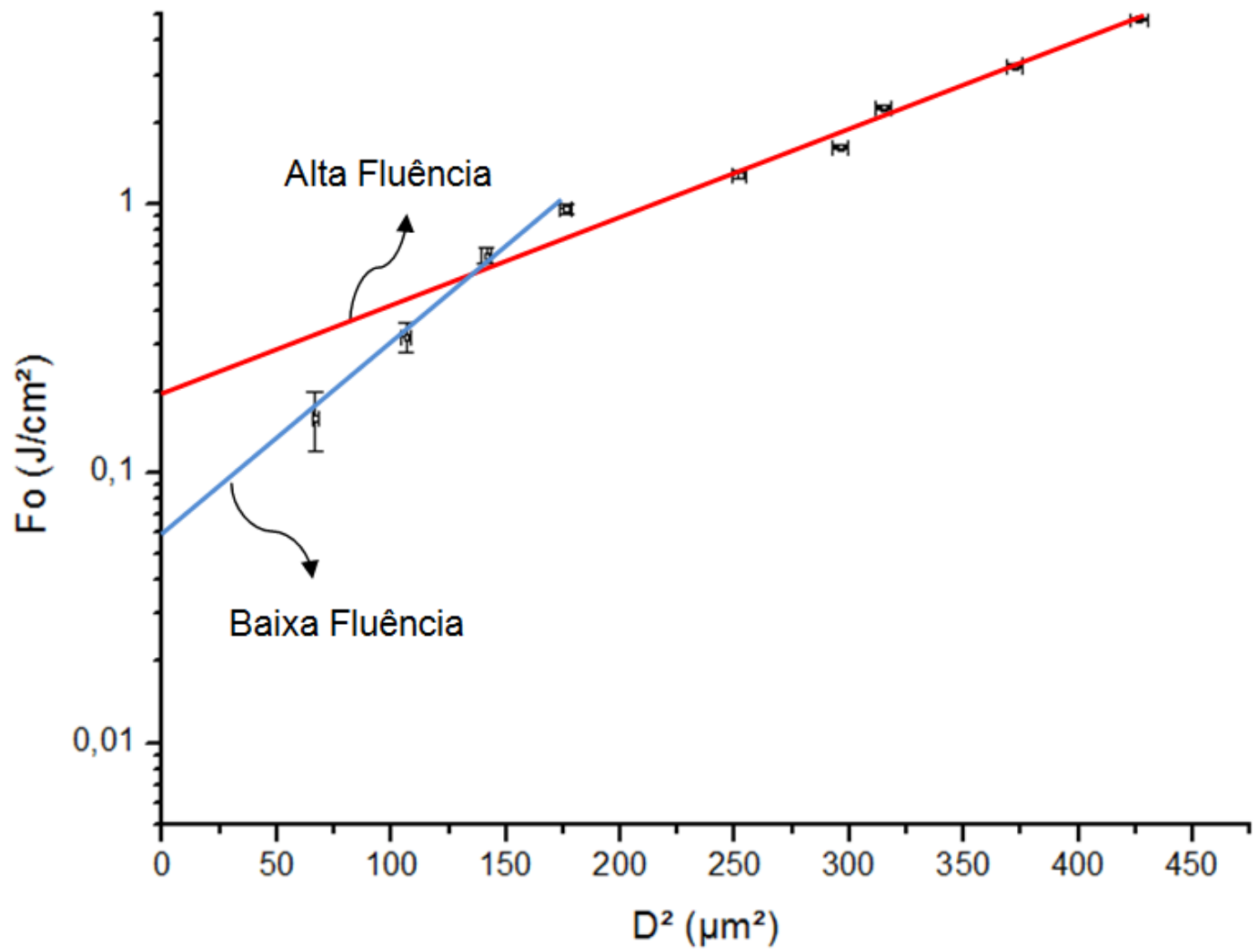

FIGURA 21 - Gráfico $F_{0} \times D^{2}$ para somente 1 pulso (sem sobreposição) pelo método Dano Zero.

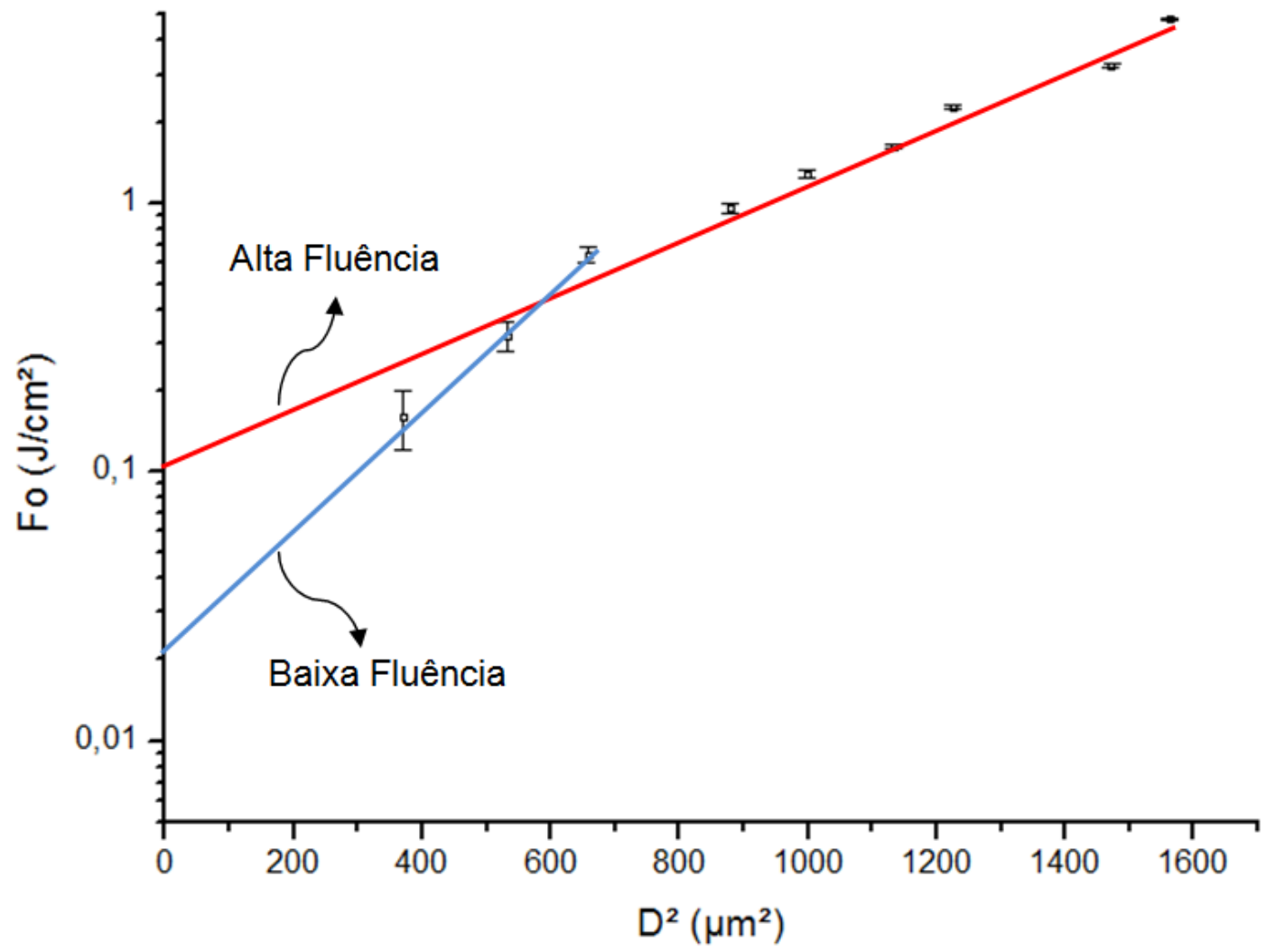

FIGURA 22 - Gráfico $\mathrm{F}_{0} \times \mathrm{D}^{2}$ para sobreposição de 1024 pulsos pelo método Dano Zero. 
TABELA 9 - Valores dos limiares de ablação do Ti Gr.2 CP para cada sobreposição de pulsos

\begin{tabular}{ccc}
\hline Sobreposição de pulsos & $\begin{array}{c}\text { Limiar de ablação para Baixa } \\
\text { Fluência } \\
\mathbf{F}_{\text {th, L }}\left(\mathbf{J} / \mathbf{c m}^{2}\right)\end{array}$ & $\begin{array}{c}\text { Limiar de ablação para Alta } \\
\text { Fluência } \\
\mathbf{F}_{\mathrm{th}, \mathrm{L}}\left(\mathbf{J} / \mathbf{c m}^{2}\right)\end{array}$ \\
\hline $\mathbf{1}$ & 0,06 & 0,21 \\
$\mathbf{1 6}$ & 0,05 & 0,19 \\
$\mathbf{3 2}$ & 0,05 & 0,17 \\
$\mathbf{6 4}$ & 0,04 & 0,15 \\
$\mathbf{1 2 8}$ & 0,03 & 0,13 \\
$\mathbf{5 1 2}$ & 0,03 & 0,12 \\
$\mathbf{1 0 2 4}$ & 0,02 & 0,11 \\
\hline
\end{tabular}

Através dos valores da TAB. 9 pode ser traçado o gráfico do limiar de ablação para baixa fluência versus número de pulsos $\left(F_{\text {th }} \times N\right)$, conforme mostra a FIG. 23, também o gráfico $F_{\text {th }} \times N$ para alta fluência na FIG. 24. Observa-se uma diminuição constante de $F_{\text {th }}$ com o aumento da sobreposição de pulsos. Esta diminuição indica um efeito de memória, ou seja, um efeito de incubação dos defeitos formados. Nas condições utilizadas, não se observa uma saturação até $\mathrm{N}=1024$ pulsos sobrepostos.

Esta não saturação no efeito de incubação inviabiliza a realização de um arranjo de furos conforme inicialmente pretendido. Implica que é preciso manter uma fluência baixa para não haver fusão, o que leva a um furo raso. $O$ aumento da sua profundidade requer maior sobreposição de furos, o que diminui o limiar de ablação e exige uma diminuição da fluência, que, novamente diminui a profundidade do furo.

O limiar de ablação para baixa fluência analisando a FIG. 23 é $F_{\text {th(1) }}=0,06 \pm 0,02$ e o limiar de ablação para alta fluência (FIG. 24) é $F_{\text {th(1) }}=0,21 \pm 0,02$. Para ambos regimes, o parâmetro de incubação é $S=0,88 \pm 0,02$. 


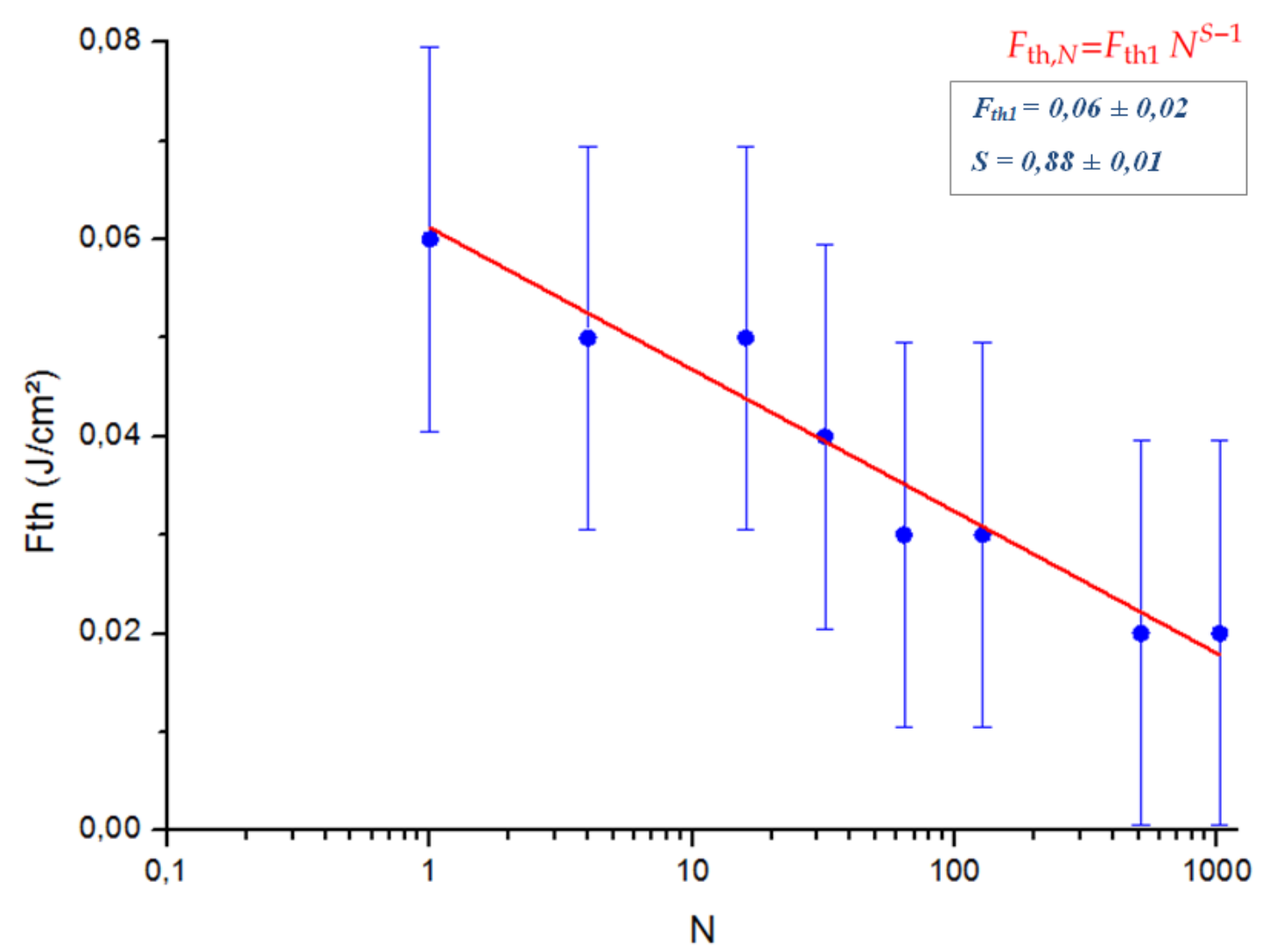

FIGURA 23 - Gráfico da fluência em função do número de pulsos sobrepostos $\left(F_{\text {th }} \times N\right)$ para o método Dano Zero (regime de baixa fluência).

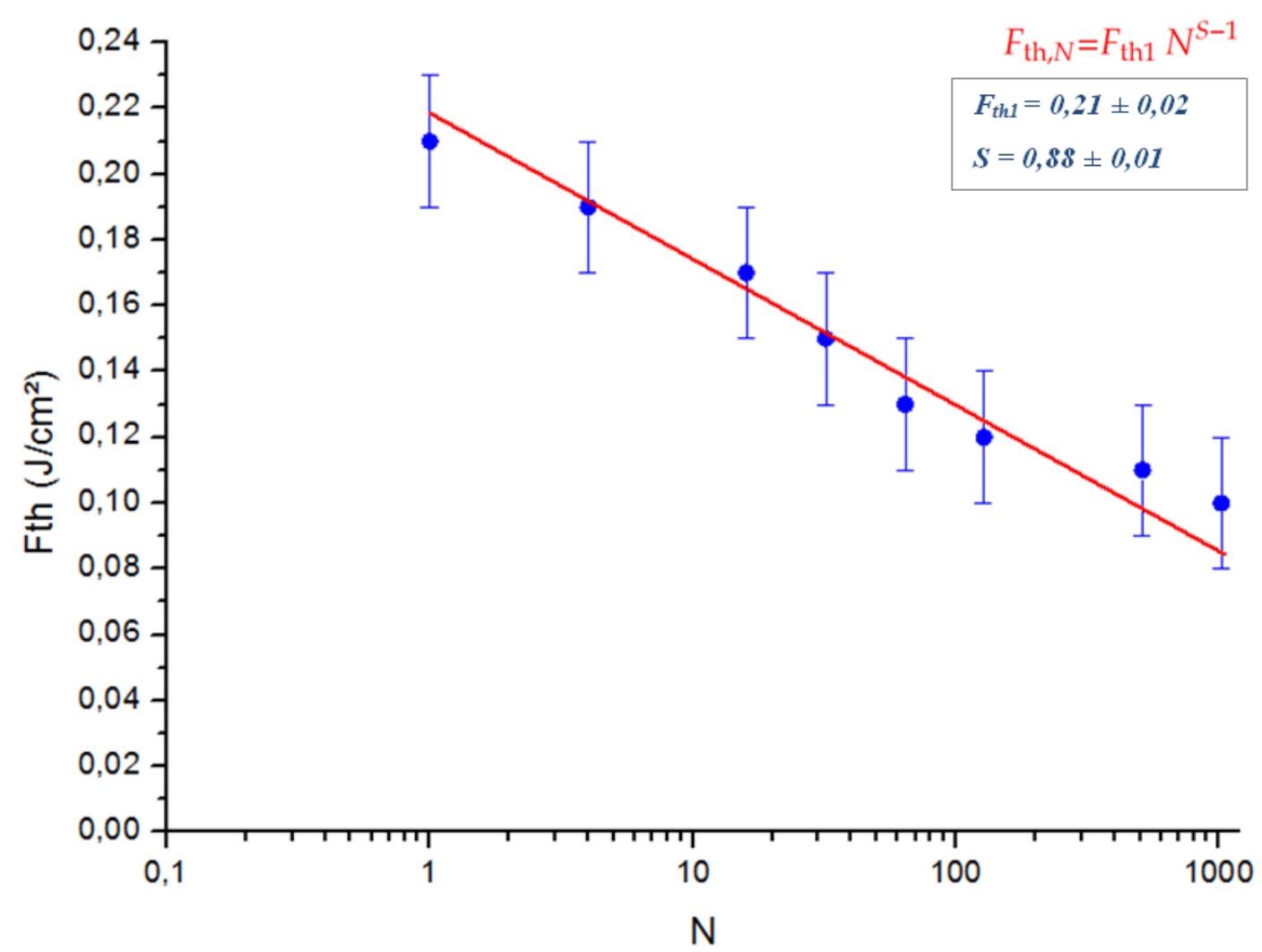

FIGURA 24 - Gráfico da fluência em função do número de pulsos sobrepostos $\left(F_{\text {th }} \times N\right)$ para o método Dano Zero (regime de alta fluência). 
Mesmo não levando em conta o efeito de incubação e utilizando alta fluência, o processo ainda se mostra inviável com o sistema disponível. A utilização sincronizada da velocidade de deslocamento da peça com a taxa de repetição do laser pode levar a pulsos com separação controlada formando um arranjo conforme desejado. Esta estratégia foi utilizada, porém para somente 1 pulso as profundidades obtidas, mesmo com valores de fluências mais elevados, não foram adequadas, com valores ínfimos. A obtenção de profundidades maiores que fossem satisfatórias para a adesão ao CFRP acarretariam, no entanto, na utilização de grande sobreposição de pulsos por ponto, implicando em paradas no deslocamento da peça para cada ponto, o que aumenta o tempo de processo a níveis impraticáveis. A FIG. 25 mostra a análise topográfica para matriz 5 e uma sobreposição de 1024 pulsos, o que resultou em uma profundidade do dano ablacionado de 2,45 $\mu \mathrm{m}$. Assim, a taxa de remoção por pulso $(2,45 \mu \mathrm{m} / 1024$ pulsos), com uma energia do feixe laser por pulso de 10,0 $\mu \mathrm{J}$, e demais condições para esta matriz é de $2,4 \mathrm{~nm} /$ pulso. Esta taxa demonstra a precisão do processo, o que permite a execução de microusinagem com tolerância submicrométrica e, inclusive a estruturação de filmes finos.

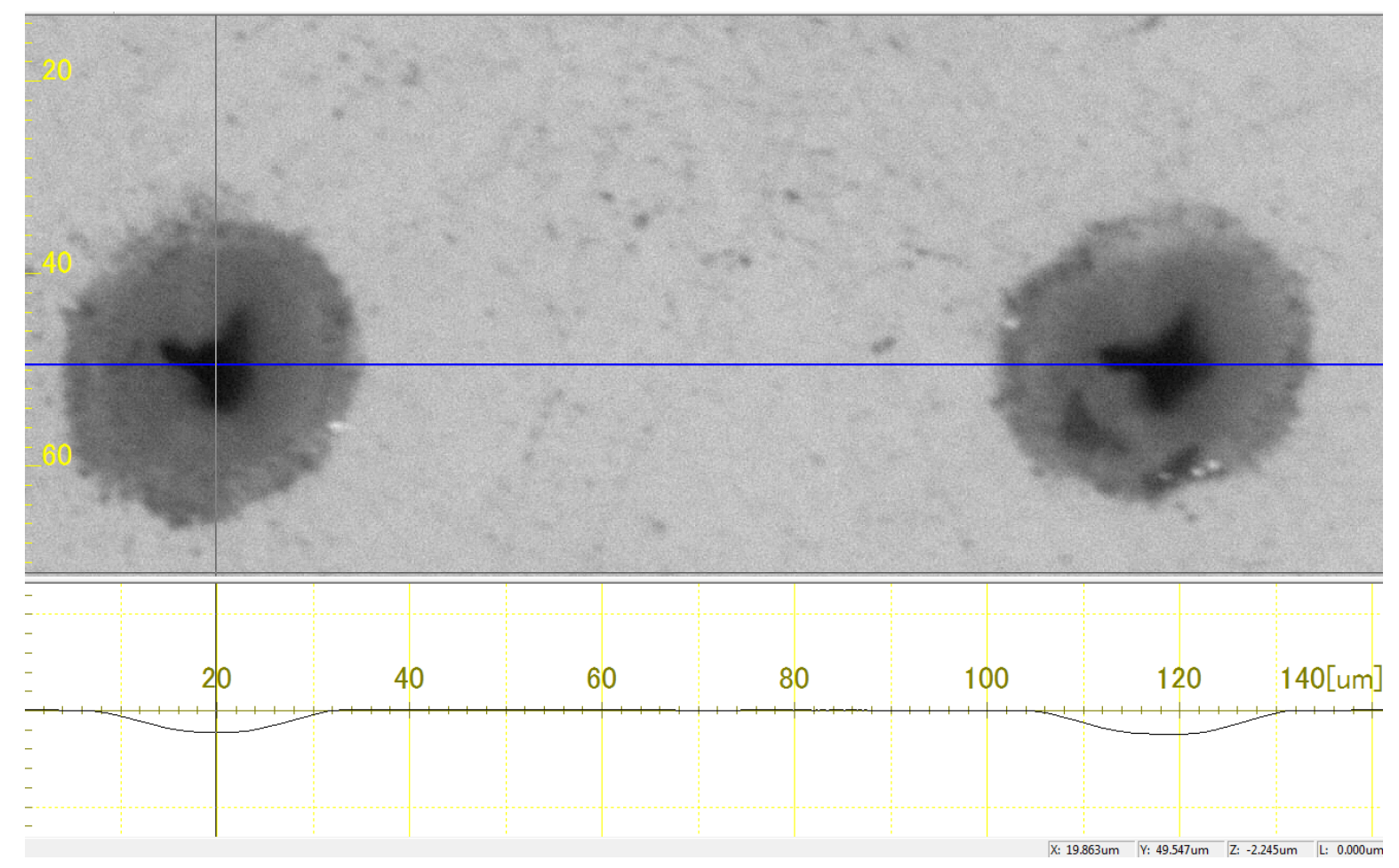

FIGURA 25 - Imagem de MEV no software 3D-Viewer para análise topográfica da superfície texturizada da matriz 5 e uma sobreposição de 1024 pulsos. Aumento de 1200x. 
Com a impossibilidade da obtenção de uma textura formada por uma matriz de pontos, passou-se então a buscar uma nova alternativa. Uma possibilidade foi a de produzir uma malha de traços formando uma trama. Neste caso, o método de Dano Zero não é mais adequado para a determinação das regiões de alta e de baixa fluências, e o método D-Scan passa a ser o mais apropriado.

\subsection{Limiar de ablação pelo método D-Scan}

Na FIG. 26 está ilustrada a amostra ablacionada pelo método D-scan, onde podem ser vistos como foram distribuídos os 28 perfis gravados.

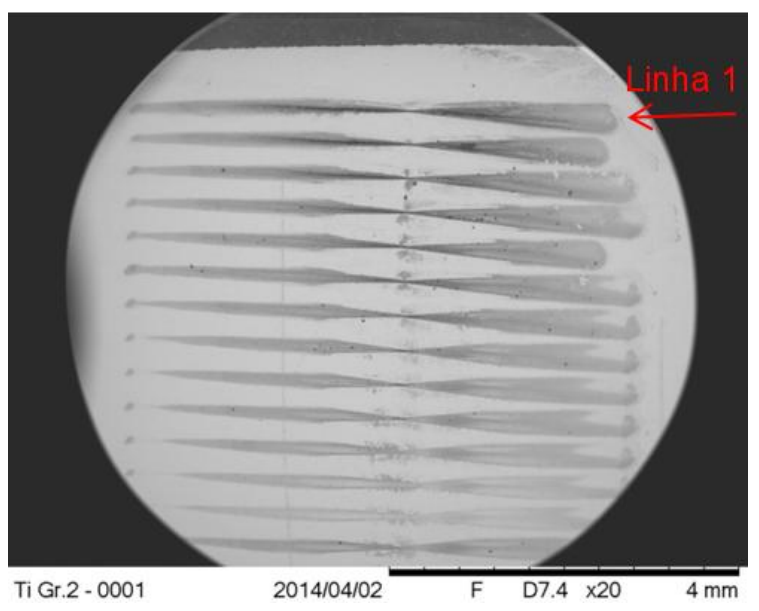

(a)

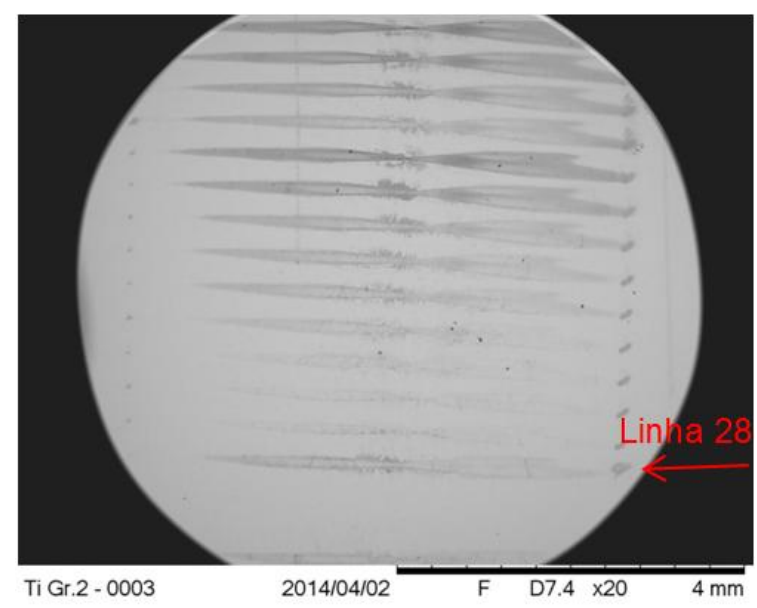

(b)

FIGURA 26 - Imagem em MEV dos traços ablacionados na amostra de Ti Gr. 2 CP pelo método D-Scan. Aumento de 20x.

O limiar de ablação pelo método D-Scan foi então determinado para o regime de baixa fluência, conforme apresentando no gráfico da FIG. 27 e também para o regime de alta fluência na FIG. 28.

Do gráfico da FIG. 27, tem-se que o limiar de ablação para o regime de baixa fluência é $F_{\text {th(1) }}=0,33 \pm 0,02 \mathrm{~J} / \mathrm{cm}^{2}$, e o limiar de ablação para o regime de alta fluência (FIG. 28) é $F_{\text {th(1) }}=0,64 \pm 0,02 \mathrm{~J} / \mathrm{cm}^{2}$. 


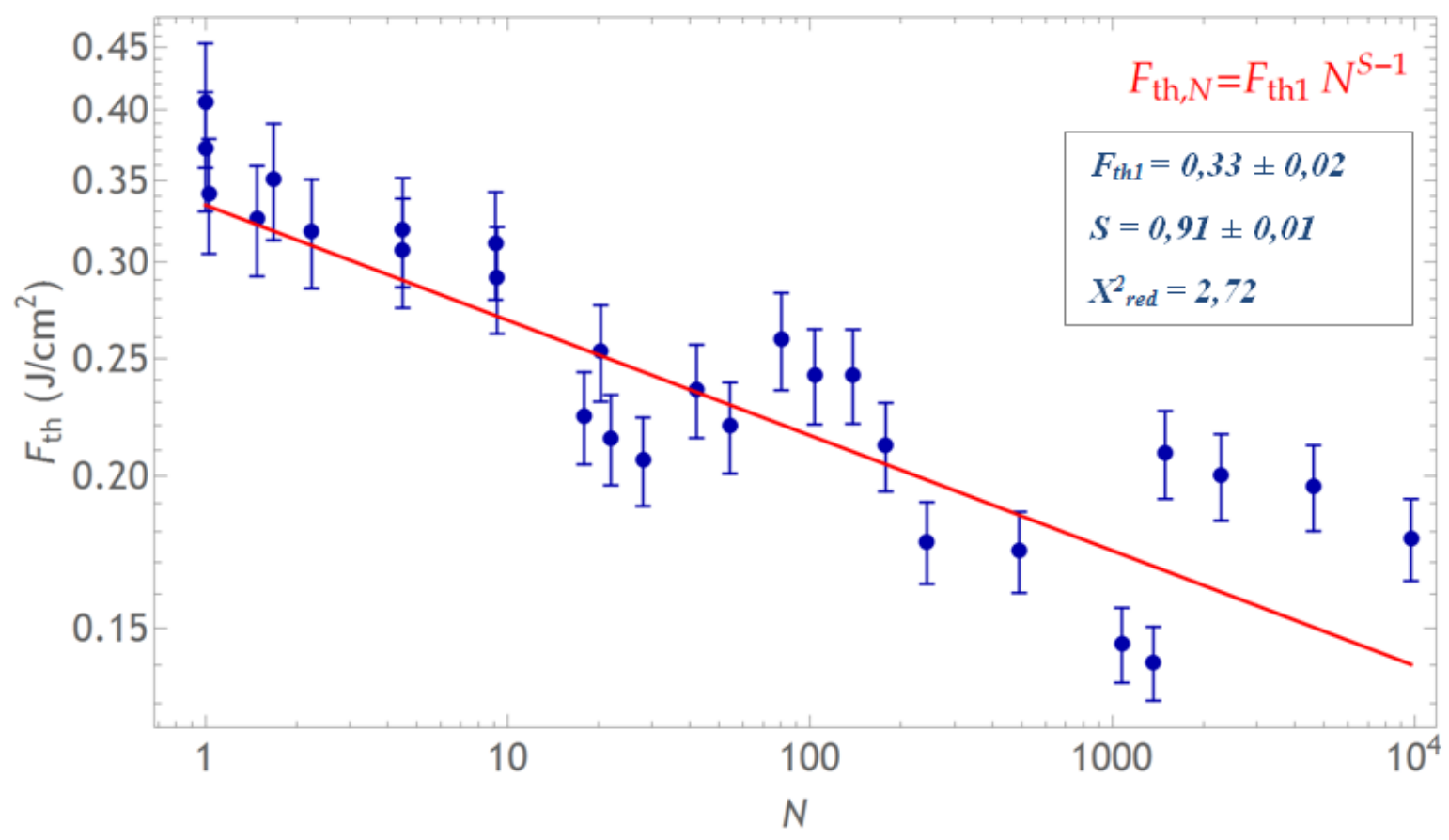

FIGURA 27 - Gráfico da fluência em função do número de pulsos sobrepostos para o método D-Scan (regime de baixa fluência).

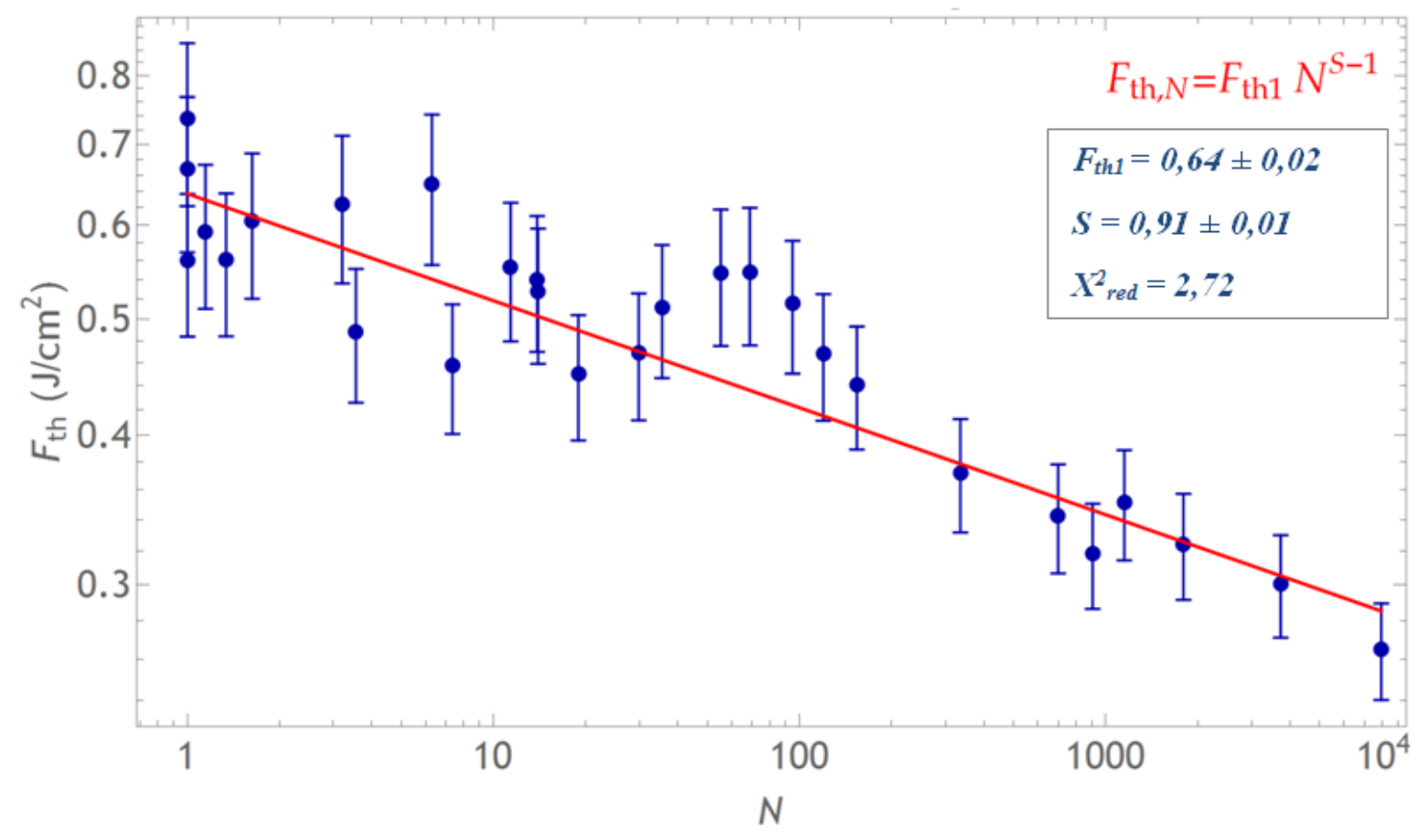

FIGURA 28 - Gráfico da fluência em função do número de pulsos sobrepostos para o método D-Scan (regime de alta fluência).

Analisando-se os resultados pelos métodos do Dano Zero e D-Scan é possível observar a diferença nos valores do limiar de ablação, com valores maiores para este segundo método. 
Esta diferença de comportamento é atribuída ao efeito colateral térmico, que surge devido à diferente distribuição espacial da energia entre os dois métodos. A técnica do Dano Zero apresenta uma distribuição espacial constante, tornando o gradiente de fluência entre o centro do feixe e a região medida muito maior que no caso do D-scan. Isso provoca no caso do Dano Zero um regime de alta fluência (no centro) com zona afetada pelo calor, subestimando o limiar de ablação para pulsos sobrepostos [9].

\subsection{Texturização de chapas de Ti Gr. 2 CP com espessura de 0,1 mm utilizando laser com pulsos ultracurtos}

$\mathrm{Na}$ determinação do limiar de ablação pelos dois métodos (Dano Zero e D-Scan), as amostras tinham a espessura de $2 \mathrm{~mm}$. Com os métodos de análise utilizados, não ficou evidenciado a ocorrência de material ressolidificado nas regiões ablacionadas, mesmo no regime de alta fluência. Isto não implica que não tenha havido produção de calor com consequente formação de ZTA. Neste caso, é provável que o material fundido tenha sido expelido da região da poça fundida através do processo de explosão de fase.

Desta forma, foram executadas texturizações em chapas com espessura de 0,1 mm, nos regimes de baixa e alta fluência, com o intuito de atestar também a ausência de empenamento.

Na TAB. 10 estão os parâmetros para a execução das texturizações. Em todos os casos foi utilizado o gás inerte argônio (Ar) com pureza superior a 99,999\% e vazão de 8,0 I/min para proteção da atmosfera. A texturização 1 implica em uma linha contínua com sobreposição de 50 pulsos. A texturização 2 mostra que os pulsos foram quase que tangentes uns aos outros. Para os outros casos, não houve sobreposição dos pulsos (estão separados). Vale aqui salientar, que o diâmetro utilizado para estes cálculos foi o diâmetro teórico do feixe laser focalizado sobre a amostra conforme Equação 22 que foi de $24 \mu \mathrm{m}$. Para fluências maiores, os danos são maiores e o espaçamento precisa ser maior. 
TABELA 10 - Parâmetros para texturizações nas chapas de $0,1 \mathrm{~mm}$ utilizando laser com pulsos ultracurtos

\begin{tabular}{ccccc}
\hline Texturização & $\begin{array}{c}\mathrm{F}_{0} \\
\left(\mathrm{~J} / \mathrm{cm}^{2}\right)\end{array}$ & $\mathrm{N}$ & $\begin{array}{c}f \\
(\mathrm{~Hz})\end{array}$ & $\begin{array}{c}\mathrm{v}_{\text {adotada }} \\
(\mathrm{mm} / \mathrm{min})\end{array}$ \\
\hline 1 & $0,44 \pm 0,04$ & 50 & 4000 & 115,00 \\
2 & $13,71 \pm 0,04$ & 1,144 & 1400 & 1764,00 \\
3 & $17,90 \pm 0,04$ & 0,654 & 800 & 1764,00 \\
4 & $17,90 \pm 0,04$ & 0,327 & 400 & 1764,00 \\
5 & $18,35 \pm 0,04$ & 0,082 & 100 & 1764,00 \\
6 & $18,35 \pm 0,04$ & 0,041 & 50 & 1764,00 \\
\hline
\end{tabular}

$\mathrm{Na}$ texturização 1, que tem a maior sobreposição, o efeito de incubação promoveu a maior redução no limiar de ablação, sendo a condição onde ocorreu o maior aporte térmico. A FIG. 29 mostra as imagens de MEV desta texturização, onde pode ser constatada a sobreposição de pulsos.

À medida que é aumentada a sobreposição, a relação entre o tamanho do dano e o diâmetro teórico do pulso no foco aumenta, o que é a consequência direta do efeito de incubação. Pode-se notar ainda que na texturização 2 a sobreposição foi mínima, ou seja, com uma sobreposição de $14,4 \%$ somente. A FIG. 30 apresenta as imagens de MEV da texturização 2. Devido à combinação dos parâmetros frequência e velocidade, nas texturizações 3, 4, 5 e 6 não houve sobreposição como pode ser constatado na TAB. 10, desta forma foram obtidas trilhas de pontos para estes casos. Na FIG. 31 estão as imagens de MEV da texturização 4.

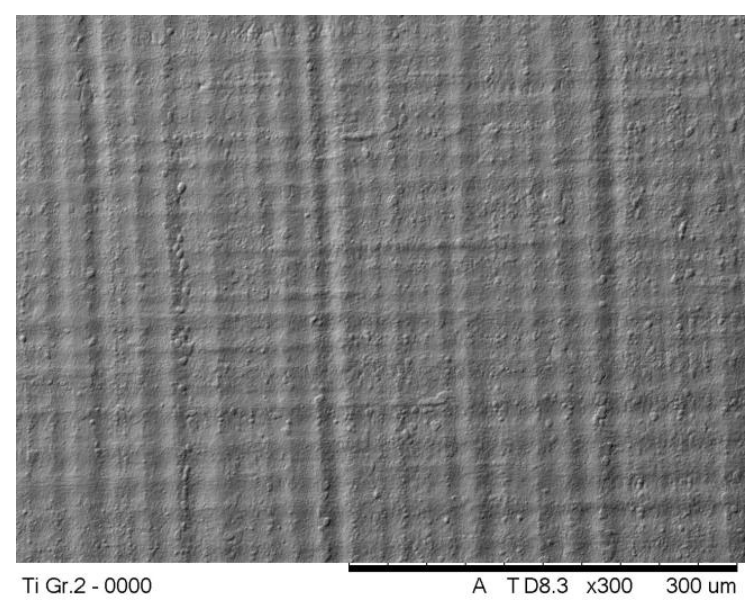

(a)

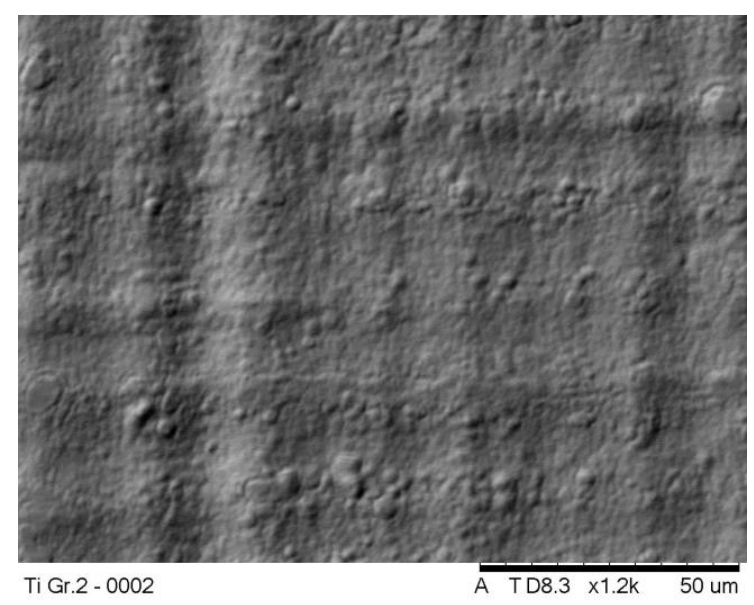

(b)

FIGURA 29 - Imagem de MEV da texturização 1 na chapa de 0,1 mm de espessura. Texturização na direção vertical. Aumento de 300x (a) e aumento de $1.200 x(b)$. 


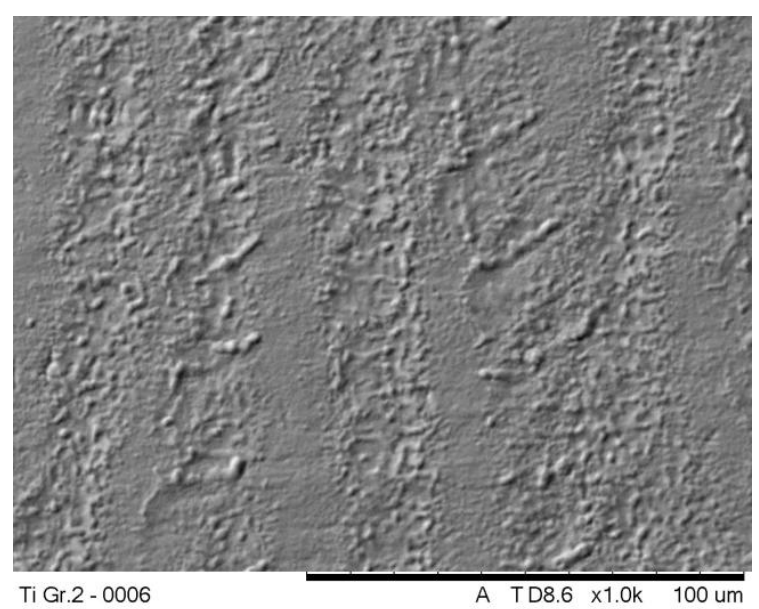

(a)

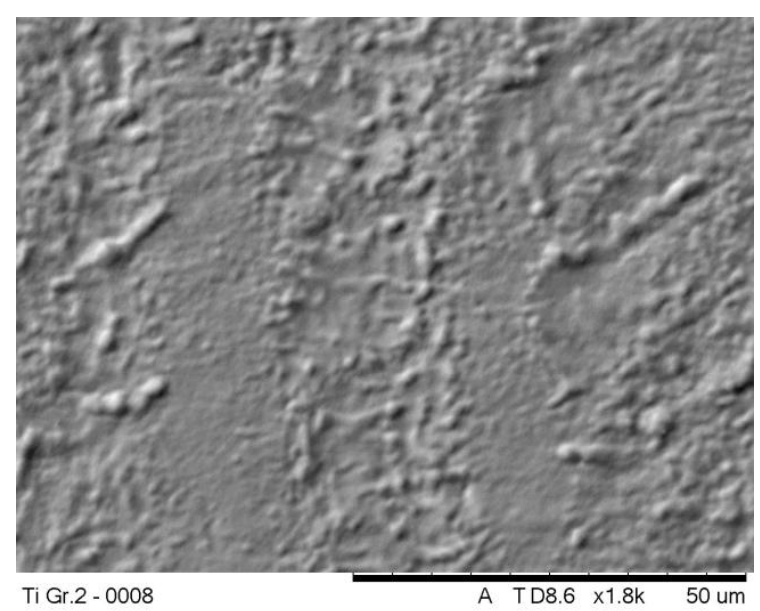

(b)

FIGURA 30 - Imagem de MEV da texturização 2 na chapa de $0,1 \mathrm{~mm}$ de espessura. Texturização na direção vertical. Aumento de 1.000x (a) e aumento de $1.800 x(b)$.

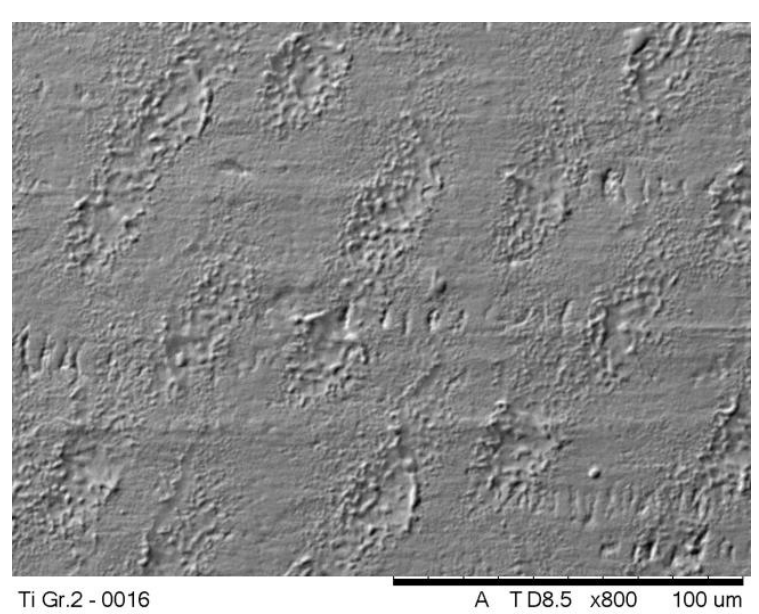

(a)

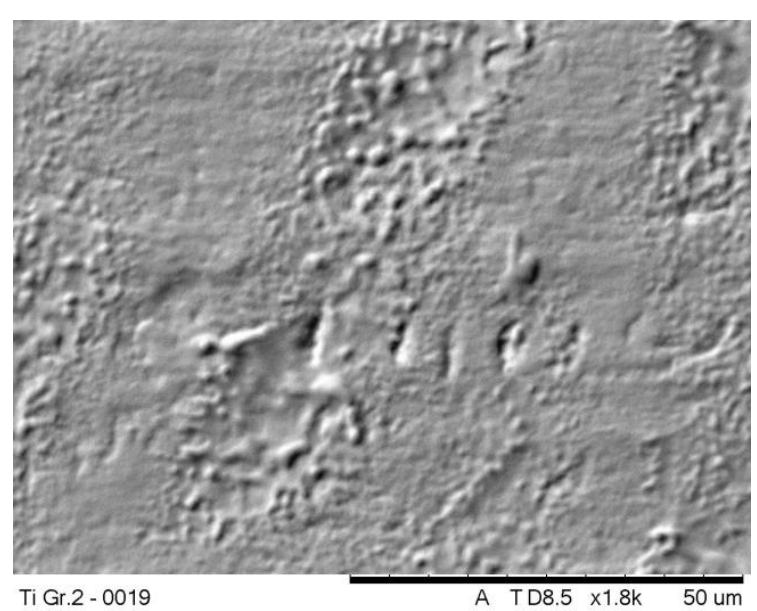

(b)

FIGURA 31 - Imagem de MEV da texturização 4 na chapa de $0,1 \mathrm{~mm}$ de espessura. Texturização na direção vertical. Aumento de 800x (a) e aumento de $1.800 x(b)$.

Mesmo na condição extrema, que foi a texturização 1, não ocorreram deformações da chapa, comprovando que mesmo no regime de alta fluência não há significativa transferência de calor à rede cristalina que pudesse causar tais deformações. A FIG. 32 mostra a chapa com esta texturização, podendo ser constatado que não houve qualquer indício de deformação superficial que causasse empenamento e distorções. 


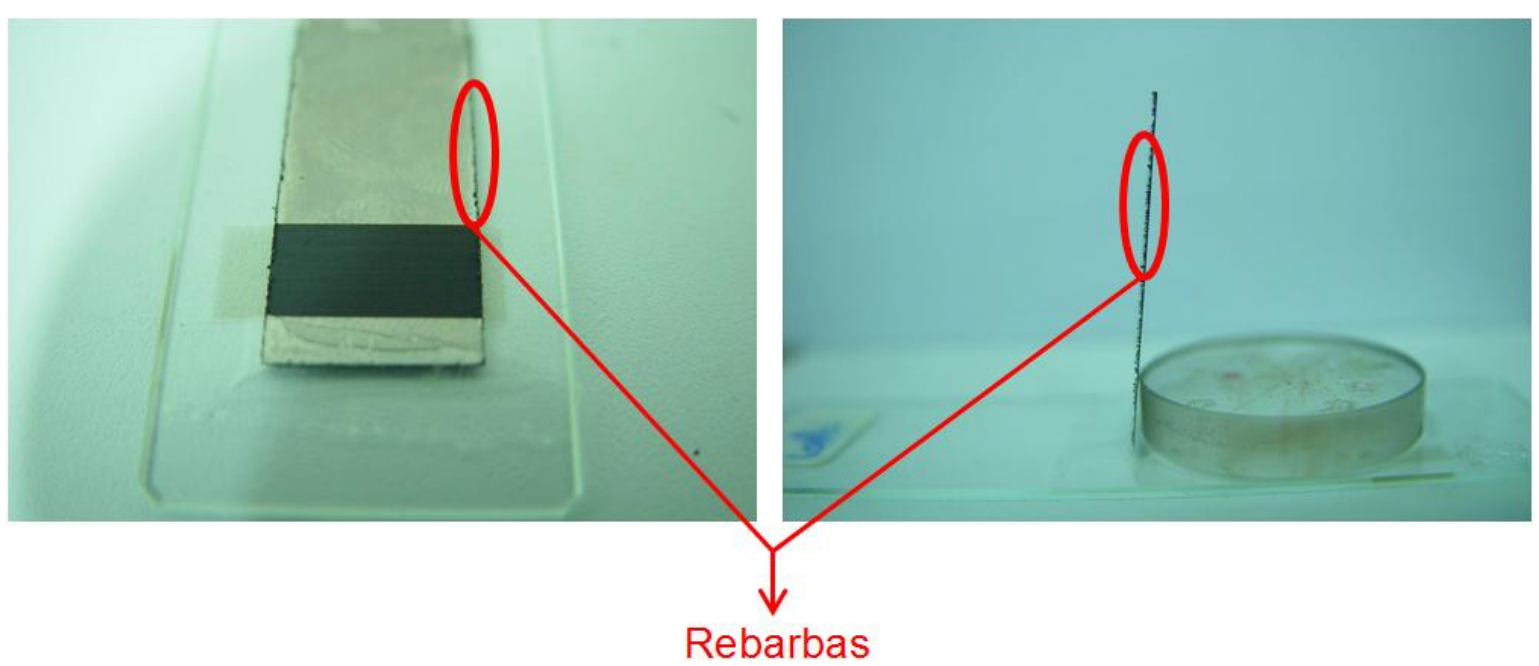

(a)

(b)

FIGURA 32 - Texturização 1 na chapa de $0,1 \mathrm{~mm}$ de espessura vista de topo (a) e vista de perfil (b).

Contudo, nas texturizações onde não ocorreu a sobreposição de pulsos, a usinagem dos "dimples" necessitaria de um tempo extremamente longo para sua execução. Isto acarreta que haveria a necessidade de repetidos passes na mesma região para que ocorresse sobreposição para garantir uma profundidade satisfatória nos pontos ablacionados. Devido às dificuldades envolvidas nesta metodologia com o sistema disponível, a realização de "dimples" foi abortada em detrimento de uma outra estratégia, que foi a realização de "traços em malhas" para a obtenção das texturizações.

Com o objetivo de determinação de parâmetros que resultassem uma situação favorável para que pudessem ser feitas as texturizações definitivas, ainda nas chapas de $0,1 \mathrm{~mm}$ de espessura, foram usinados seis traços de $10 \mathrm{~mm}$ de comprimento em diferentes condições. A TAB. 11 mostra os parâmetros utilizados, lembrando que em todos os traços foi utilizado o gás inerte $\mathrm{Ar}$ com pureza superior a 99,999\% e vazão de 8,0 l/min para proteção da atmosfera. Este procedimento foi necessário visto que a matriz de pontos produzidos no processo anterior (TAB. 10) levou a danos muito rasos, o que não deve ser adequado a uma colagem eficiente. Com a microusinagem de traços, é possível uma grande sobreposição de pulsos e a produção de sulcos profundos. 
TABELA 11 - Parâmetros para microusinagem de traços nas chapas de $0,1 \mathrm{~mm}$

\begin{tabular}{ccccc}
\hline Traço & $\begin{array}{c}\mathrm{F}_{0} \\
\left(\mathrm{~J} / \mathrm{cm}^{2}\right)\end{array}$ & $\mathrm{N}$ & $\begin{array}{c}f \\
(\mathrm{~Hz})\end{array}$ & $\begin{array}{c}\mathrm{V}_{\text {adotada }} \\
(\mathrm{mm} / \mathrm{min})\end{array}$ \\
\hline 1 & $3,32 \pm 0,04$ & 1150 & 4000 & 5,00 \\
2 & $3,32 \pm 0,04$ & 575 & 4000 & 10,00 \\
3 & $3,32 \pm 0,04$ & 287,5 & 4000 & 20,00 \\
4 & $6,63 \pm 0,04$ & 1150 & 4000 & 5,00 \\
5 & $6,63 \pm 0,04$ & 575 & 4000 & 10,00 \\
6 & $6,63 \pm 0,04$ & 287,5 & 4000 & 20,00 \\
\hline
\end{tabular}

Como visto na TAB. 11 a combinação dos parâmetros proporcionaram três sobreposições, que são proporcionais à variação da velocidade, uma vez que a taxa de repetição foi mantida inalterada.

A FIG. 33 apresenta a distribuição dos traços na chapa. A microusinagem dos seis traços concentrou-se no regime de alta fluência, uma vez que foi constatado que não há deformações macroscópicas.

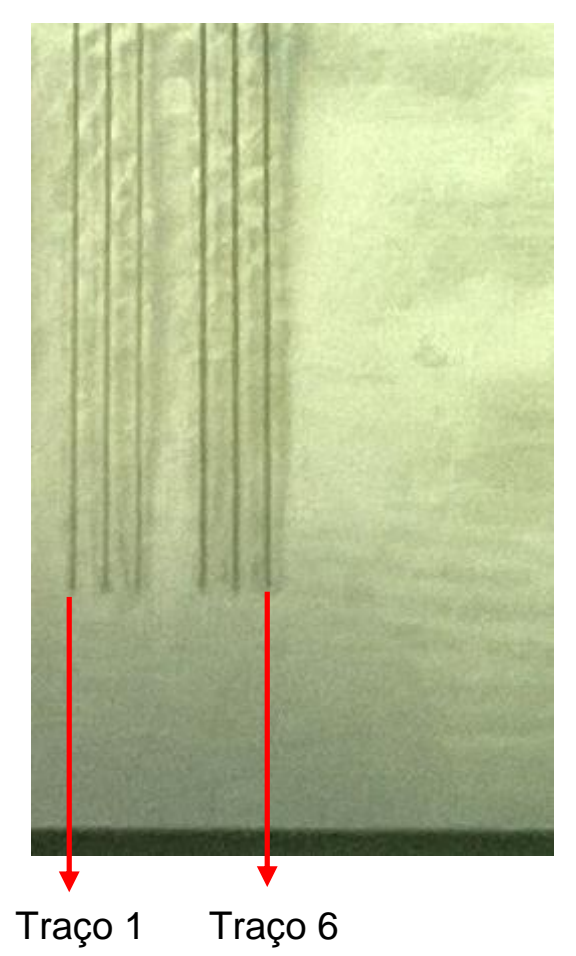

FIGURA 33 - Traços de 1 a 6 em chapa de 0,1 mm de espessura.

Da FIG. 34 até a FIG. 38 estão ilustradas as imagens de MEV dos traços ablacionados. É possível notar que nos seis traços realizados, o aspecto visual não apresenta grandes variações, pois embora tenha ocorrido variação na 
sobreposição $\mathrm{N}$, as fluências diferentes para os traços de 1 a 3 e de 4 a 6 contribuíram para a relativa semelhança entre os danos causados.

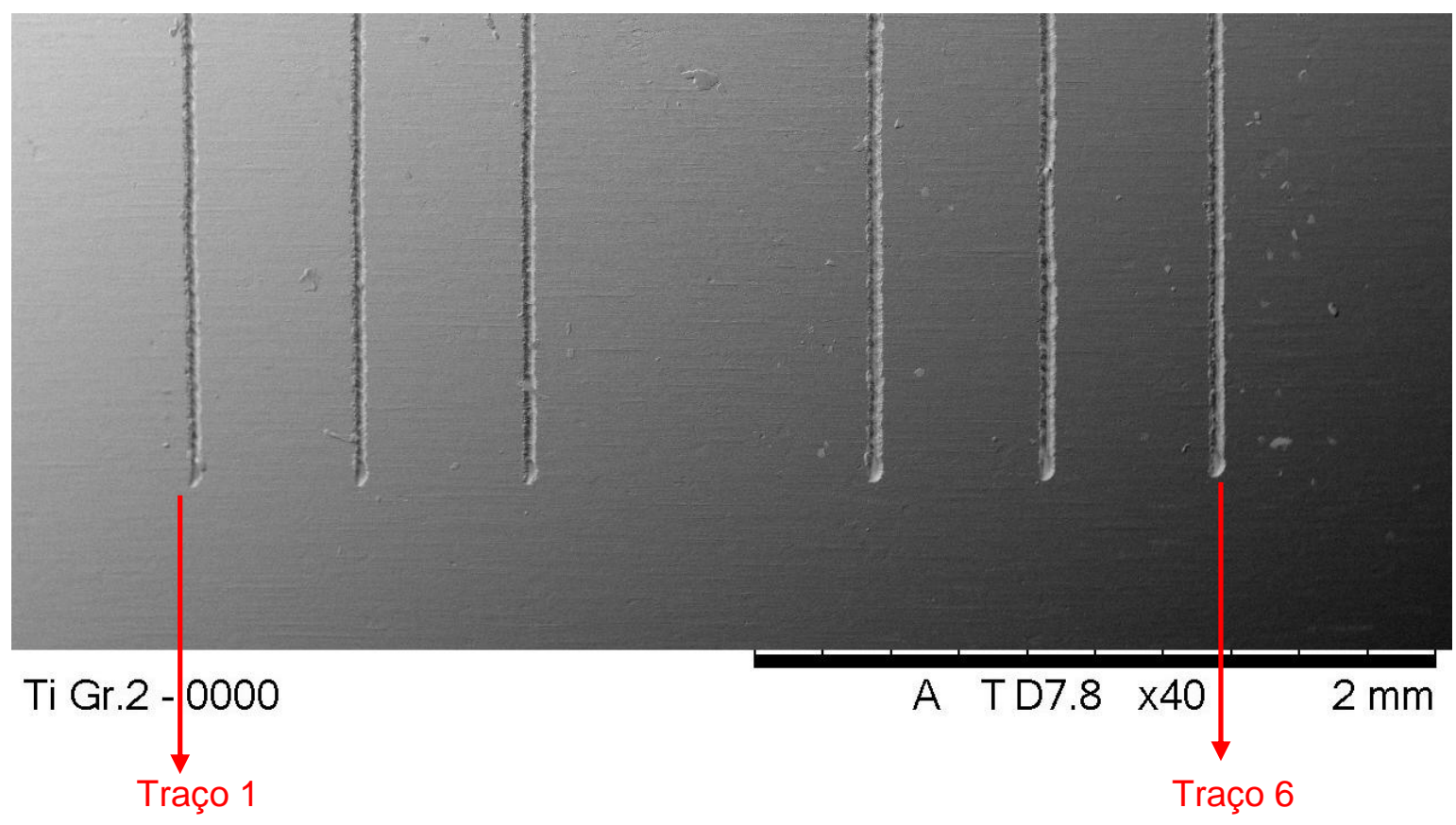

FIGURA 34 - Imagem de MEV dos traços de 1 a 6 em chapa de 0,1 mm de espessura. Aumento de 40x.

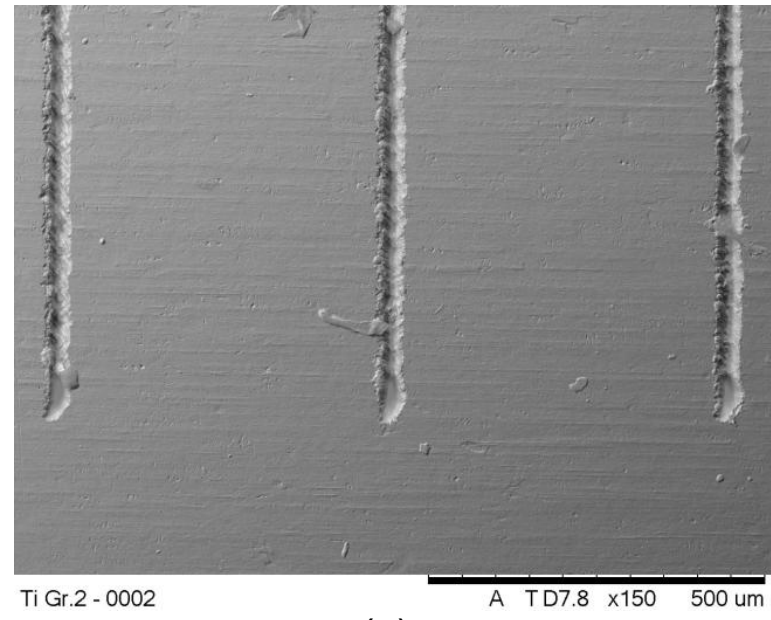

(a)

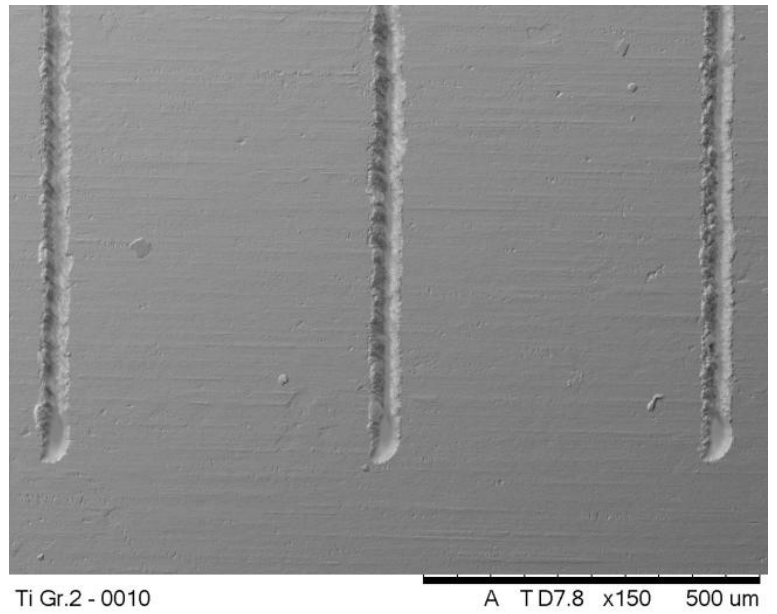

(b)

FIGURA 35 - Imagens de MEV dos traços 1, 2 e 3 (a) e dos traços 4, 5 e 6 (b). Aumento de 150x. 


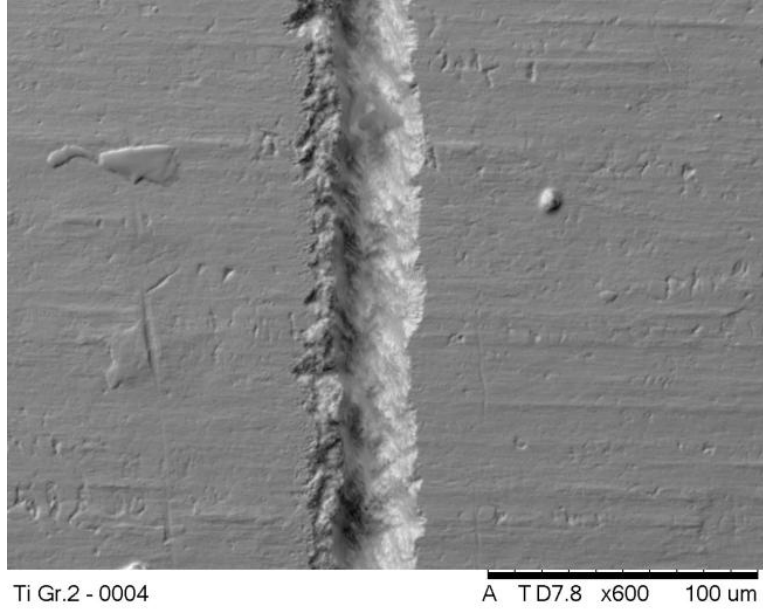

(a)

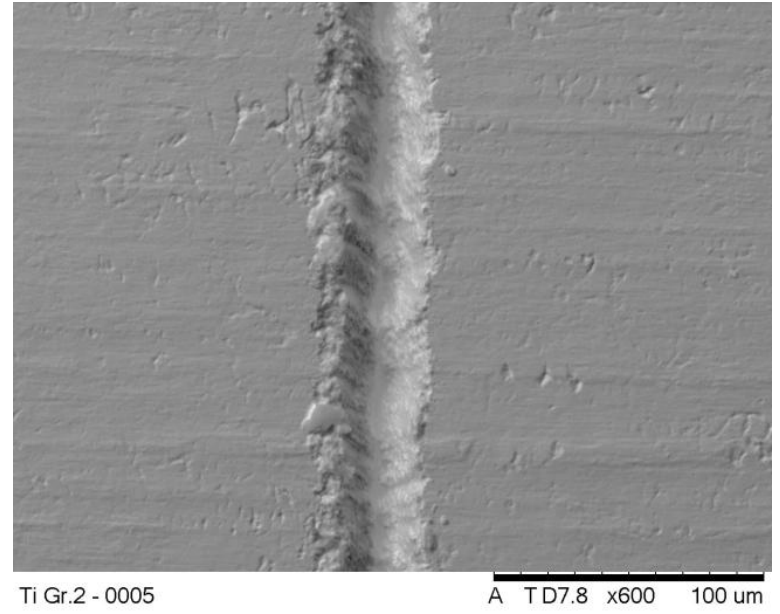

(b)

FIGURA 36 - Imagens de MEV dos traços 1 (a) 2 (b). Aumento de 600x.

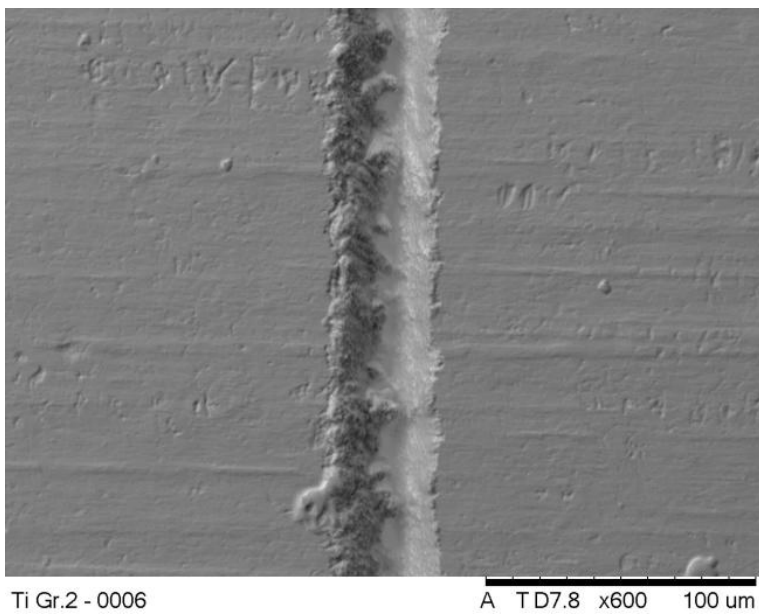

(a)

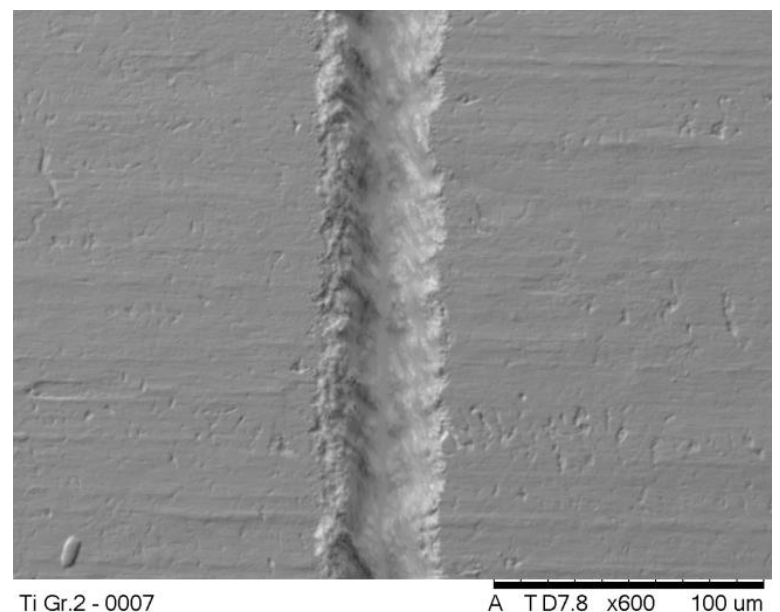

(b)

FIGURA 37 - Imagens de MEV dos traços 3 (a) e 4 (b). Aumento de 600x.

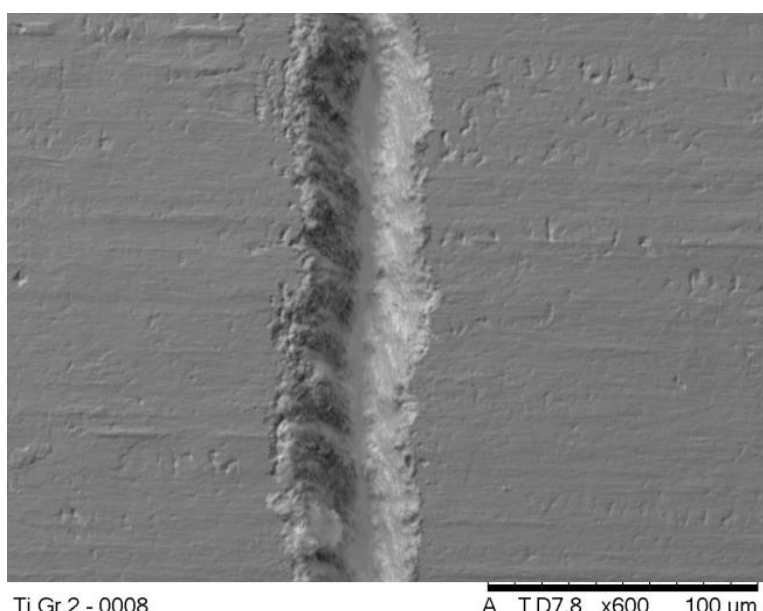

(a)

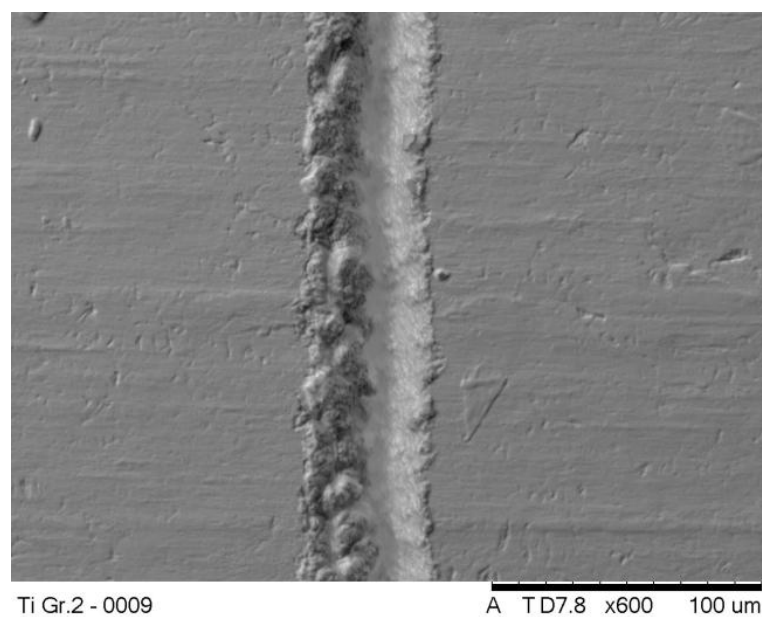

(b)

FIGURA 38 - Imagens de MEV dos traços 5 (a) 6 (b). Aumento de 600x. 
Em seguida, definiu-se que seriam utilizadas três geometrias diferentes para a execução das texturizações. Optou-se por executar uma microusinagem em zig-zag cruzada na chapa de $0,1 \mathrm{~mm}$, de forma a proporcionar uma melhor condição para posterior colagem do CFRP. Estas geometrias em zig-zag foram obtidas por meio de programa CNC, gerado pelo software MasterCam. Para a execução das três texturizações, somente houve a variação do passo entre as linhas usinadas. Com estas geometrias, o principal objetivo seria a análise comparativa sobre a influência da superfície para a adesão do CFRP, uma vez que tais modificações superficiais no TI G. 2 CP acarretariam em condições diferentes para o comportamento e propriedades fluídicas do adesivo estrutural.

Os parâmetros utilizados para a microusinagem das três geometrias foram os mesmos do traço 1 apresentados na TAB. 11, visto que tais parâmetros utilizados para a confecção deste traço proporcionaram uma condição bastante favorável em virtude de haver uma sobreposição considerável de pulsos e ter promovido uma profundidade satisfatória, além de não ter evidenciado a existência de material ressolidificado e tampouco apresentado indícios de empenamento. Com estas condições, esperava-se que a colagem teria uma boa eficiência. Estão apresentados os parâmetros para microusinagem destas três texturizações na TAB. 12.

TABELA 12 - Parâmetros para texturizações nas chapas de 0,1 mm de espessura

\begin{tabular}{cccccc}
\hline Texturização & $\mathrm{F}_{0}\left(\mathrm{~J} / \mathrm{cm}^{2}\right)$ & $\mathrm{N}$ & $\mathrm{f}(\mathrm{Hz})$ & $\begin{array}{c}\mathrm{Passo}^{*} \\
(\mu \mathrm{m})\end{array}$ & $\begin{array}{c}\mathrm{V}_{\text {adotada }} \\
(\mathrm{mm} / \mathrm{min})\end{array}$ \\
\hline 01 & $3,32 \pm 0,04$ & 1150 & 4000 & 75 & 5,00 \\
02 & $3,32 \pm 0,04$ & 1150 & 4000 & 100 & 5,00 \\
03 & $3,32 \pm 0,04$ & 1150 & 4000 & 200 & 5,00 \\
\hline
\end{tabular}

* - Distância entre as linhas de texturização

Após a execução das texturizações foram feitas análises no MEV e também geradas algumas imagens em três dimensões e analisadas com o auxílio do software 3D-Image Viewer.

$\mathrm{Na}$ FIG. 39 são ilustradas as imagens obtidas em MEV das texturizações. 


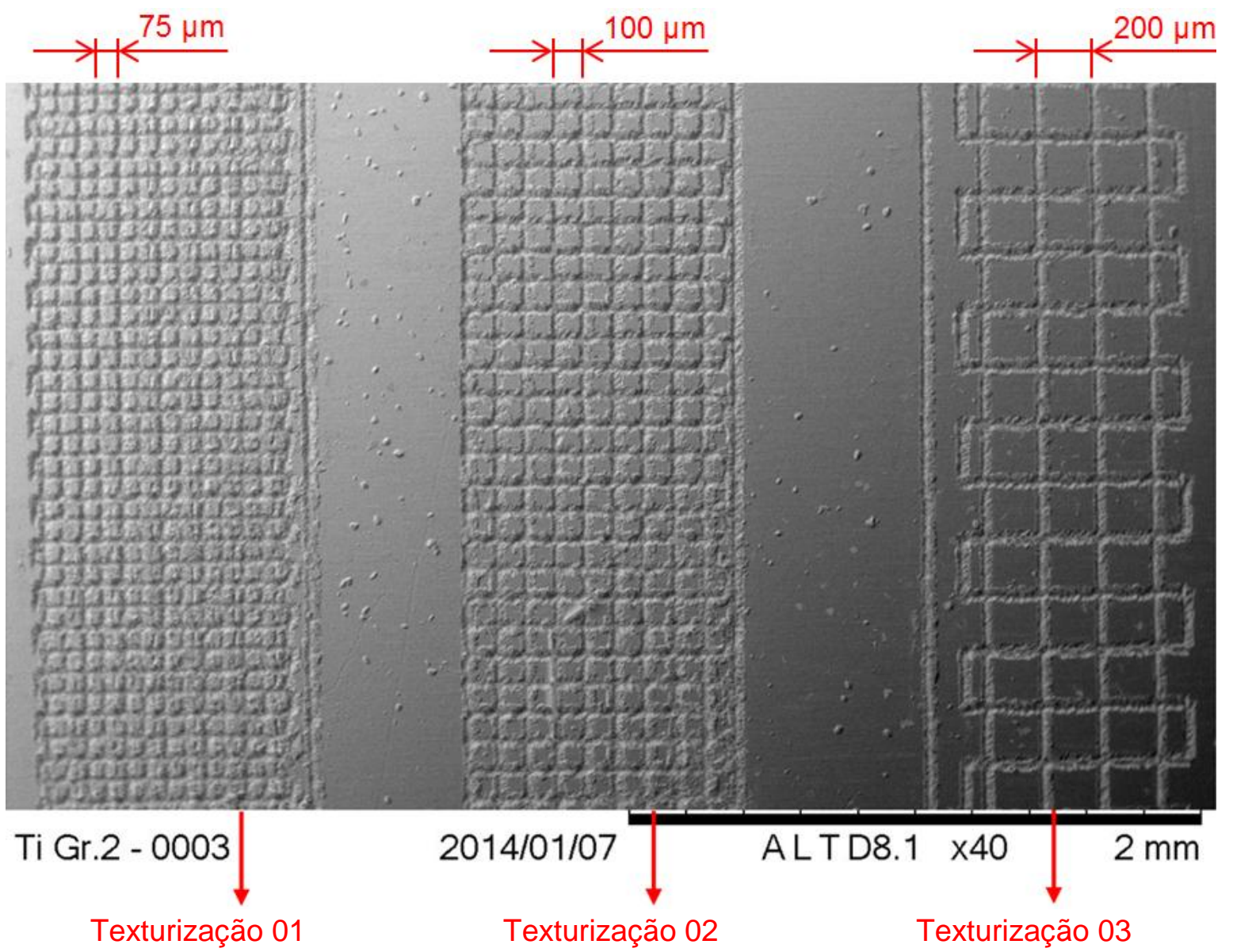

FIGURA 39 - Imagem de MEV das texturizações 01, 02 e 03 com geometrias zigzag cruzadas em chapa de $0,1 \mathrm{~mm}$ de espessura. Aumento de 40x.

São apresentadas em sequência a FIG. 40, FIG. 41 e FIG. 42 estas texturizações em detalhes, onde são notadas as aparências da microusinagem, remetendo inclusive a percepção das profundidades alcançadas.

Através do MEV, foi analisado e constatado que mesmo nesta condição extrema da geometria em zig-zag, ou seja, uma condição onde foi promovida uma considerável remoção de material, não houve deformação da chapa. Vale ressaltar que o diâmetro do feixe na superfície da amostra é o calculado anteriormente, ou seja, 16,4 $\mu \mathrm{m}$. 

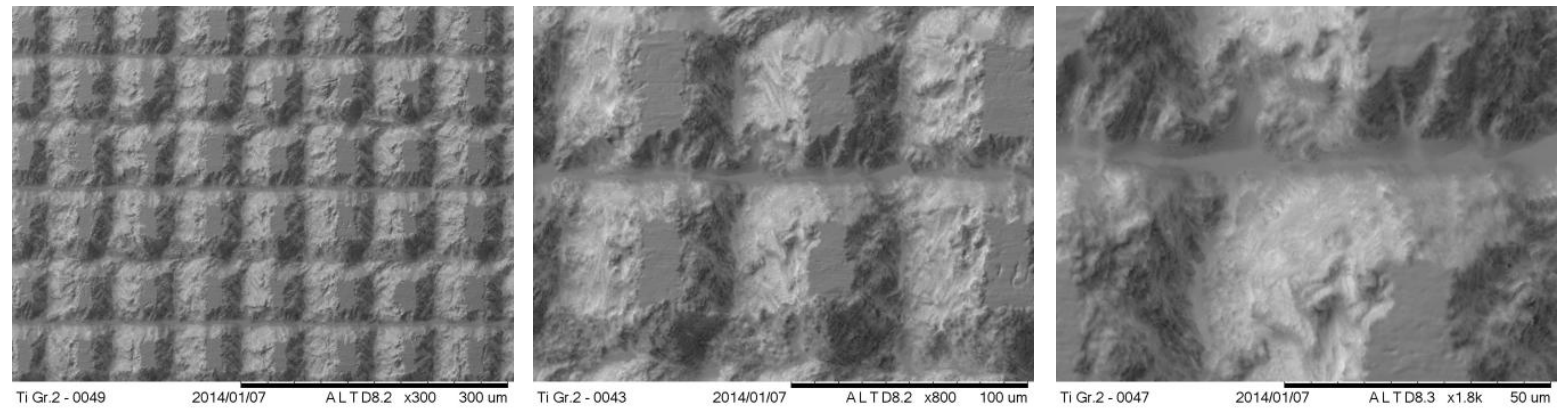

FIGURA 40 - Imagem de MEV da texturização 01 com geometria zig-zag cruzada em chapa de $0,1 \mathrm{~mm}$ de espessura. Aumentos de 300x, 800x e 1.800x.
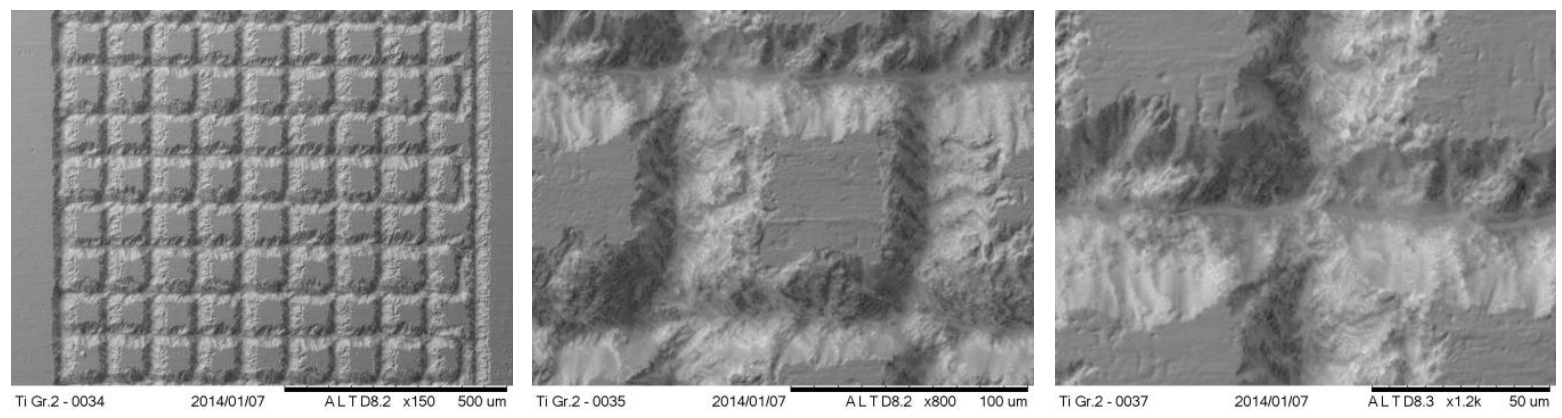

FIGURA 41 - Imagem de MEV da texturização 02 com geometria zig-zag cruzada em chapa de 0,1 mm de espessura. Aumentos de 150x, 800x e 1.200x.
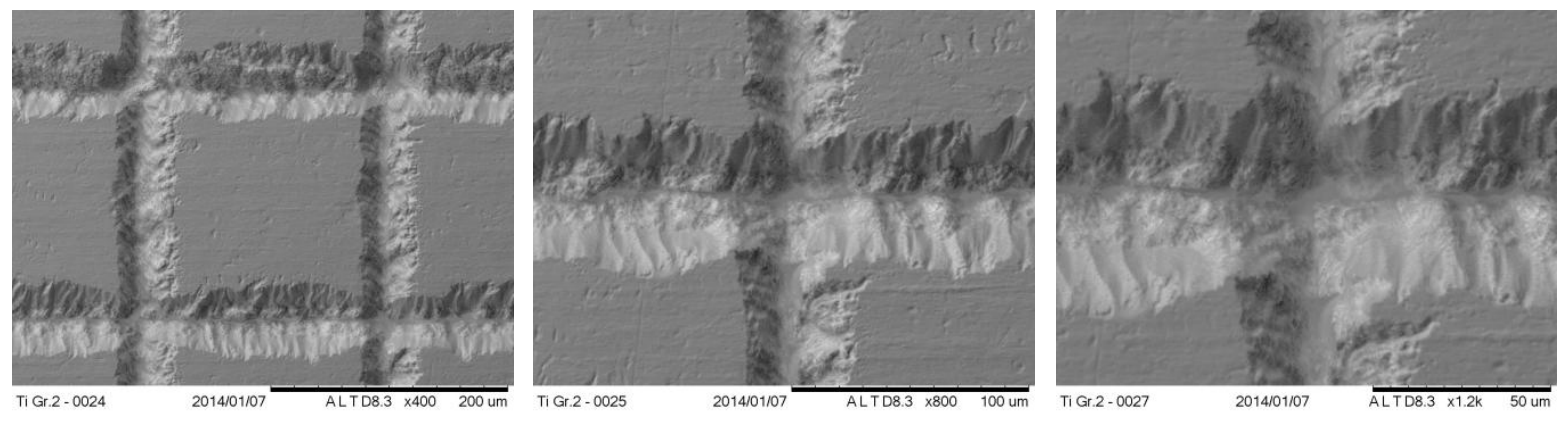

FIGURA 42 - Imagem de MEV da texturização 03 com geometria zig-zag cruzada em chapa de 0,1 mm de espessura. Aumentos de 400x, 800x e 1.200x.

A FIG. 43 mostra imagens da texturização 01 em três dimensões obtidas no MEV com o auxílio do software 3D-Image Viewer. Na FIG. 44 é ilustrada a transição entre a região ablacionada e não ablacionada na chapa de 0,1 mm. Ainda na FIG. 44, na análise da topografia, foi possível medir a profundidade das regiões texturizadas, que resultou em um valor médio de 14,50 $\mu \mathrm{m}$. 

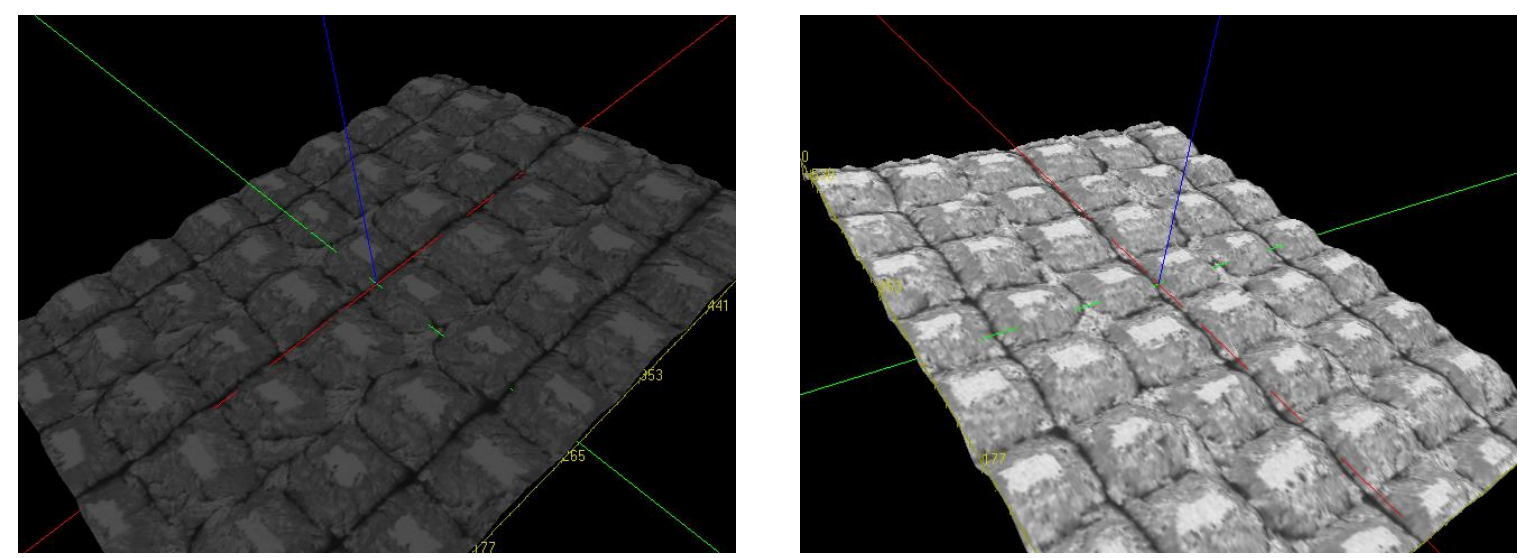

FIGURA 43 - Imagens de MEV em três dimensões da texturização 01 através do software 3D-Image Viewer.

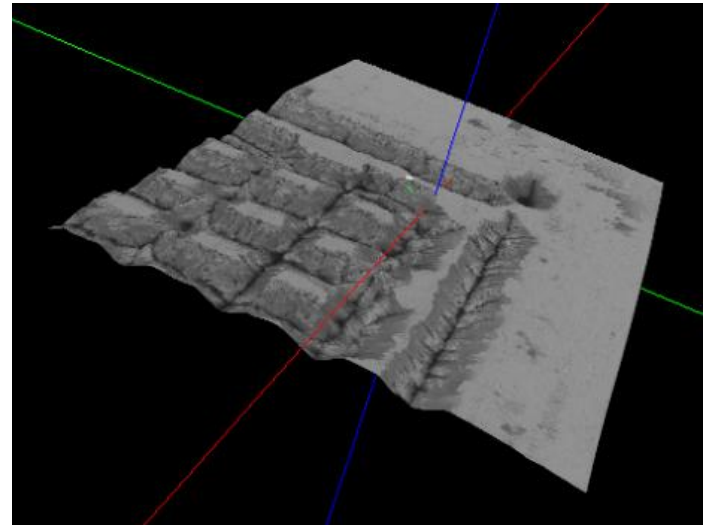

(a)

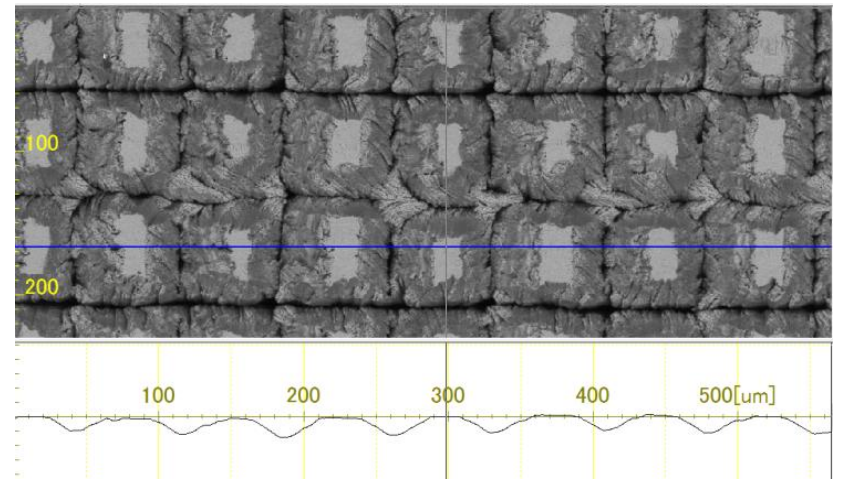

(b)

FIGURA 44 - Imagens de MEV em três dimensões da texturização 01 através do software 3D-Image Viewer.

\subsection{Texturização em amostras de $2 \mathrm{~mm}$ de espessura}

A partir da conclusão de que seria possível atuar no regime de alta fluência sem que houvesse deformações nas amostras, foram então texturizadas amostras com $2 \mathrm{~mm}$ de espessura. Isto foi necessário, pois para os casos das chapas de 0,1 mm não seria possível a realização de ensaios de tração.

A FIG. 45 ilustra as dimensões das amostras, bem como a região texturizada. Estas geometrias em zig-zag cruzadas também foram obtidas por meio de programa CNC, gerado pelo software MasterCam. Para proteção da atmosfera foi utilizado o gás inerte Ar com pureza superior a 99,999\%. 


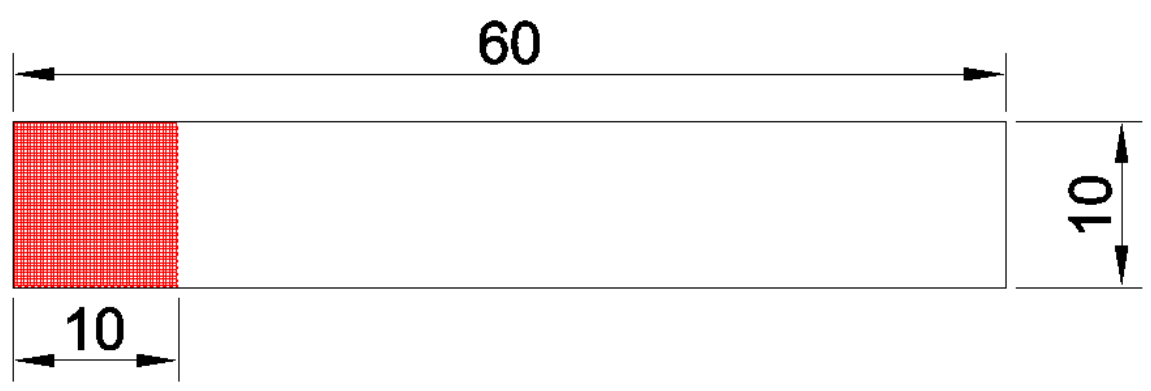

FIGURA 45 - Geometria das texturizações em zig-zag executadas nas chapas de $2,0 \mathrm{~mm}$.

Os parâmetros definidos para a execução das usinagens de texturização estão apresentados na TAB. 13, onde é possível notar as três diferentes texturizações e que foram utilizadas 15 amostras para a realização desta etapa de experimentos.

TABELA 13 - Parâmetros para texturizações em amostras de $2 \mathrm{~mm}$ de espessura

\begin{tabular}{cccccccc}
\hline Texturização & Amostra & $\begin{array}{c}\text { Energia } \\
(\mu \mathrm{J})\end{array}$ & $\begin{array}{c}\mathrm{F}_{0} \\
\left(\mathrm{~J} / \mathrm{cm}^{2}\right)\end{array}$ & $\mathrm{N}$ & $\mathrm{f}(\mathrm{Hz})$ & $\begin{array}{c}\text { Passo } \\
{ }^{*}(\mu \mathrm{m})\end{array}$ & $\begin{array}{c}\mathrm{V}_{\text {adotada }} \\
(\mathrm{mm} / \mathrm{min})\end{array}$ \\
\hline \multirow{2}{*}{01} & 1 & 105,0 & $23,21 \pm 0,04$ & 165 & 4000 & 75 & 35,00 \\
& 2 & 105,0 & $23,21 \pm 0,04$ & 165 & 4000 & 75 & 35,00 \\
& 3 & 105,0 & $23,21 \pm 0,04$ & 165 & 4000 & 75 & 35,00 \\
02 & 1 & 15,0 & $3,32 \pm 0,04$ & 1150 & 4000 & 100 & 5,00 \\
& 2 & 15,0 & $3,32 \pm 0,04$ & 1150 & 4000 & 100 & 5,00 \\
& 3 & 15,0 & $3,32 \pm 0,04$ & 1150 & 4000 & 100 & 5,00 \\
02 & $1 \mathrm{~A}$ & 105,0 & $23,21 \pm 0,04$ & 165 & 4000 & 100 & 35,00 \\
& $2 \mathrm{~A}$ & 105,0 & $23,21 \pm 0,04$ & 165 & 4000 & 100 & 35,00 \\
& $3 \mathrm{~A}$ & 105,0 & $23,21 \pm 0,04$ & 165 & 4000 & 100 & 35,00 \\
03 & 1 & 15,0 & $3,32 \pm 0,04$ & 1150 & 4000 & 200 & 5,00 \\
& 2 & 15,0 & $3,32 \pm 0,04$ & 1150 & 4000 & 200 & 5,00 \\
& 3 & 15,0 & $3,32 \pm 0,04$ & 1150 & 4000 & 200 & 5,00 \\
03 & $1 \mathrm{~A}$ & 105,0 & $23,21 \pm 0,04$ & 165 & 4000 & 200 & 35,00 \\
& $2 \mathrm{~A}$ & 105,0 & $23,21 \pm 0,04$ & 165 & 4000 & 200 & 35,00 \\
& 3A & 105,0 & $23,21 \pm 0,04$ & 165 & 4000 & 200 & 35,00 \\
\hline
\end{tabular}

*distância entre as linhas na geometria zig-zag

Como é possível notar, a TAB. 13 apresenta dois valores de energias e de velocidades para as texturizações. Na prática os valores de energia foram aumentados de $15,0 \mu \mathrm{J}$ para $105,0 \mu \mathrm{J}$, de modo que resultasse na diminuição nos tempos de microusinagem. Assim as velocidades foram aumentadas proporcionalmente na razão de 7 (sete) vezes, resultando no valor de 35,00 $\mathrm{mm} / \mathrm{min}$. Com isto a sobreposição de pulsos foi reduzida na mesma proporção. 
Da FIG. 46 até a FIG. 50 estão ilustradas as texturizações realizadas nas amostras de $2 \mathrm{~mm}$ de espessura.
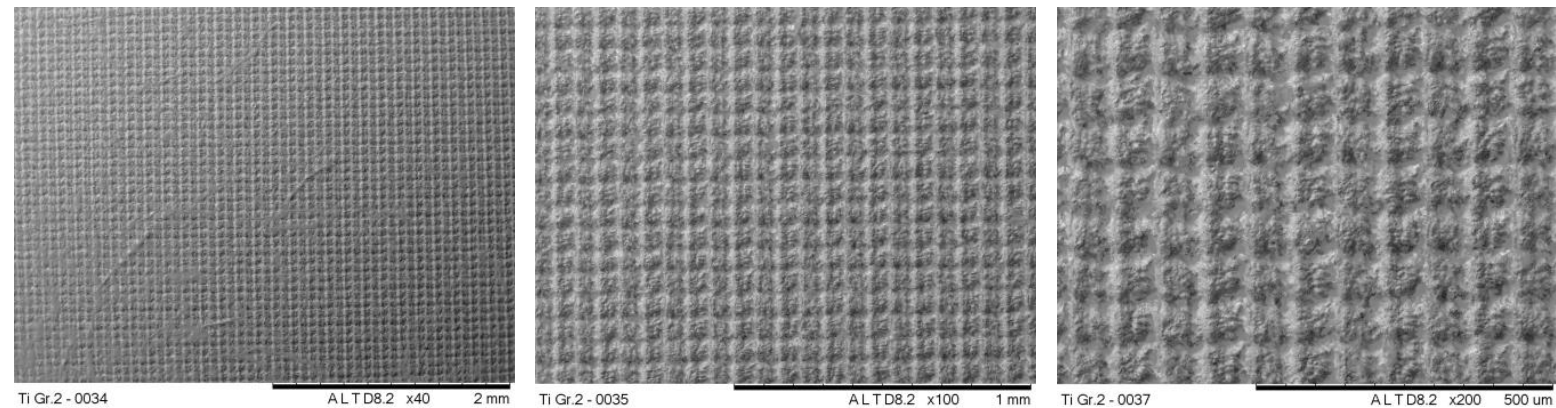

FIGURA 46 - Imagem de MEV da texturização 01 com passo $75 \mu \mathrm{m}$, energia 105 $\mu \mathrm{J}$ e velocidade $35 \mathrm{~mm} / \mathrm{min}$ em chapa de $2,0 \mathrm{~mm}$ de espessura. Aumentos de 40x, 100x e 200x.
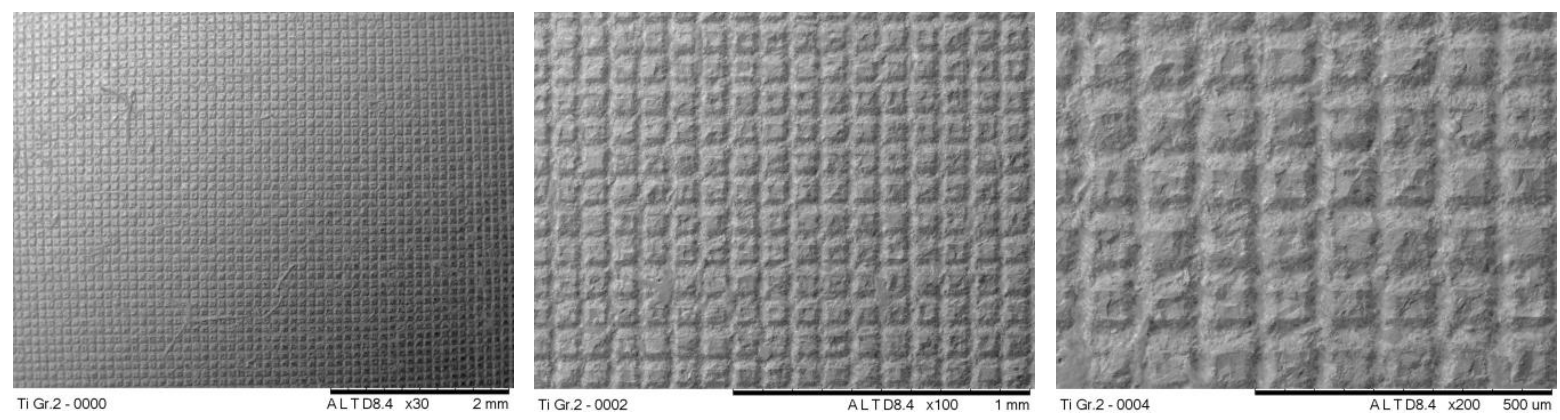

FIGURA 47 - Imagem de MEV da texturização 02 com passo $100 \mu \mathrm{m}$, energia 15 $\mu \mathrm{J}$ e velocidade $5 \mathrm{~mm} / \mathrm{min}$ em chapa de $2,0 \mathrm{~mm}$ de espessura. Aumentos de 30x, 100x e 200x.
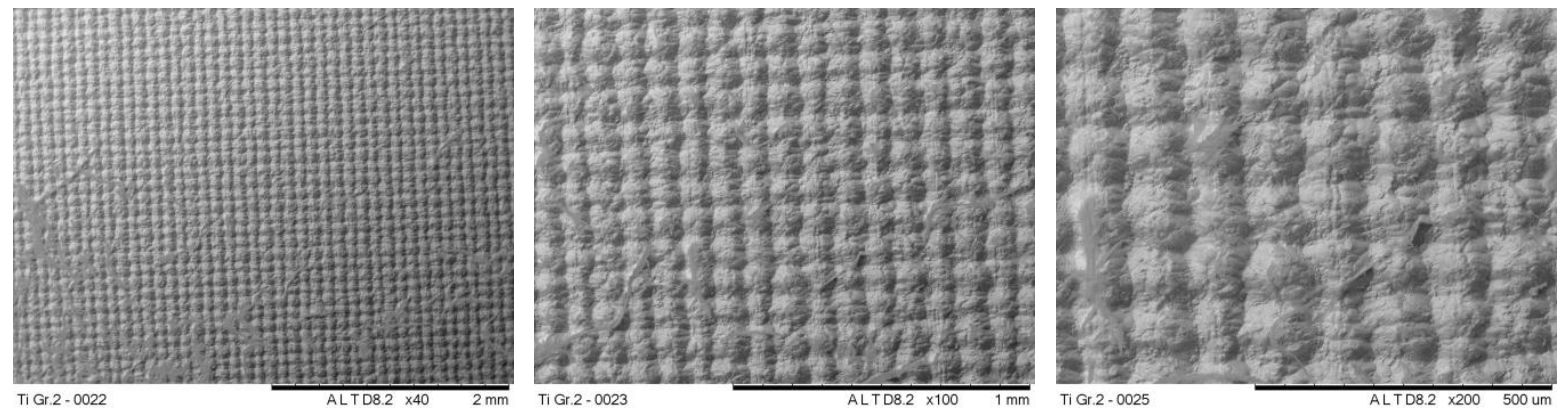

FIGURA 48 - Imagem de MEV da texturização 02 com passo $100 \mu \mathrm{m}$, energia $105 \mu \mathrm{J}$ e velocidade $35 \mathrm{~mm} / \mathrm{min}$ em chapa de $2,0 \mathrm{~mm}$ de espessura. Aumentos de $40 x, 100 x$ e $200 x$. 

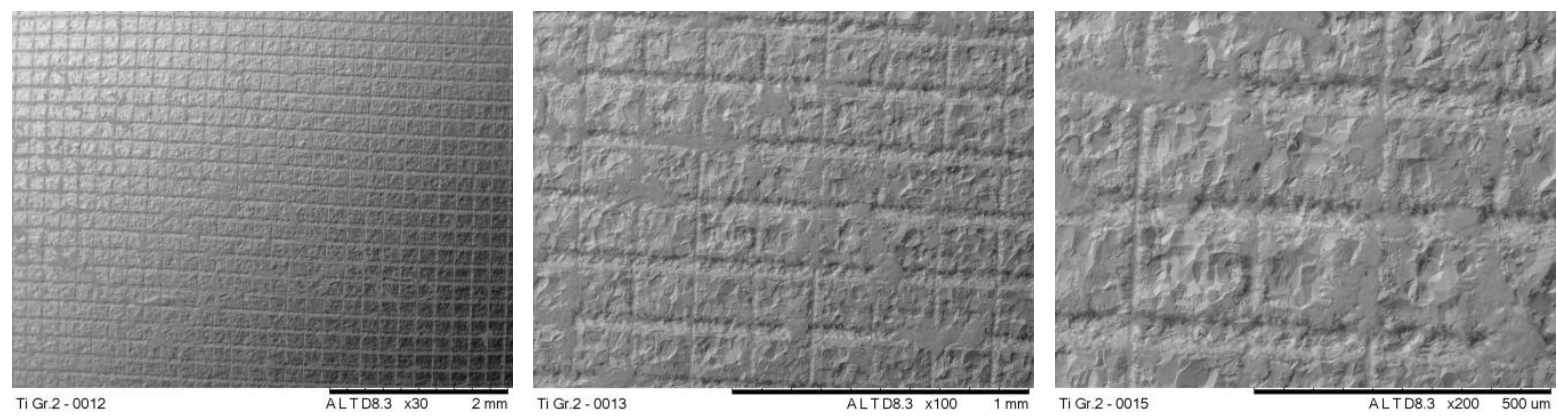

FIGURA 49 - Imagem de MEV da texturização 03 com passo $200 \mu \mathrm{m}$, energia 15 $\mu \mathrm{J}$ e velocidade $5 \mathrm{~mm} / \mathrm{min}$ em chapa de $2,0 \mathrm{~mm}$ de espessura. Aumentos de 30x, $100 x$ e 200x.
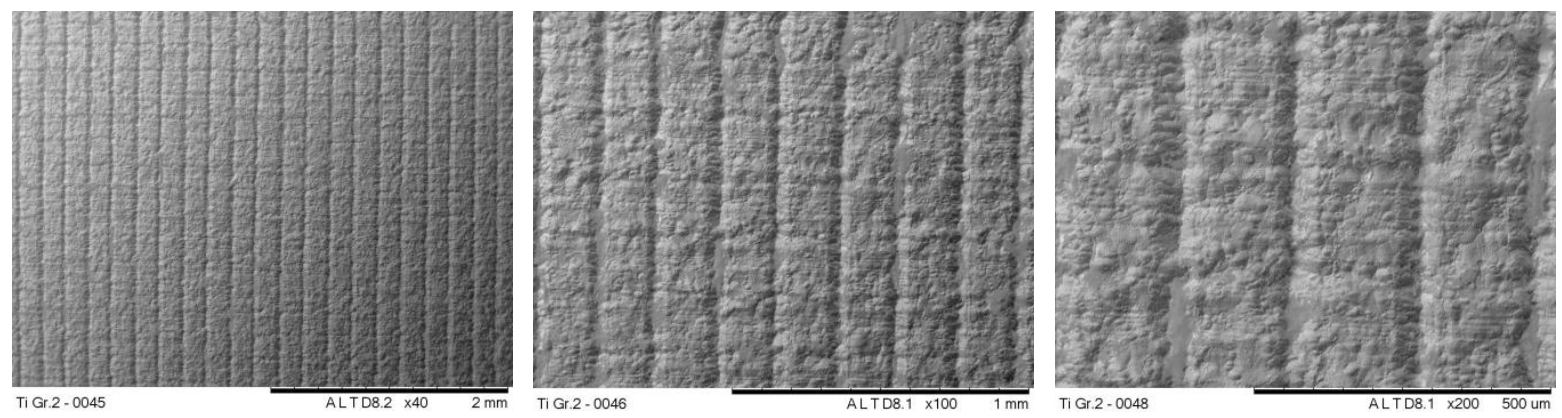

FIGURA 50 - Imagem de MEV da texturização 03 com passo $200 \mu \mathrm{m}$, energia $105 \mu \mathrm{J}$ e velocidade $35 \mathrm{~mm} / \mathrm{min}$ em chapa de $2,0 \mathrm{~mm}$ de espessura. Aumentos de $40 x, 100 x$ e 200x.

\subsection{Difratometria de raios-X (DRX) em amostras de $2,0 \mathrm{~mm}$ de espessura} texturizadas com laser com pulsos ultracurtos

Os difratogramas de raios- $X$ das amostras com texturização 01 , texturização 03 e não texturizada estão apresentados nas FIG. 51, FIG. 52 e FIG. 53 respectivamente. 


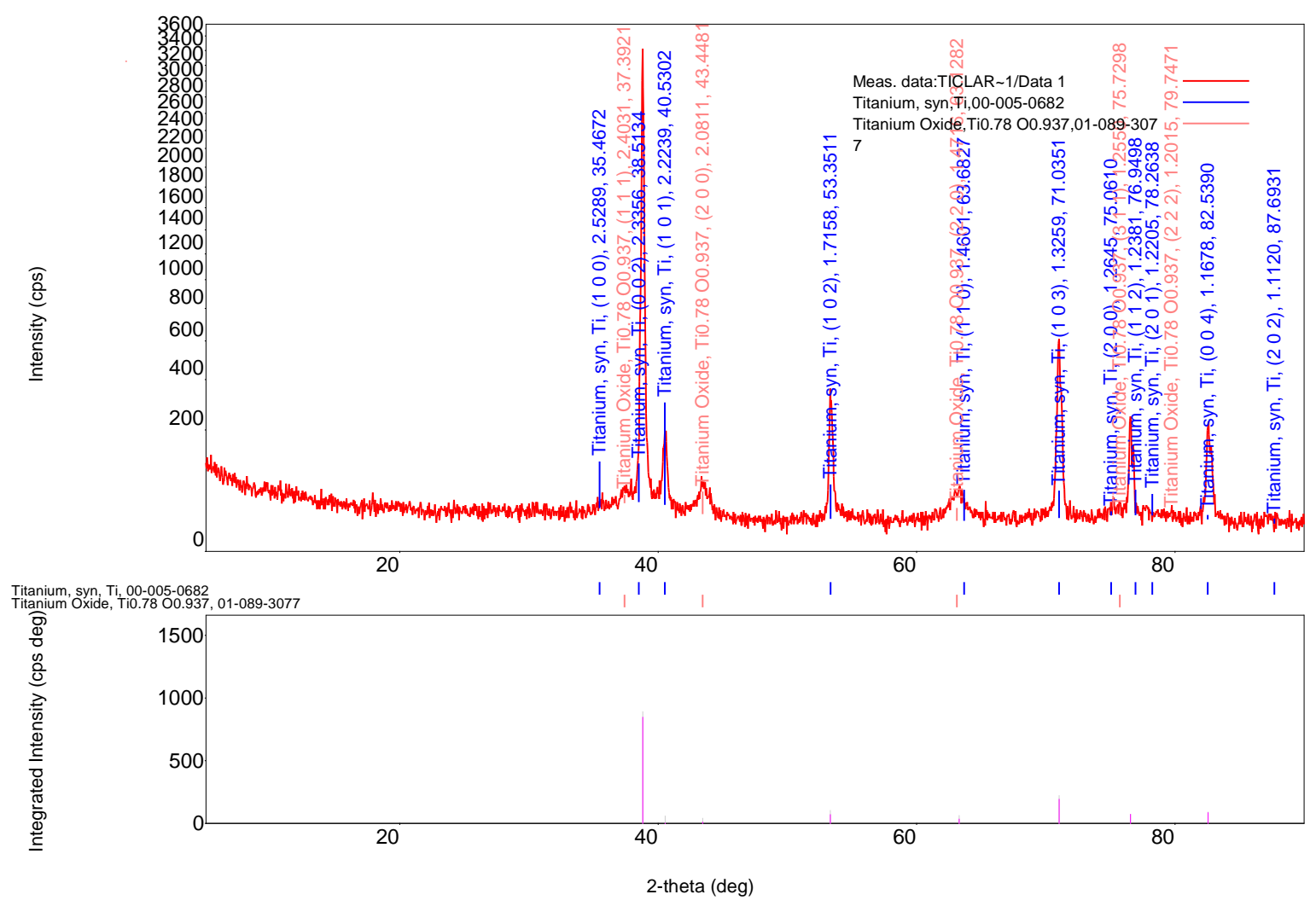

FIGURA 51 - Difratograma de raios-X em amostra com a texturização 01.

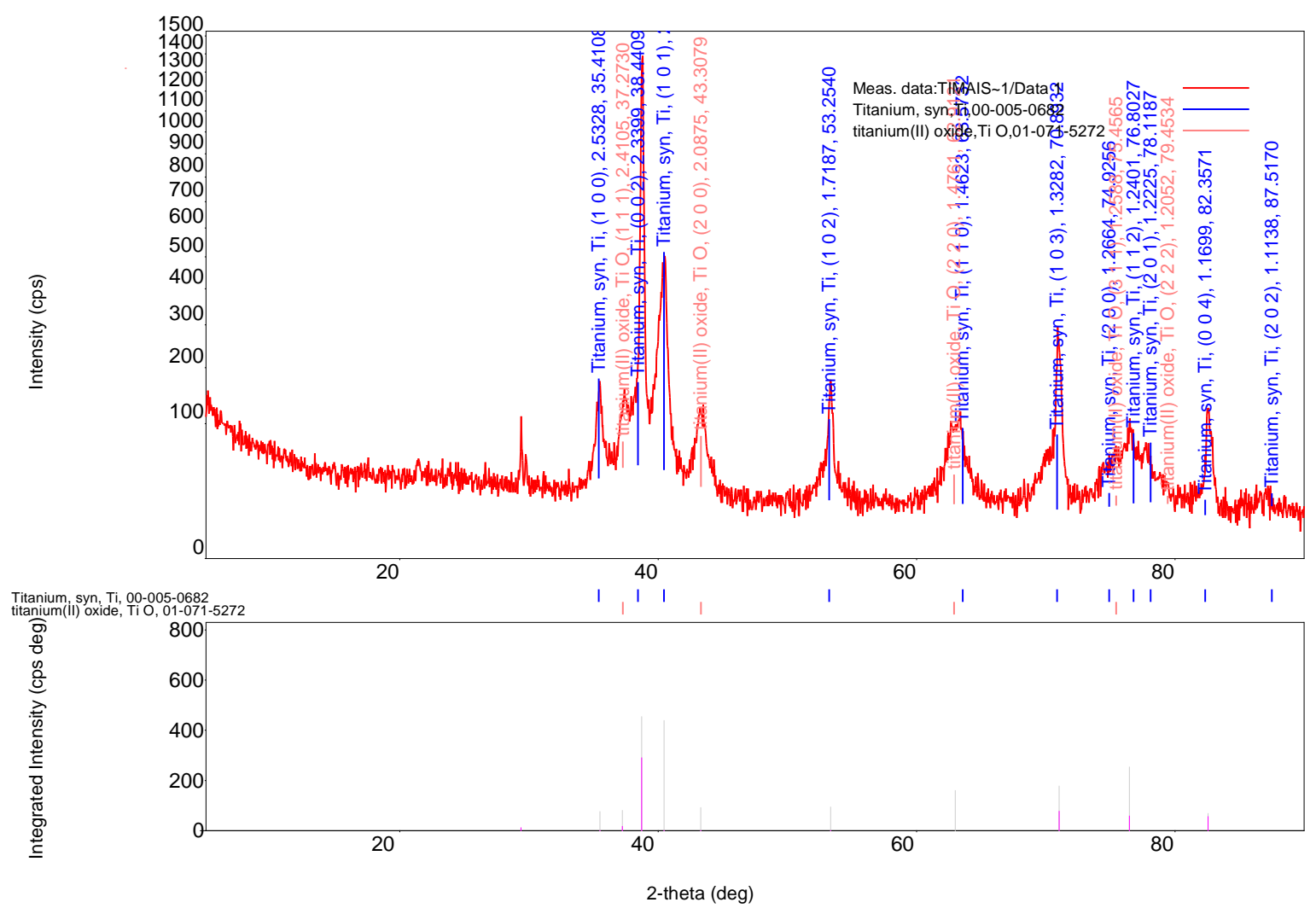

FIGURA 52 - Difratograma de raios-X em amostra com a texturização 03. 


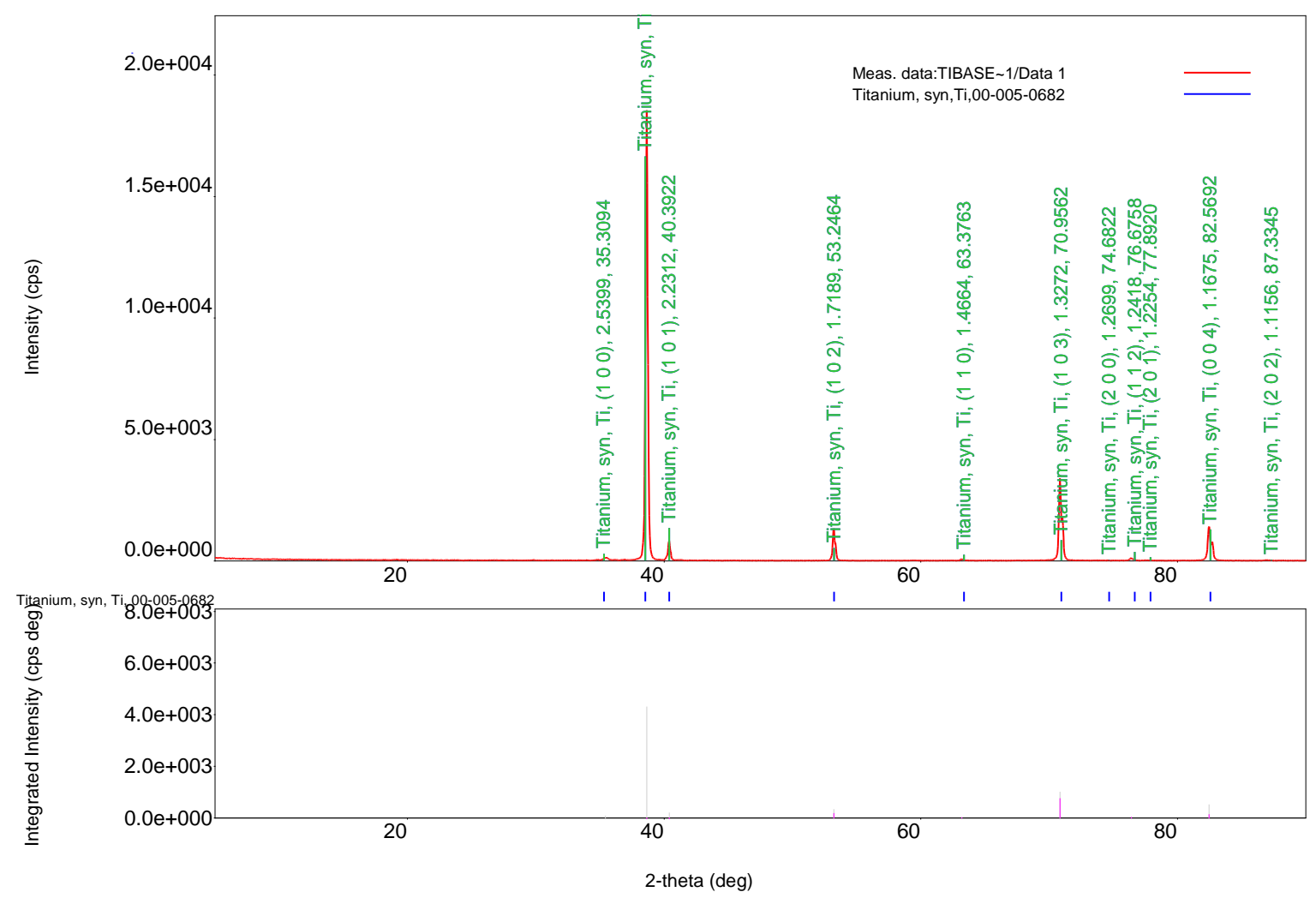

FIGURA 53 - Difratograma de raios-X em amostra com a texturização 03.

Pela análise dos difratogramas, assim como ocorreu no caso do laser com pulsos de nanossegundos, foi verificada somente a presença da fase $\alpha$ (Powder Diffraction File - PDF 05-0682). Vale ressaltar mais uma vez que a técnica utilizada tem sensibilidade para detectar em uma camada de até 1 (um) $\mu \mathrm{m}$, desta forma se houver a presença de fase $\beta$, ela estaria em uma camada menor que 1 (um) $\mu \mathrm{m}$. De forma evidente, no processo de ablação por laser com pulsos ultracurtos também não houve a presença de fase $\beta$ após o resfriamento.

Mesmo atuando no regime de alta fluência, e que acarretou formação de fase líquida, não se nota material ressolidificado. Isto provavelmente ocorreu porque o material fundido foi ejetado para fora da região afetada, e não houve tempo (ou energia suficiente) para aquecer a região vizinha e provocar uma zona afetada pelo calor detectável. Assim, mesmo com alta fluência, a estrutura cristalina da superfície não é modificada e não gera tensões que levem à deformação da peça.

Contudo, como o titânio possui alta afinidade com o oxigênio, pode-se verificar a presença de $\mathrm{TiO}$ na amostra com a texturização 01 (Powder Diffraction File - PDF 89-3077) e na amostra com a texturização 03 (Powder Diffraction File 
- PDF 71-5272), porém com picos de baixa intensidade relativa, uma vez que houve proteção da atmosfera de interação com gás inerte. Desta forma, mesmo com a utilização do argônio ainda assim houve a reação com o oxigênio e a consequente formação de óxido de titânio, visto que o titânio é extremamente reativo com o oxigênio. Uma forma de se evitar ou reduzir este efeito seria a utilização de uma "glove box" com baixíssima concentração de oxigênio.

\subsection{Perfilometria óptica}

Para a determinação de um parâmetro que permitisse uma análise quantitativa da eficiência da junta colada, foram utilizados como parâmetros os valores dos perímetros médios e os volumes médios para cada célula unitária resultante das texturizações.

As imagens para cada texturização seguem da FIG. 54 até a FIG. 56 e mostram as imagens das análises realizadas no perfilômetro.

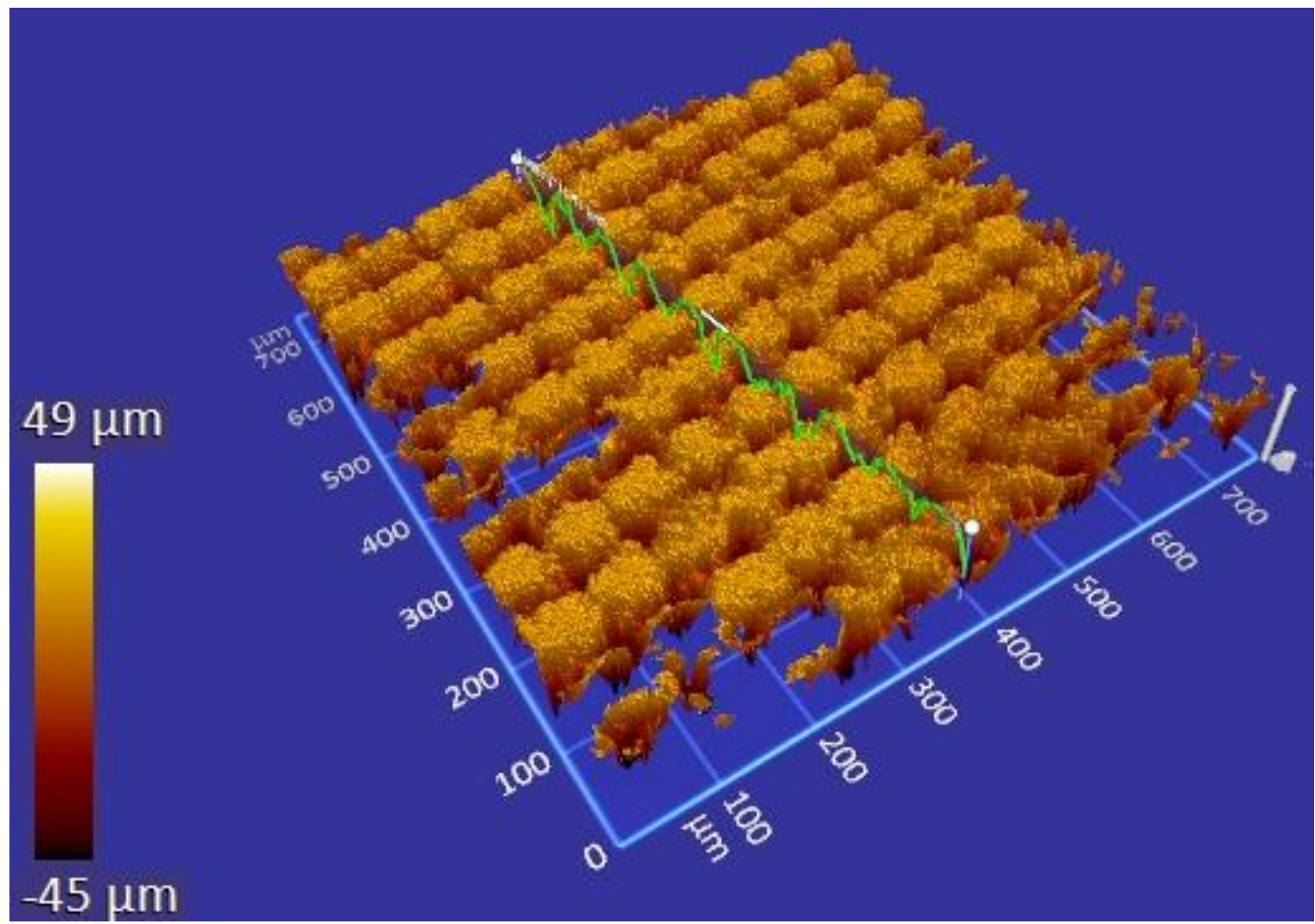

FIGURA 54 - Perfilometria da amostra 3 da texturização 01. 


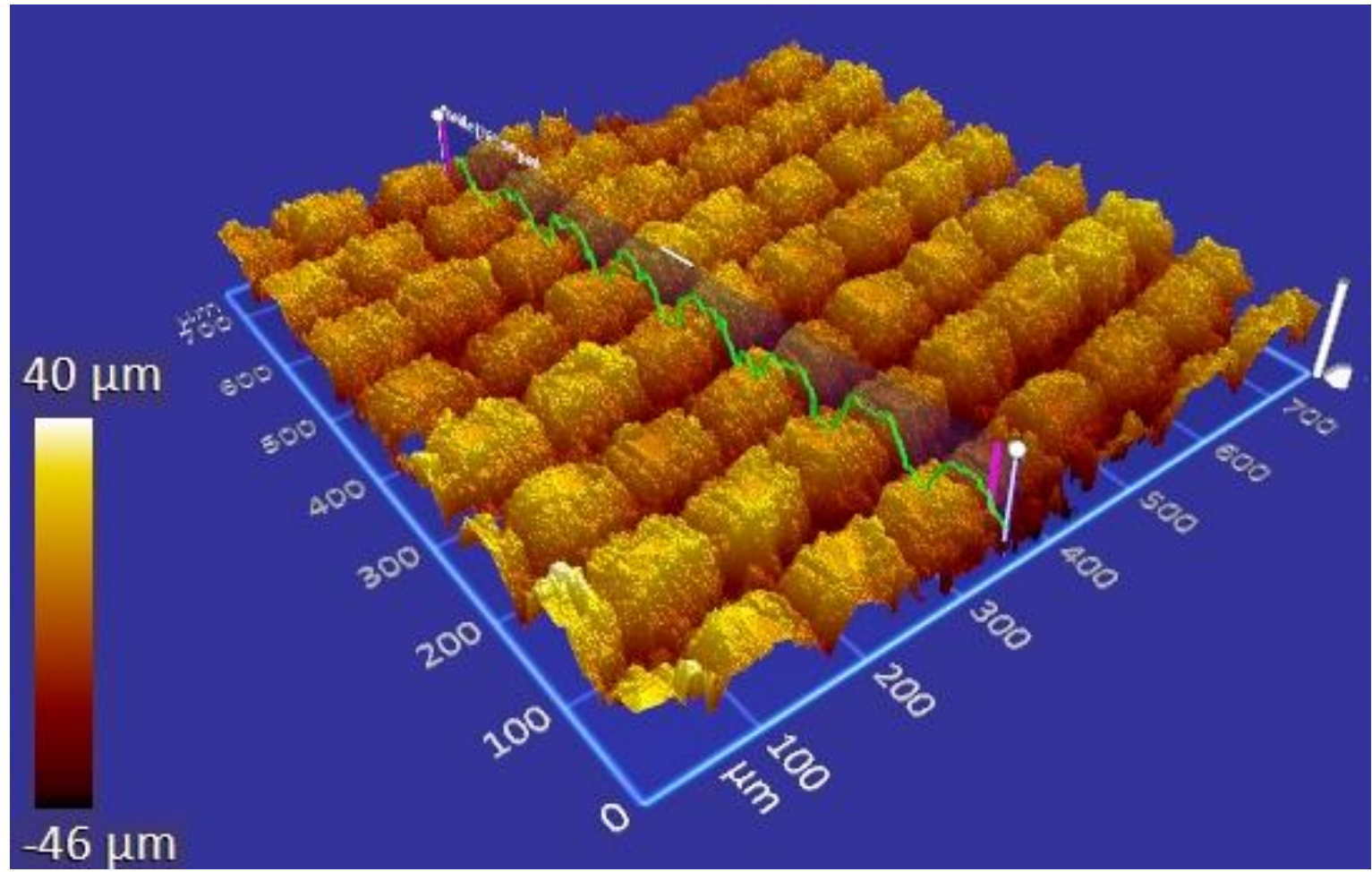

FIGURA 55 - Perfilometria da amostra 3 da texturização 02.

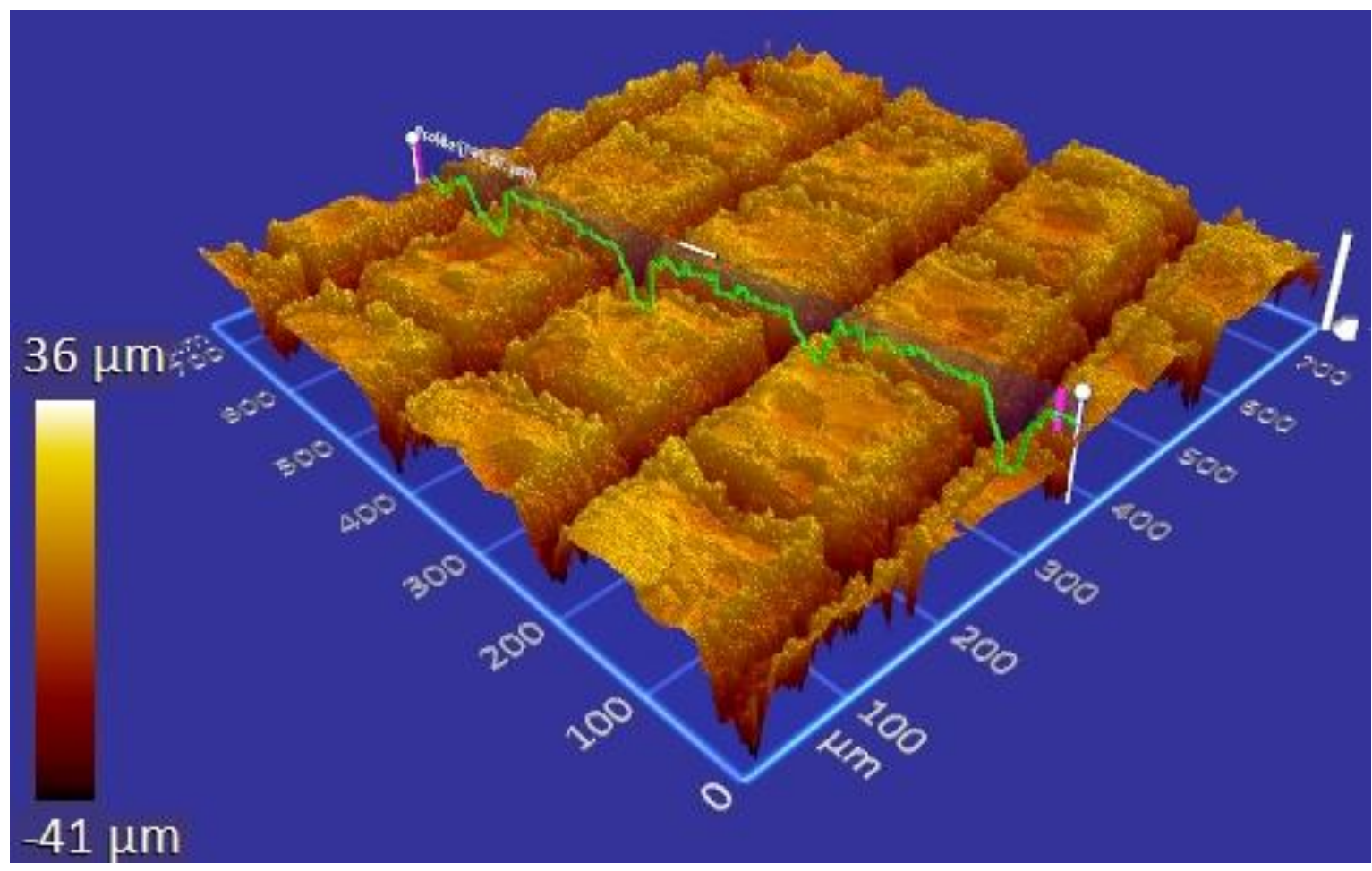

FIGURA 56 - Perfilometria da amostra 3 da texturização 03.

Na FIG. 57 tem-se o detalhe da célula unitária para a texturização 03. 


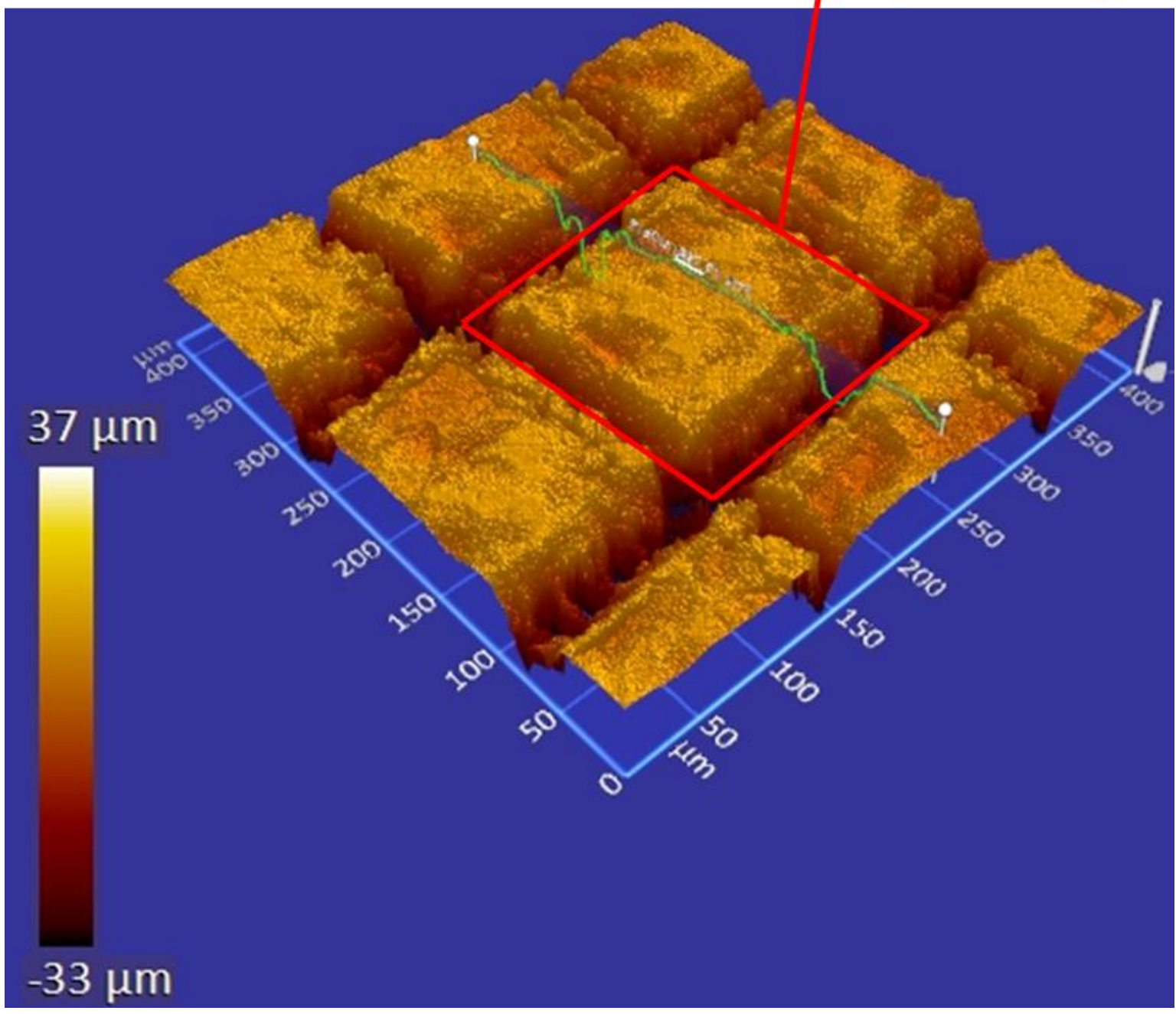

FIGURA 57 - Detalhe das células unitárias da amostra 3 da texturização 03.

Na FIG. 57, é possível notar a linha do perfil da microusinagem. Tal perfil, que pode ser visto em detalhe na FIG. 58, foi utilizado para determinação do perímetro específico médio e volume específico médio.

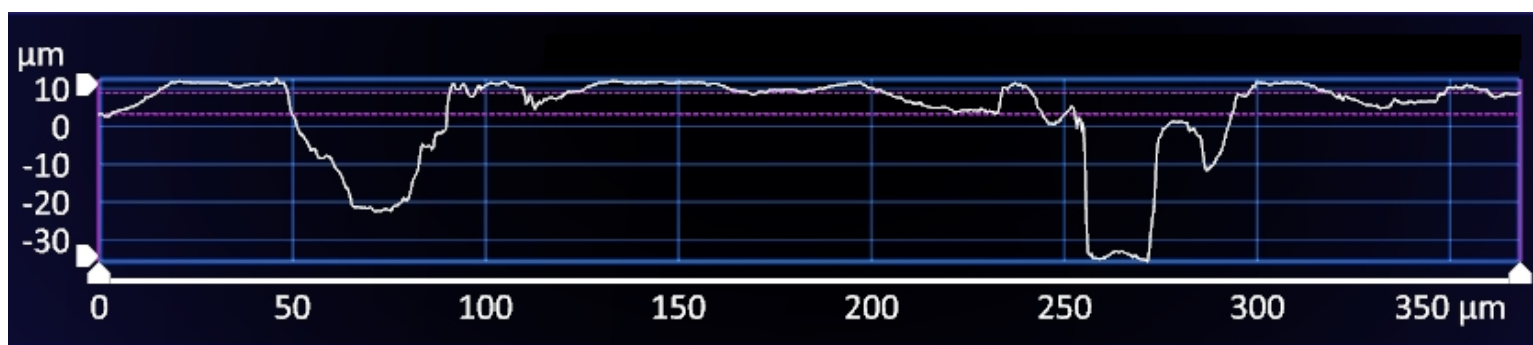

FIGURA 58 - Perfil da microusinagem para determinação do perímetro e volume específicos da texturização 03. 
Através da imagem da FIG. 58 foi obtida a FIG. 59, onde estão as linhas limitadoras das células unitárias. A partir destas linhas foram traçadas, utilizando o software AutoCad, as linhas para obtenção do perímetro e determinação dos volumes das células unitárias, conforme visto na FIG. 60.

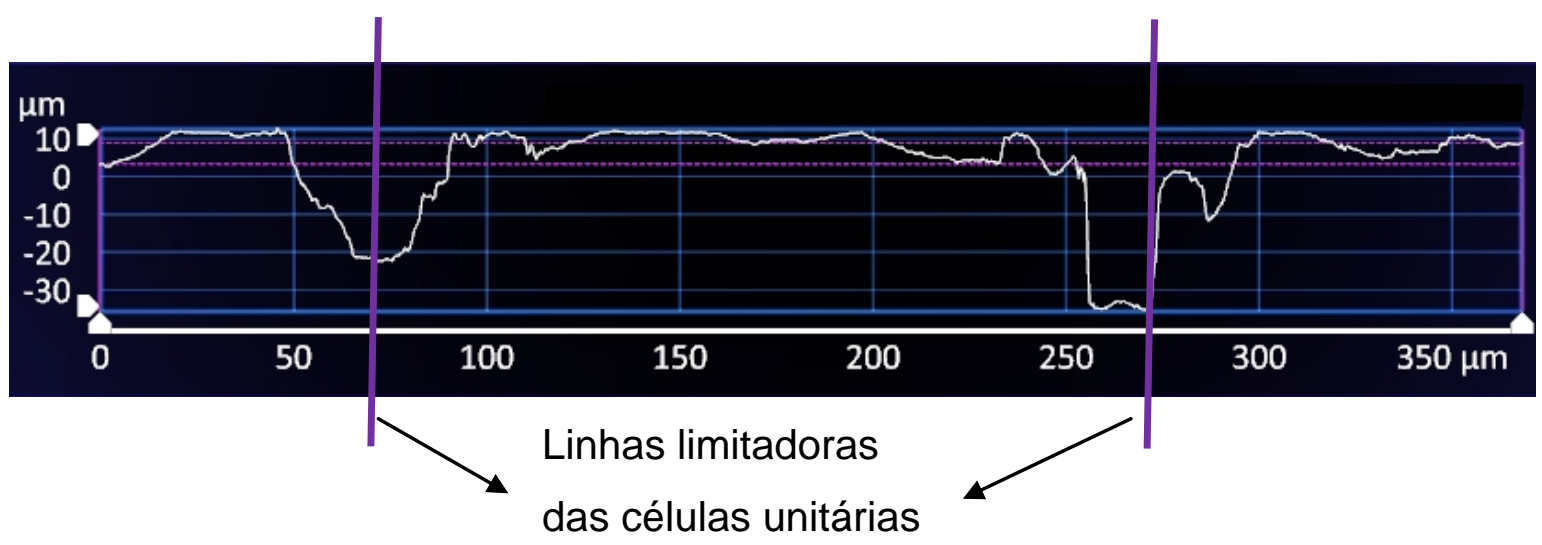

FIGURA 59 - Detalhe das linhas limitadoras das células unitárias no perfil da microusinagem da texturização 03.

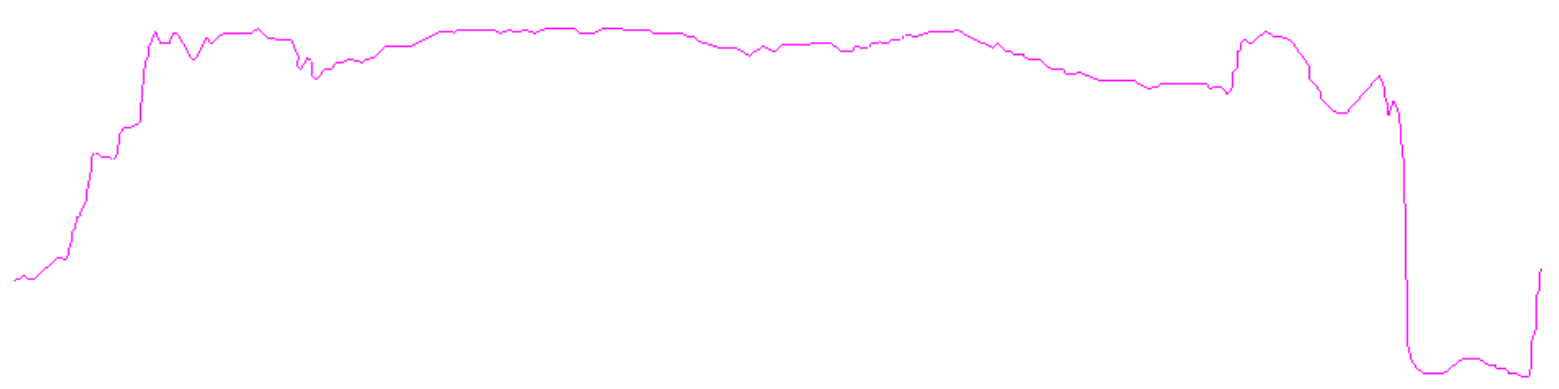

(a)

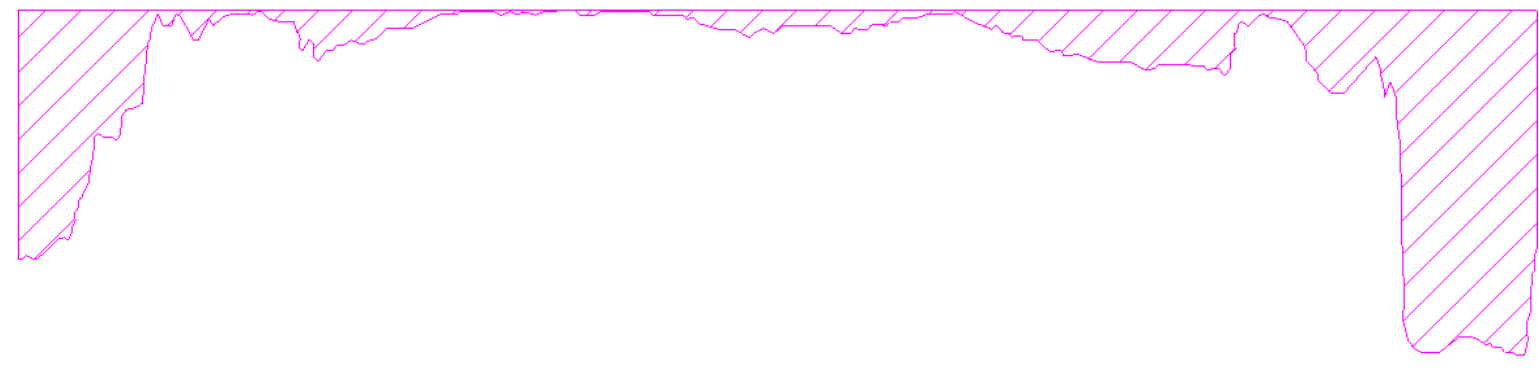

(b)

FIGURA 60 - Linha para obtenção do perímetro específico da célula unitária da texturização 03 (a) e área específica da célula unitária para determinação do volume específico (b). 
Desta forma, puderam ser determinados os perímetros específicos simplesmente pelo dimensionamento do percurso total da linha do perfil da texturização. De forma análoga foram dimensionadas as áreas acima do perfil e assim, através do produto pelo comprimento de cada célula unitária foram calculados os volumes específicos. Importante salientar que o perímetro aqui colocado refere-se à região de cada célula unitária, e não ao perímetro de toda a região texturizada.

$\mathrm{Na}$ TAB. 14 são apresentados os valores obtidos com a análise do perfil para cada texturização, que são as médias de 5 valores de células unitárias diferentes. Como pode ser visto, apesar do perímetro específico ser menor para a célula unitária da texturização 01 , o volume específico é maior, visto que as irregularidades são maiores nesta texturização. Analogamente, na texturização 03, que apresenta uma maior regularidade, o volume específico da célula unitária é menor.

TABELA 14 - Valores do perímetro e volume específicos para as três geometrias de texturização realizadas

\begin{tabular}{ccc}
\hline Texturização & $\begin{array}{c}\text { Perímetro Específico } \\
(\mu \mathrm{m})\end{array}$ & $\begin{array}{c}\text { Volume Específico } \\
\left(\mathrm{mm}^{3}\right)\end{array}$ \\
\hline 01 & 112,50 & $3,010 \times 10^{-4}$ \\
02 & 143,32 & $1,733 \times 10^{-4}$ \\
03 & 303,52 & $1,104 \times 10^{-4}$ \\
\hline
\end{tabular}

A TAB. 15 apresenta as quantidades de células unitárias, bem como o volume total.

TABELA 15 - Valores do perímetro e volume específicos para as três geometrias de texturização realizadas

\begin{tabular}{ccccc}
\hline Texturização & $\begin{array}{c}\text { Quantidade } \\
\text { de células } \\
\text { unitárias }\end{array}$ & $\begin{array}{c}\text { Perímetro total } \\
\text { com texturas } \\
(\mathrm{mm})\end{array}$ & $\begin{array}{c}\text { Volume } \\
\text { Total } \\
\left(\mathrm{mm}^{3}\right)\end{array}$ & $\begin{array}{c}\text { Razão entre } \\
\text { volumes com } \\
\text { e sem textura }\end{array}$ \\
\hline 01 & 17.777 & 60,0 & 5,351 & 53,5 \\
02 & 10.000 & 57,2 & 1,733 & 17,3 \\
03 & 2.500 & 60,7 & 0,273 & 2,76 \\
\hline
\end{tabular}

Supondo que o volume de cola necessário para a adesão no caso da não existência das texturas seria o produto da área de colagem (10 mm x $10 \mathrm{~mm}$ ) 
por um ínfima espessura da ordem de $1 \mu \mathrm{m}$ (valor teórico de acordo com 0 fabricante), este resultaria no valor de $0,1 \mathrm{~mm}^{3}$. Assim pode-se notar analisando a TAB. 15 que a razão entre os volumes com e sem textura aumenta consideravelmente com o aumento do número de células. Avançando na análise, pelos valores de perímetro, há um considerável ganho, visto que a região de colagem desconsiderando as texturas tem um perímetro total de $40 \mathrm{~mm}$. Desta forma pode-se avaliar que este acréscimo está em torno $50 \%$.

Como pode ser visto na FIG. 61, a imagem de perfilometria óptica da superfície da amostra de Ti Gr.2 CP sem texturização apresenta uma regularidade com baixa rugosidade.

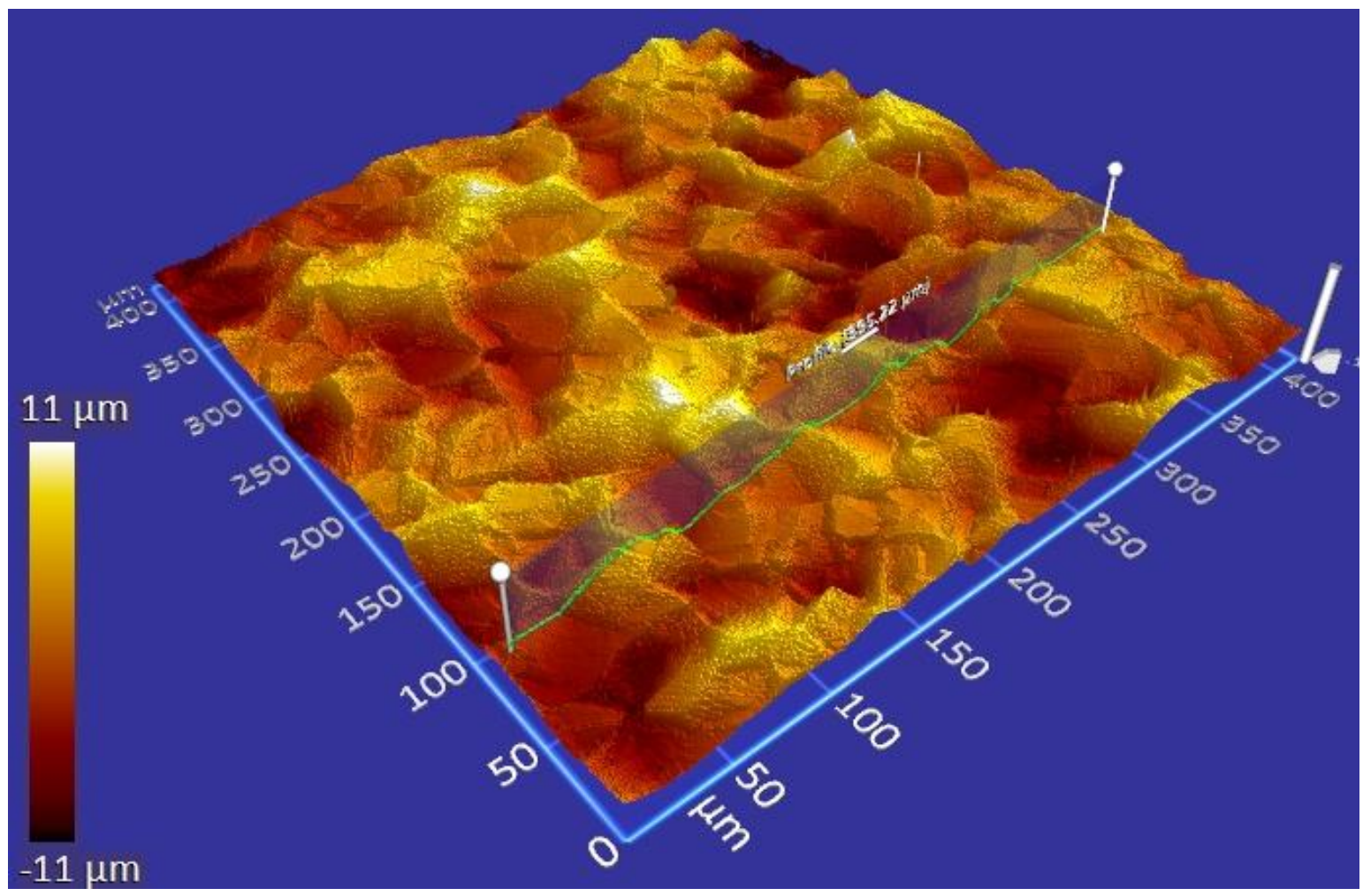

FIGURA 61 - Perfilometria da amostra 3 da texturização 01 sem texturização.

\subsection{Medição da molhabilidade}

As imagens dos perfis das gotas estão apresentadas da FIG. 62 até a FIG. 65.

A FIG. 66 mostra a imagem da gota na texturização 03 obtida no software ImageJ para determinação do ângulo de contato. 


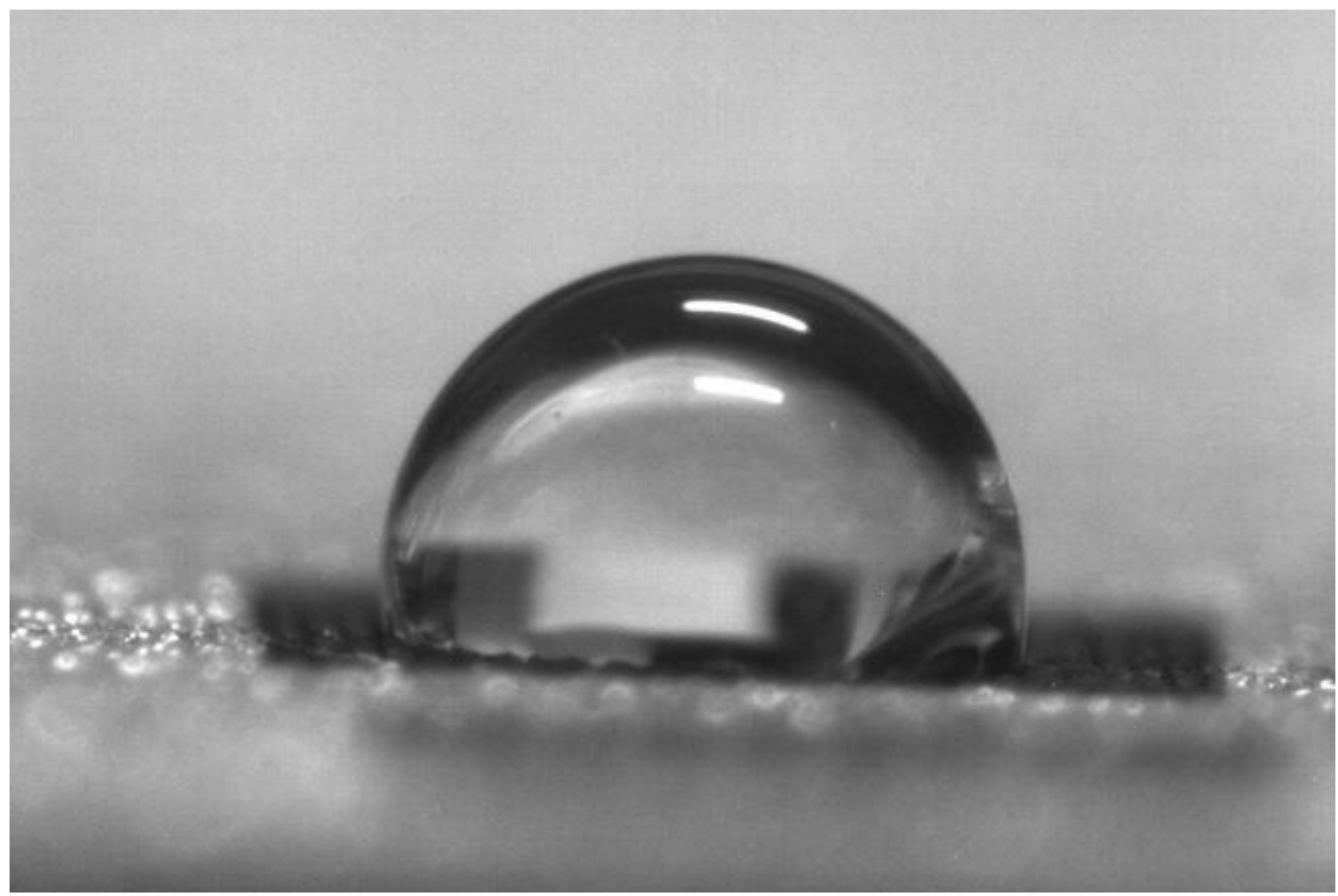

FIGURA 62 - Imagem do perfil da gota para medição da molhabilidade pelo método da gota séssil na texturização 01 .

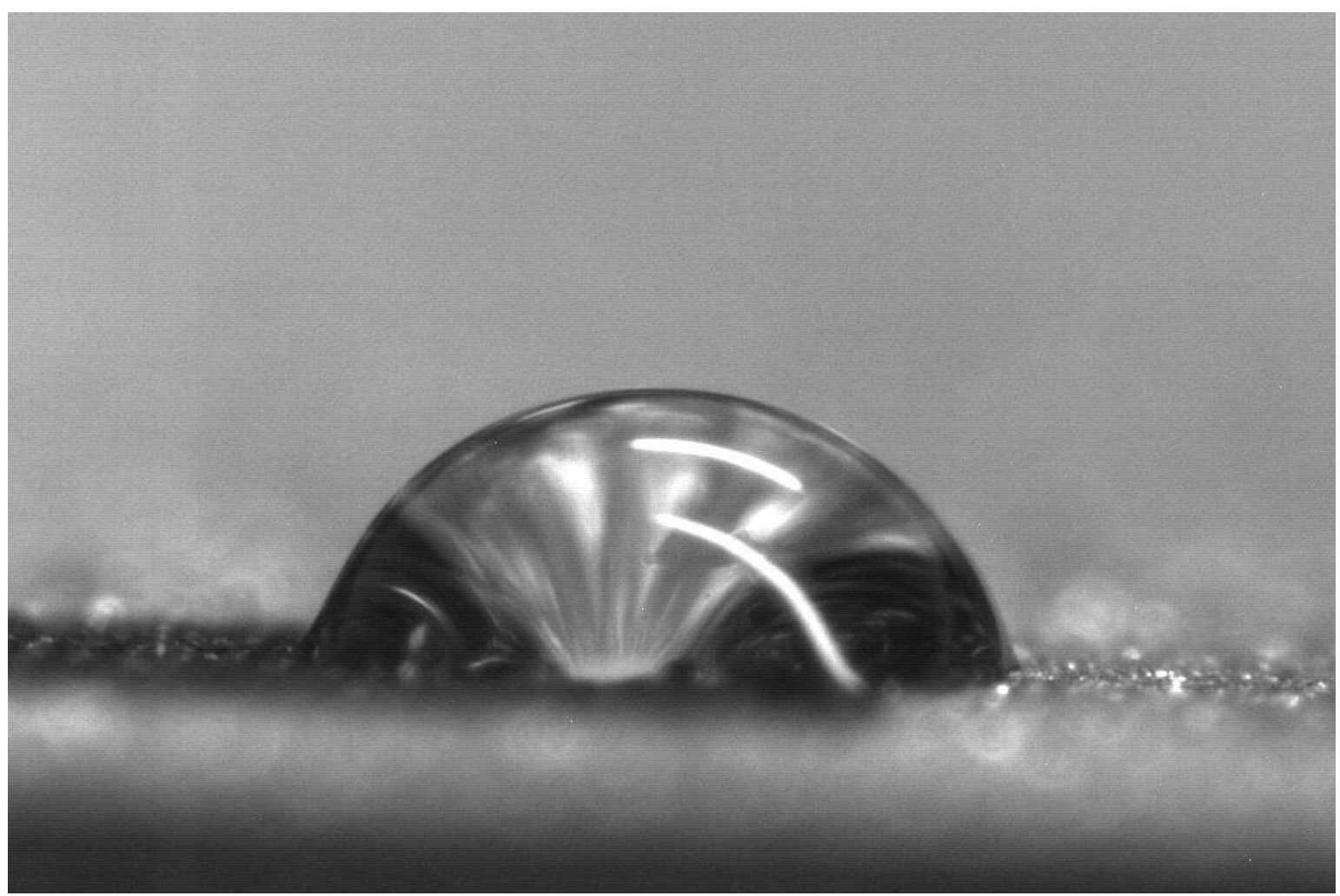

FIGURA 63 - Imagem do perfil da gota para medição da molhabilidade pelo método da gota séssil na texturização 02 . 


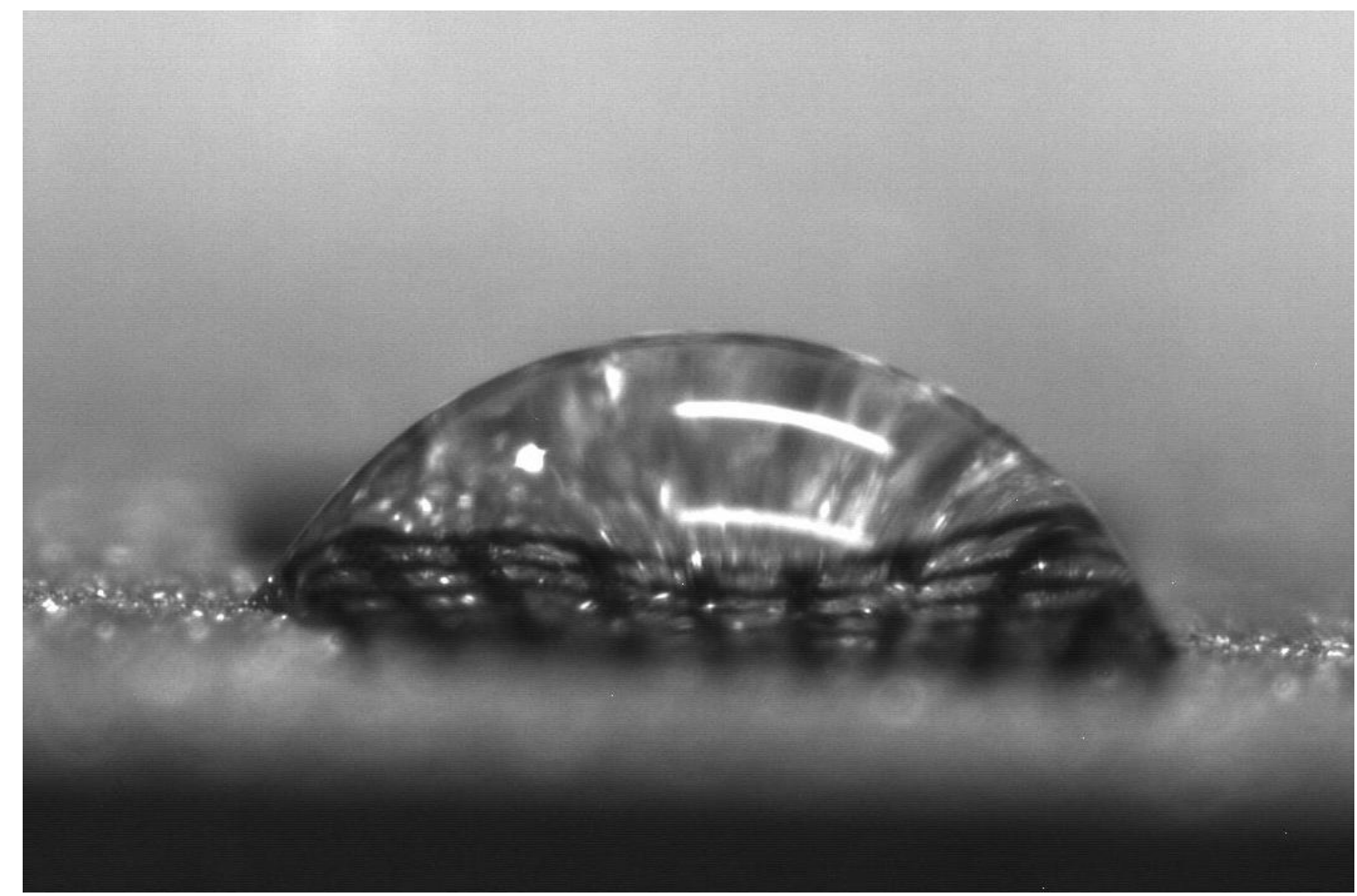

FIGURA 64 - Imagem do perfil da gota para medição da molhabilidade pelo método da gota séssil na texturização 03.

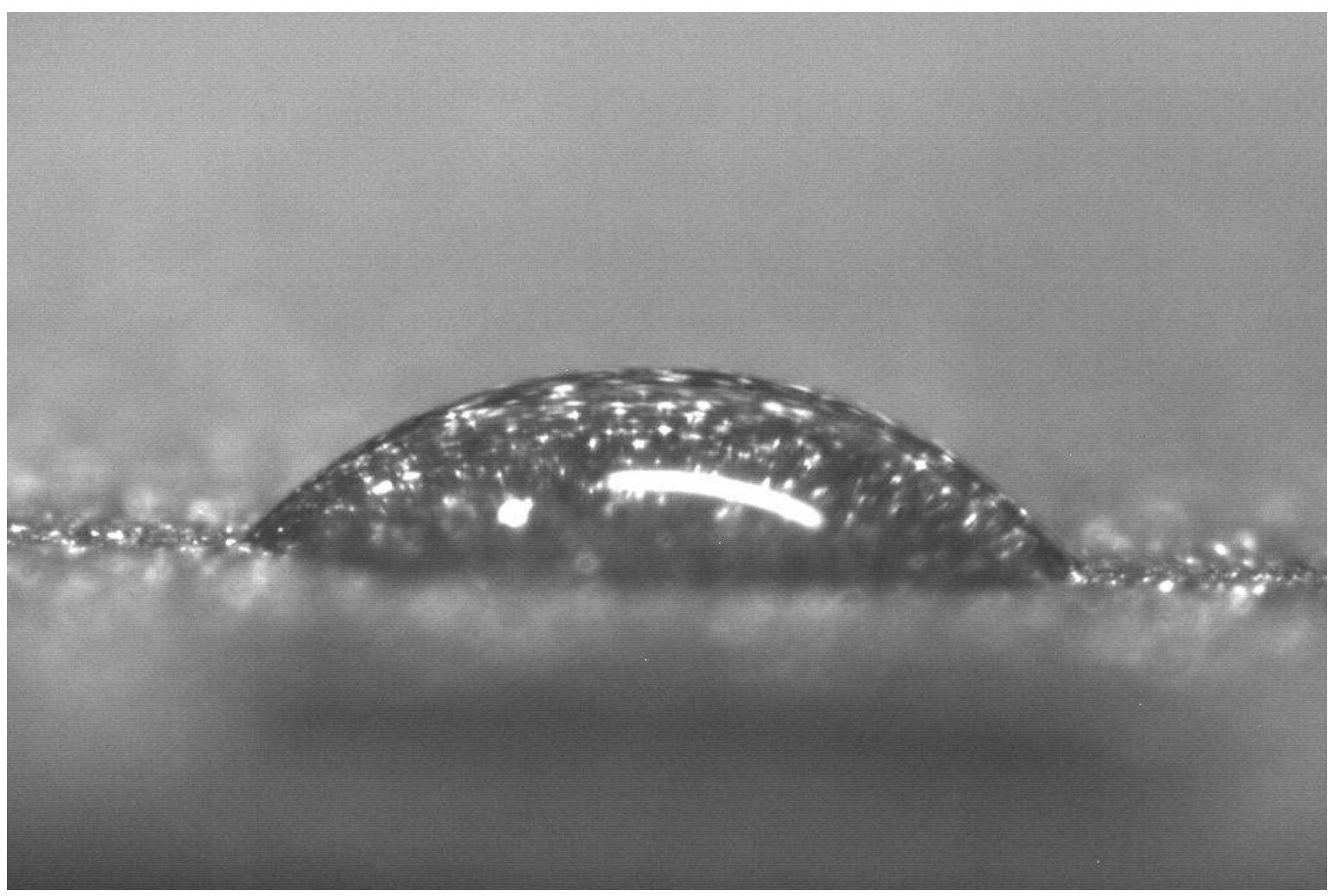

FIGURA 65 - Imagem do perfil da gota para medição da molhabilidade pelo método da gota séssil em amostra sem texturização. 


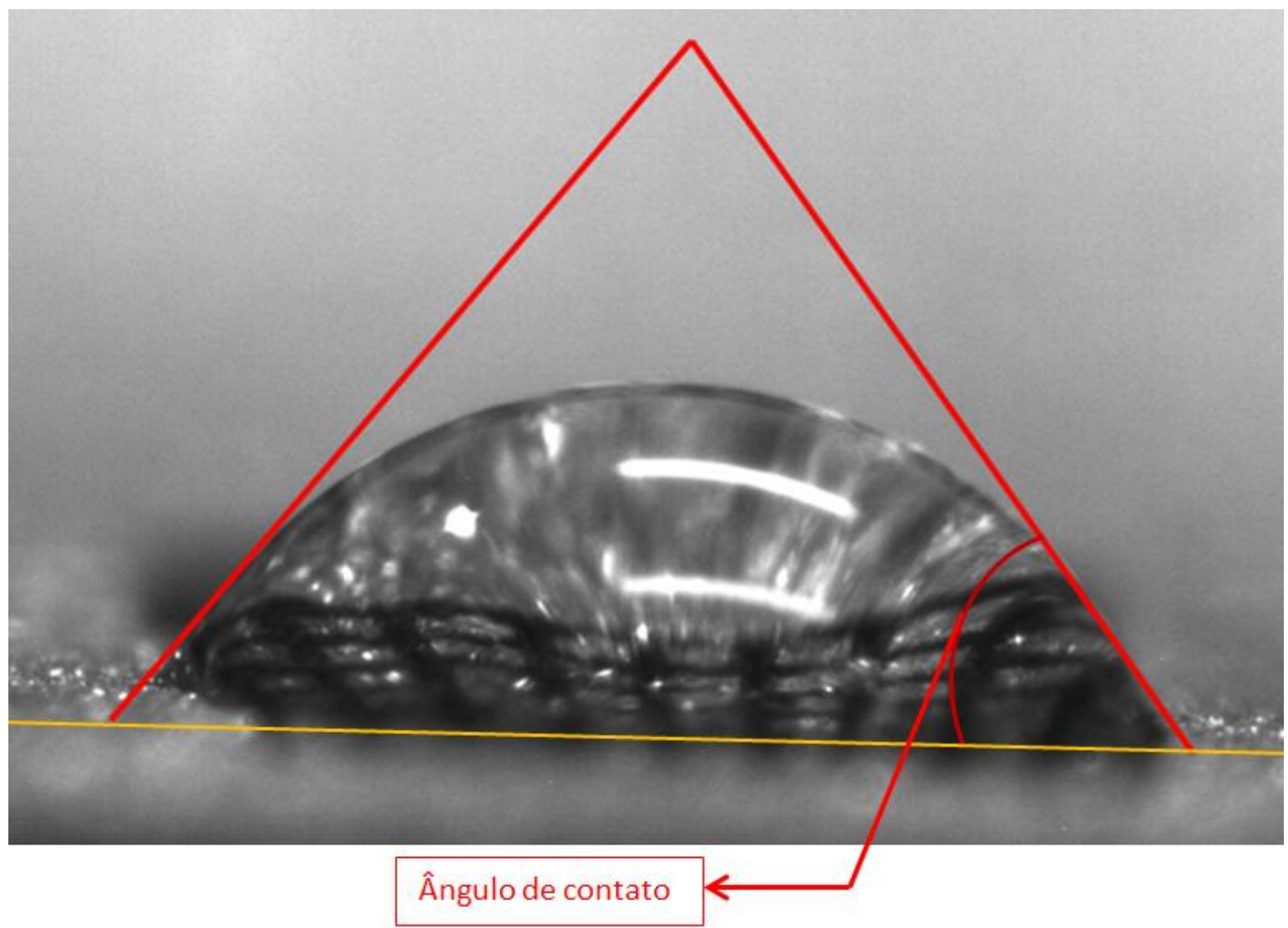

FIGURA 66 - Imagem do perfil da gota na texturização 03 no software Image J linhas representam as referências para determinação do ângulo de contato pelo método da gota séssil.

$\mathrm{Na}$ TAB. 16 estão os resultados da molhabilidade para cada amostra. Os resultados indicam o decréscimo do ângulo de contato com o aumento do passo de texturização, o que aumentou a hidrofilia da superfície e consequentemente melhorou a molhabilidade. Ou seja, a texturização 01 é a mais hidrofóbica. Ainda pode-se perceber que a amostra sem texturização apresenta a melhor molhabilidade, sendo a mais hidrofílica em relação às demais amostras.

TABELA 16 - Valores do ângulo de contato da gota para mensuração da molhabilidade

\begin{tabular}{cc}
\hline Amostra & $\begin{array}{c}\text { Ángulo de contato } \\
\left({ }^{\circ}\right)\end{array}$ \\
\hline Texturização 01 & 99,85 \\
Texturização 02 & 83,56 \\
Texturização 03 & 50,08 \\
Sem Texturização & 39,54 \\
\hline
\end{tabular}


É importante ressaltar que neste experimento, apesar de o método utilizado seguir as recomendações da ASTM D 5725-99 [48], não foi utilizado um equipamento específico para medição de molhabilidade, e desta forma os valores obtidos podem apresentar alguma variação em relação ao que seriam encontrados em tal equipamento, sendo assim a análise quantitativa não oferece confiabilidade quanto aos exatos valores, porém permite analisar as variações para cada textura usinada. Desta forma os valores da TAB. 16 tem um caráter muito mais qualitativo para fins de comparação no desempenho da adesão de cada texturização realizada do que propriamente para determinação de características de molhabilidade das superfícies.

O efeito imediato da texturização da superfície é a influência exercida no ângulo de contato da gota. Estes resultados podem ser utilizados para prever teoricamente a eficiência de adesão na superfície do titânio [4].

\subsection{Junção por adesão das amostras de Ti Gr.2 CP e CFRP}

Inicialmente foi realizada a adesão de amostras de Ti Gr.2 CP não texturizadas em amostras de CFRP, de modo que seria feita uma comparação com os resultados obtidos para adesão em amostras texturizadas. Na FIG. 67 estão ilustradas as imagens das amostras de Ti Gr.2 CP sem texturizações coladas às amostras de CFRP. No entanto, a junta adesiva não teve eficiência, visto que as amostras simplesmente não se mantiveram unidas, mesmo após o tempo de cura do adesivo. $O$ fato deve-se a questão de que tal união sem tratamento da superfície não tem a tenacidade suficiente.

Como a eficiência da colagem depende de alguns aspectos, a utilização do laser de femtossegundos teve um aspecto extremamente favorável quanto aos objetivos deste trabalho, visto que caso tivesse presente material ressolidificado, a aderência do adesivo à superfície poderia ficar prejudicada. Desta forma, foram feitas as junções por adesão das amostras de Ti Gr.2 CP texturizadas às amostras de CFRP, conforme apresentado nas imagens da FIG. 68. 


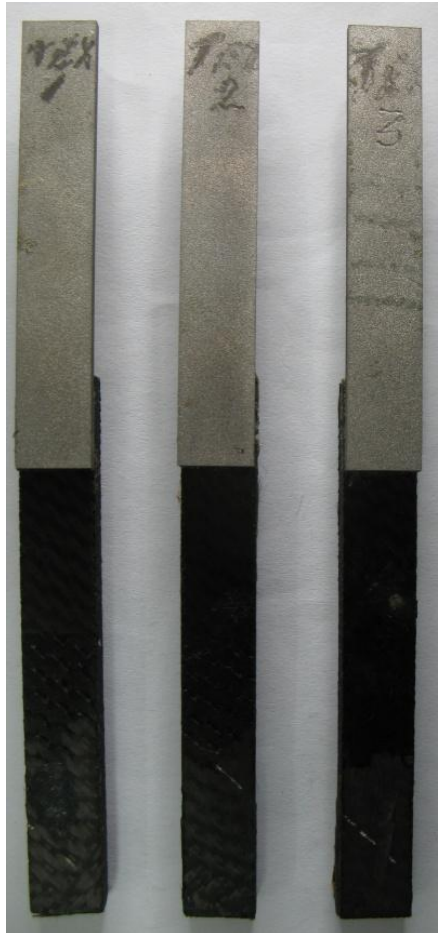

(a)

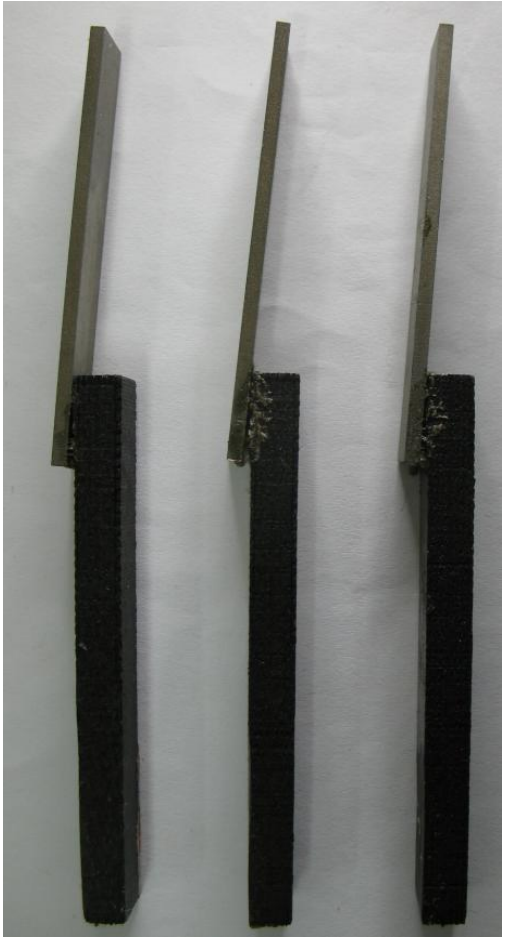

(b)

FIGURA 67 - Amostras de Ti Gr.2 CP sem textura coladas às amostras de CFRPa) Vista de topo; b) vista de perfil mostrando a adesão ineficiente.

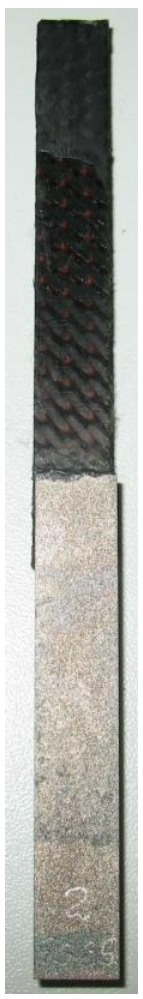

(a)

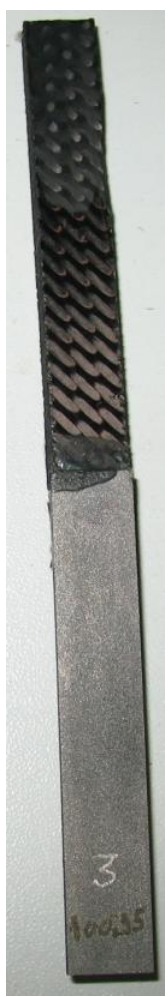

(b)

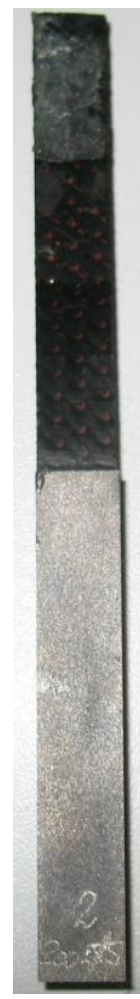

(c)

FIGURA 68 - Amostras coladas a) Texturização 01 amostra 2; b) Texturização 02 amostra $3 A$; c) Texturização 03 amostra 2. 


\subsection{Ensaios de tração}

Foram realizados os ensaios de tração nas amostras coladas para que fossem determinados os limites de ruptura ao cisalhamento da região colada, em função das diferentes geometrias texturizadas.

Da FIG. 69 até a FIG. 75 seguem as imagens de MEV das amostras de Ti Gr.2 CP texturizadas após a ruptura nos ensaios de tração.

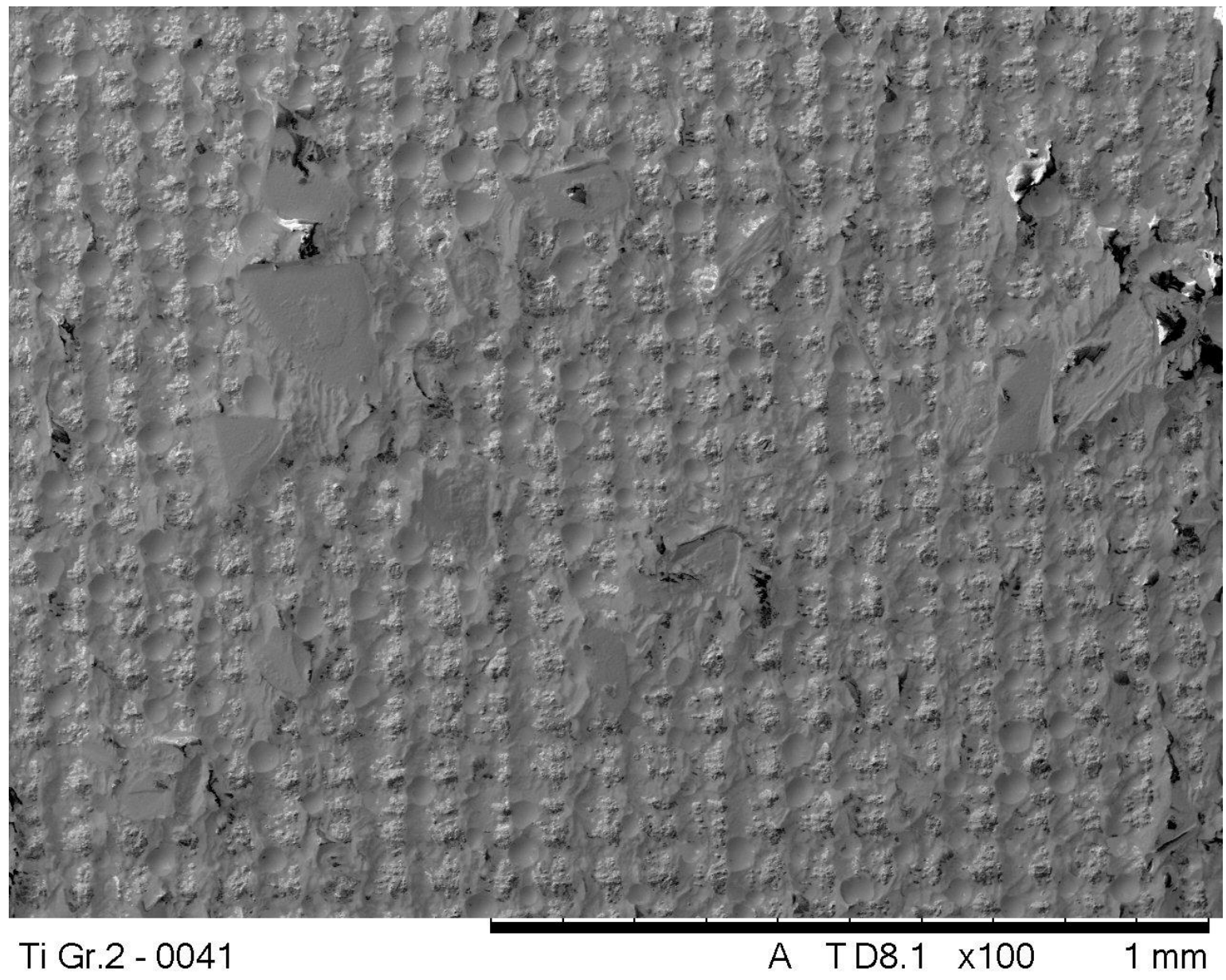

FIGURA 69 - Imagem de MEV após ruptura por cisalhamento da amostra 3 da texturização 01 no Ti Gr. 2 CP. Aumento de 100x. 


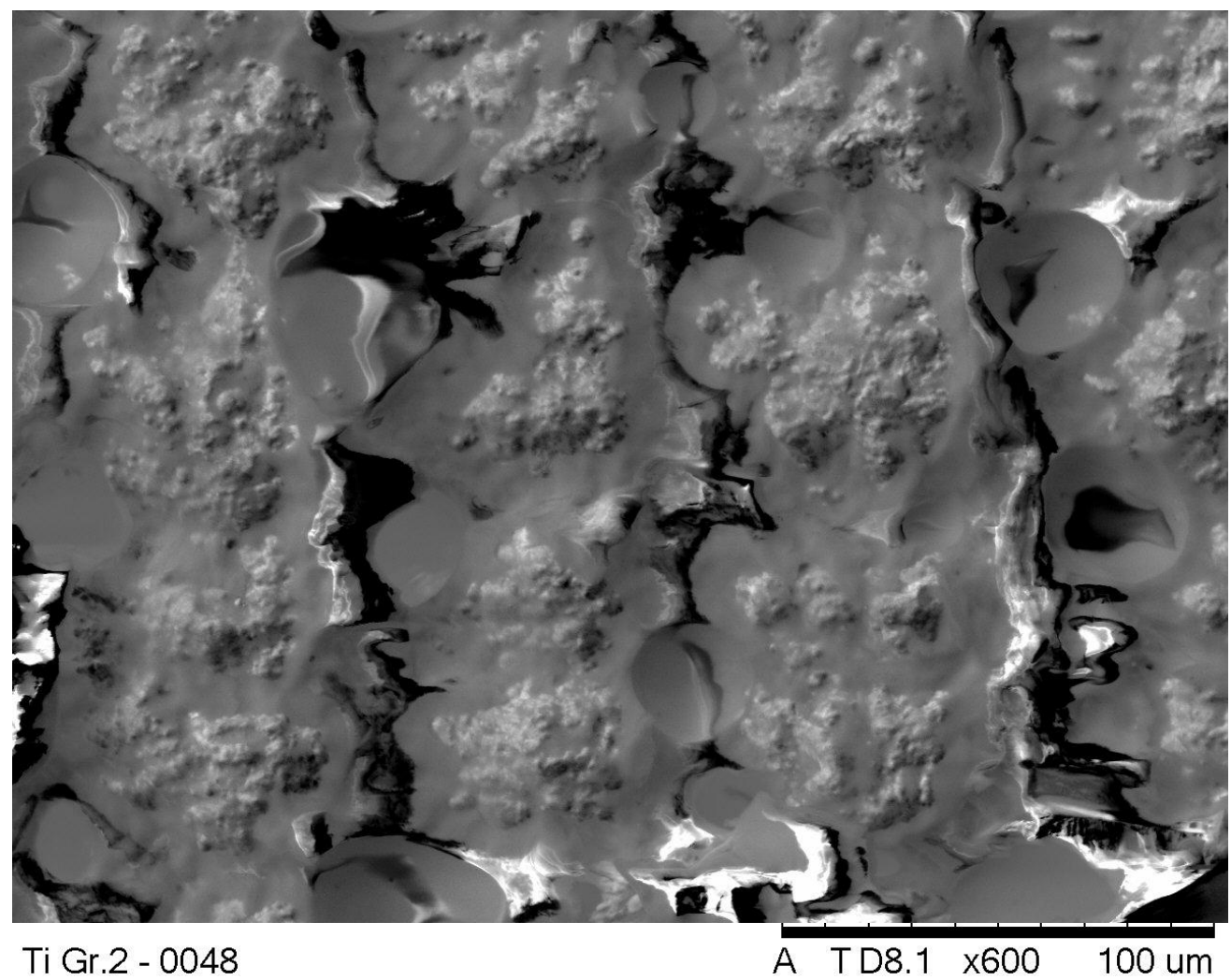

FIGURA 70 - Imagem de MEV após ruptura por cisalhamento da amostra 3 da texturização 01 no Ti Gr. 2 CP. Aumento de 600x.

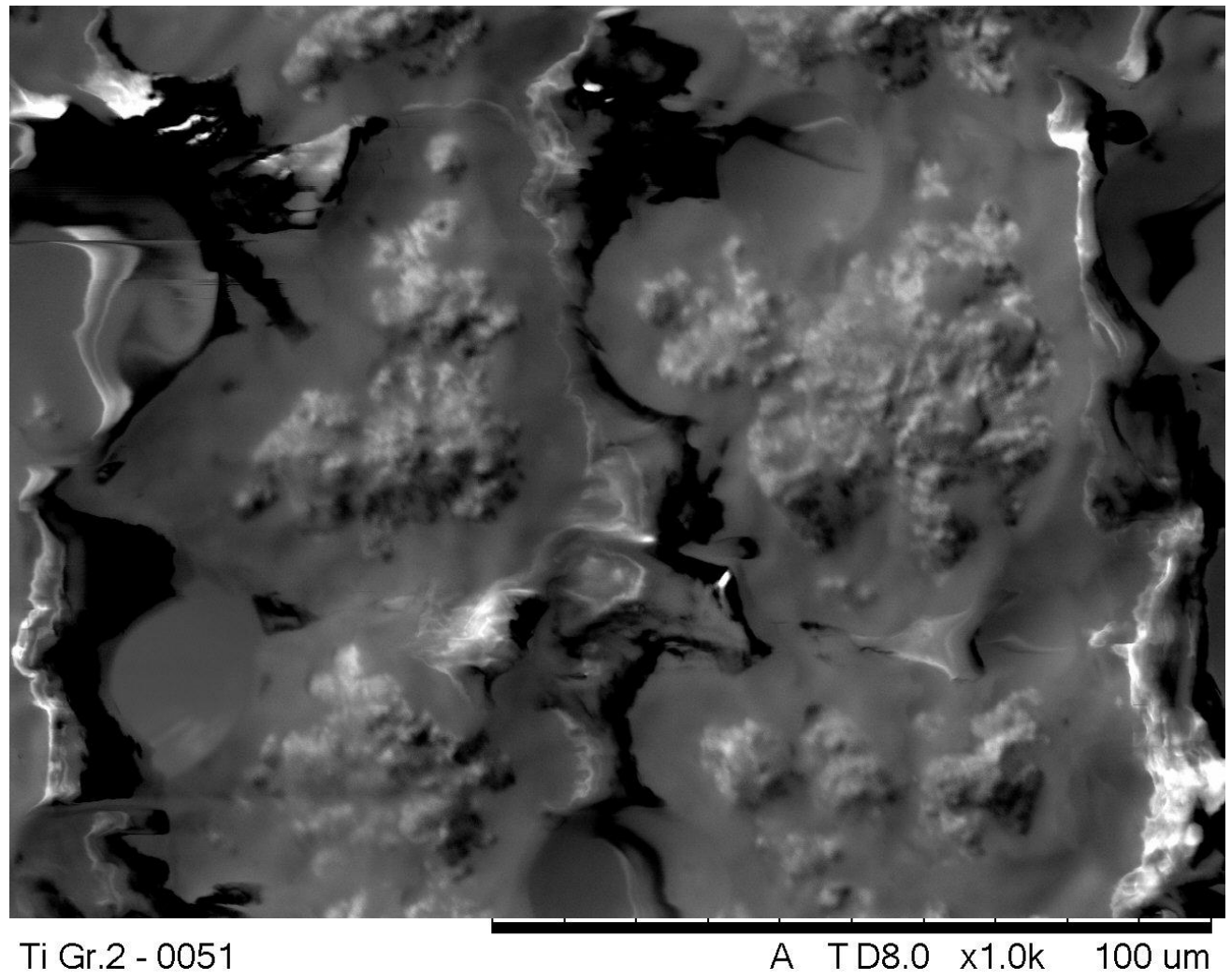

FIGURA 71 - Imagem de MEV após ruptura por cisalhamento da amostra 3 da texturização 01 no Ti Gr. 2 CP. Aumento de 1000x. 


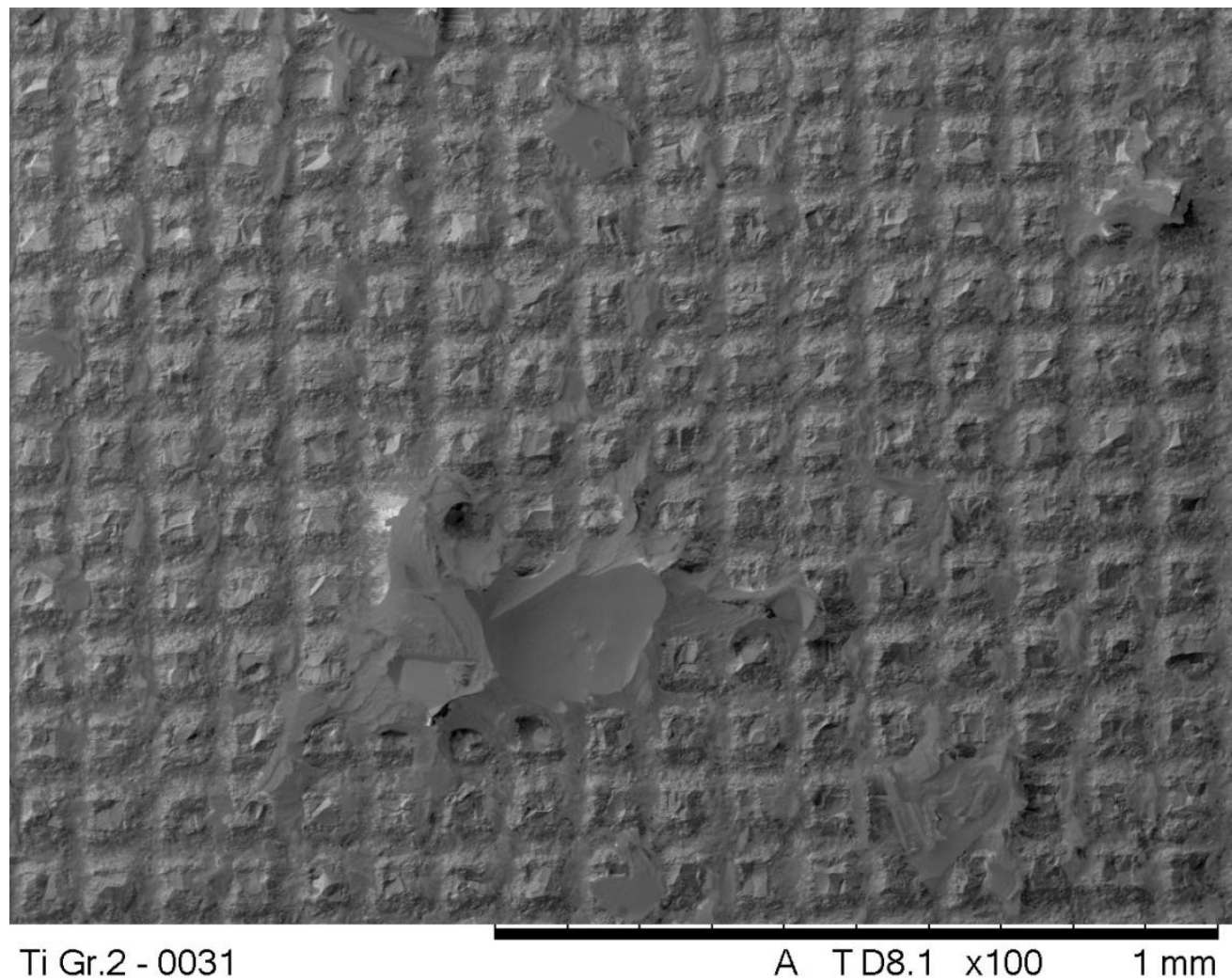

FIGURA 72 - Imagem de MEV após ruptura por cisalhamento da amostra 1 da texturização 02 no Ti Gr. 2 CP. Aumento de 100x.

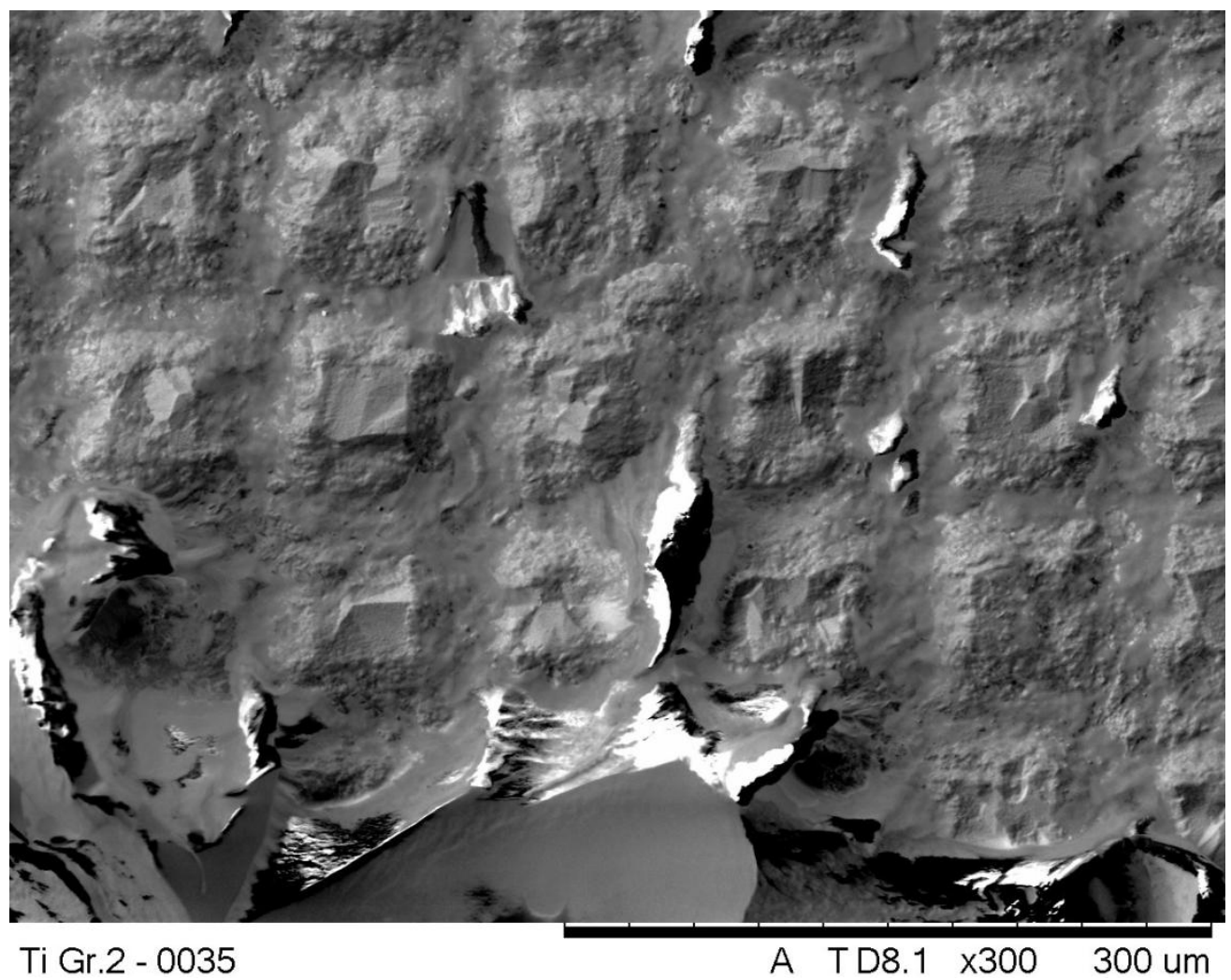

FIGURA 73 - Imagem de MEV após ruptura por cisalhamento da amostra 1 da texturização 02 no Ti Gr. 2 CP. Aumento de 300x. 


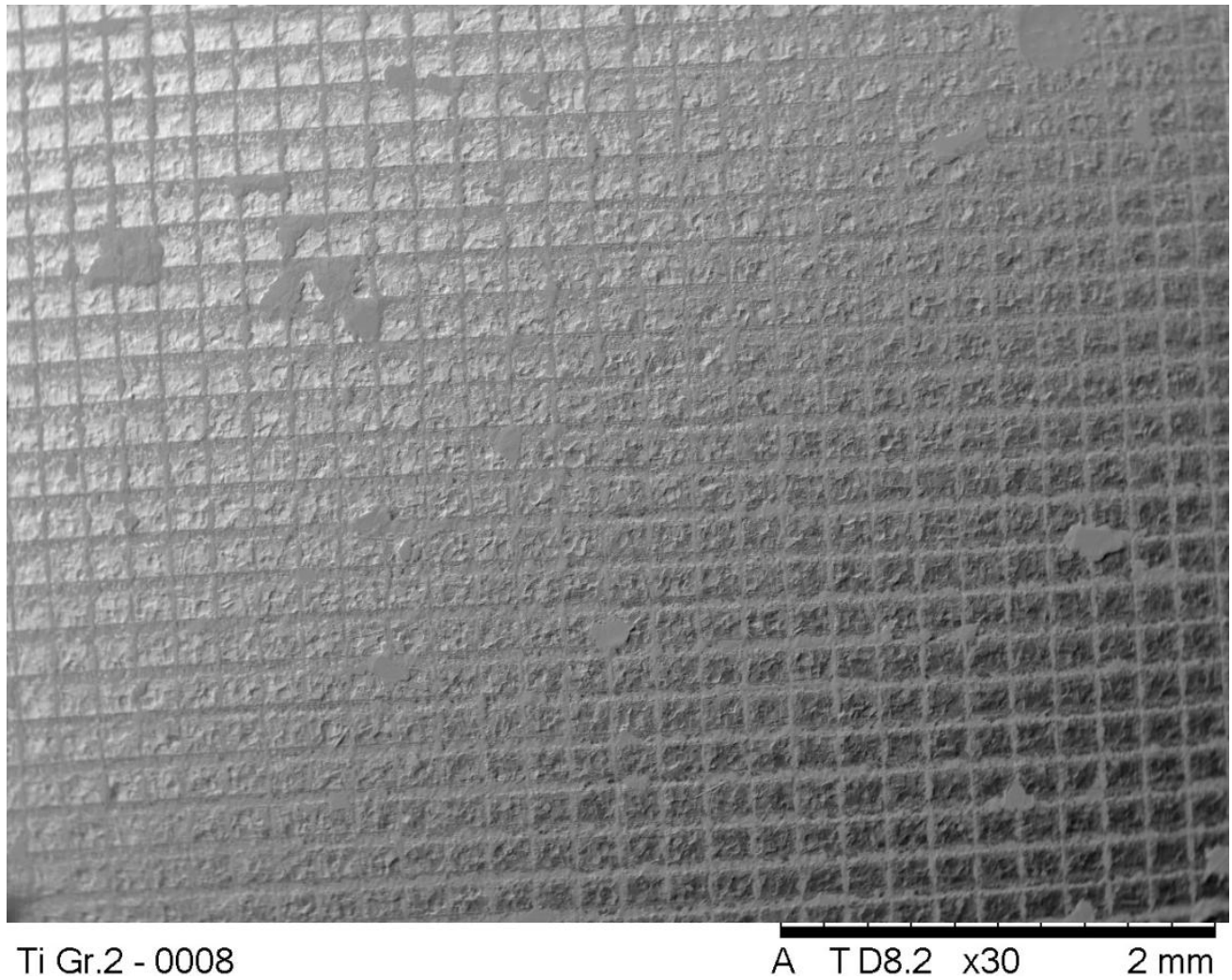

FIGURA 74 - Imagem de MEV após ruptura por cisalhamento da amostra 1 da texturização 03 no Ti Gr. 2 CP. Aumento de 30x.

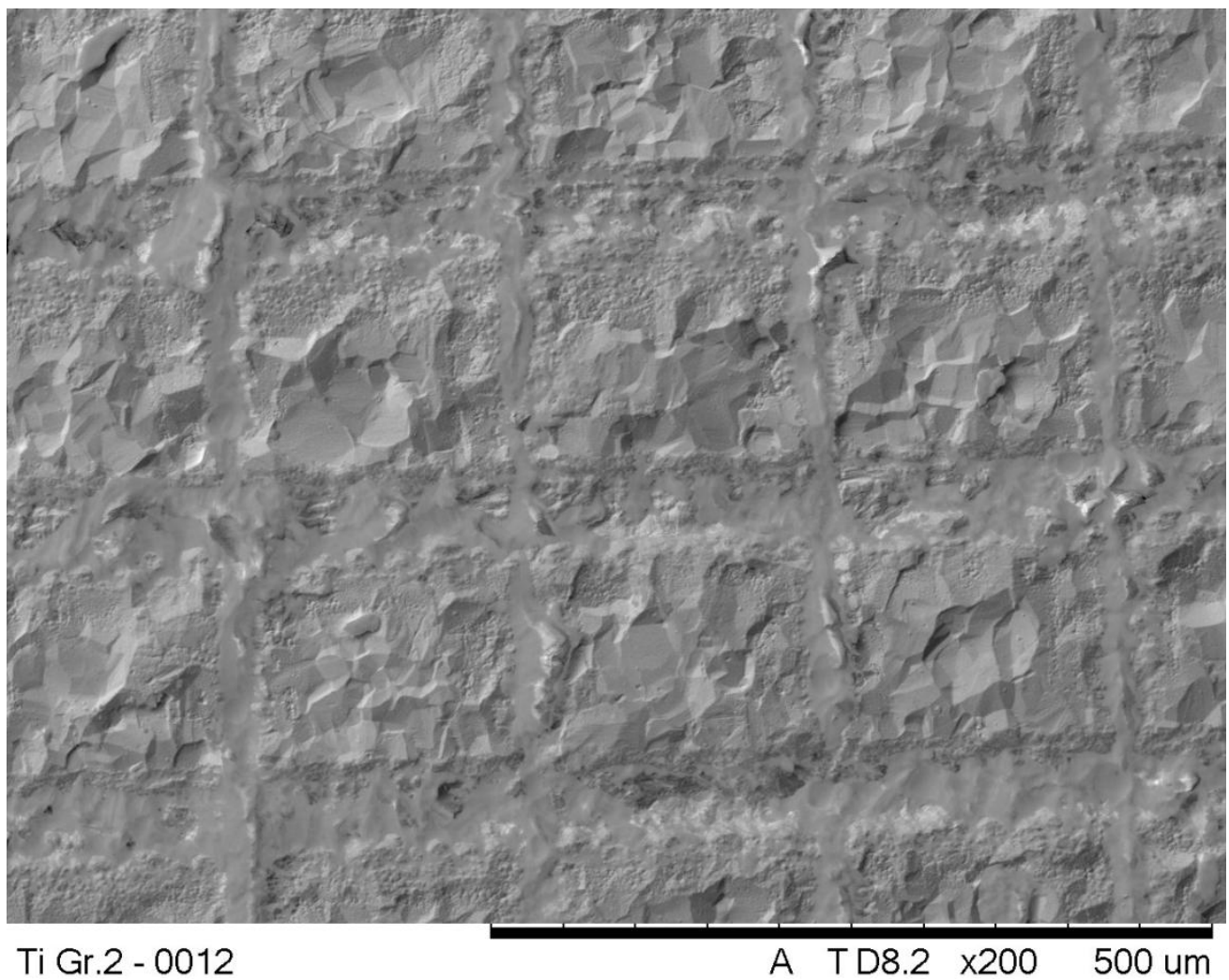

FIGURA 75 - Imagem de MEV após ruptura por cisalhamento da amostra 1 da texturização 03 no Ti Gr. 2 CP. Aumento de 200x. 
Analisando as imagens é claro notar que o adesivo penetrou nas linhas texturizadas e que de uma forma geral não se observa a presença de nenhum resquício na região não usinada, ou seja, no topo das texturizações. Isto permite concluir que o cisalhamento ocorreu de uma forma relativamente uniforme ao longo de toda a área texturizada, ocorrendo o arrancamento por completo da cola na região de contato com o CFRP (topo das regiões texturizadas).

Na TAB. 17 estão os valores das áreas de colagem para cada amostra após as medições realizadas e as tensões de ruptura ao cisalhamento da junta adesiva.

TABELA 17 - Áreas de colagem e Tensão de ruptura ao cisalhamento

\begin{tabular}{cccc}
\hline Texturização & Amostra & Área $\left(\mathrm{mm}^{2}\right)$ & $\begin{array}{c}\text { Tensão de ruptura } \\
\text { ao cisalhamento } \\
(\mathrm{MPa})\end{array}$ \\
\hline \multirow{2}{*}{01} & 1 & $93,71 \pm 0,20$ & $---^{*}$ \\
& 2 & $93,11 \pm 0,20$ & $20,35 \pm 0,08$ \\
& 3 & $89,81 \pm 0,20$ & $21,29 \pm 0,08$ \\
02 & 1 & $99,05 \pm 0,20$ & $18,82 \pm 0,08$ \\
& 2 & $91,24 \pm 0,20$ & $19,48 \pm 0,08$ \\
& 3 & $97,84 \pm 0,20$ & $19,52 \pm 0,08$ \\
02 & $1 \mathrm{~A}$ & $91,31 \pm 0,20$ & $19,03 \pm 0,08$ \\
& $2 \mathrm{~A}$ & $92,09 \pm 0,20$ & $20,50 \pm 0,08$ \\
& $3 \mathrm{~A}$ & $101,08 \pm 0,20$ & $18,39 \pm 0,08$ \\
& 1 & $94,98 \pm 0,20$ & $17,41 \pm 0,08$ \\
& 2 & $96,18 \pm 0,20$ & $18,69 \pm 0,08$ \\
& 3 & $96,47 \pm 0,20$ & $16,61 \pm 0,08$ \\
& $1 \mathrm{~A}$ & $98,25 \pm 0,20$ & $16,86 \pm 0,08$ \\
& $2 \mathrm{~A}$ & $95,07 \pm 0,20$ & $16,42 \pm 0,08$ \\
& $3 \mathrm{~A}$ & $98,88 \pm 0,20$ & $17,67 \pm 0,08$ \\
\hline
\end{tabular}

* valor foi descartado em função de problema ocorrido durante o ensaio.

Na TAB. 18 são apresentadas as médias e erros baseados nos desvios padrões dos resultados apresentados na TAB. 17. Para tal foram consideradas duas amostras da texturização 01, seis amostras da texturização 02 e seis amostras da texturização 03 . Podem ser analisados os resultados também pelo gráfico da FIG. 76. 
TABELA 18 - Médias e desvios padrões dos resultados da tensão de ruptura ao cisalhamento

\begin{tabular}{cc}
\hline \multicolumn{1}{c}{ Texturização } & $\begin{array}{c}\text { Média da Tensão de ruptura } \\
\text { ao cisalhamento } \\
(\mathrm{MPa})\end{array}$ \\
\hline 01 (passo de $75 \mu \mathrm{m})$ & $19,49 \pm 0,66$ \\
02 (passo de $100 \mu \mathrm{m})$ & $18,21 \pm 1,02$ \\
03 (passo de $200 \mu \mathrm{m})$ & $17,28 \pm 0,89$ \\
\hline
\end{tabular}

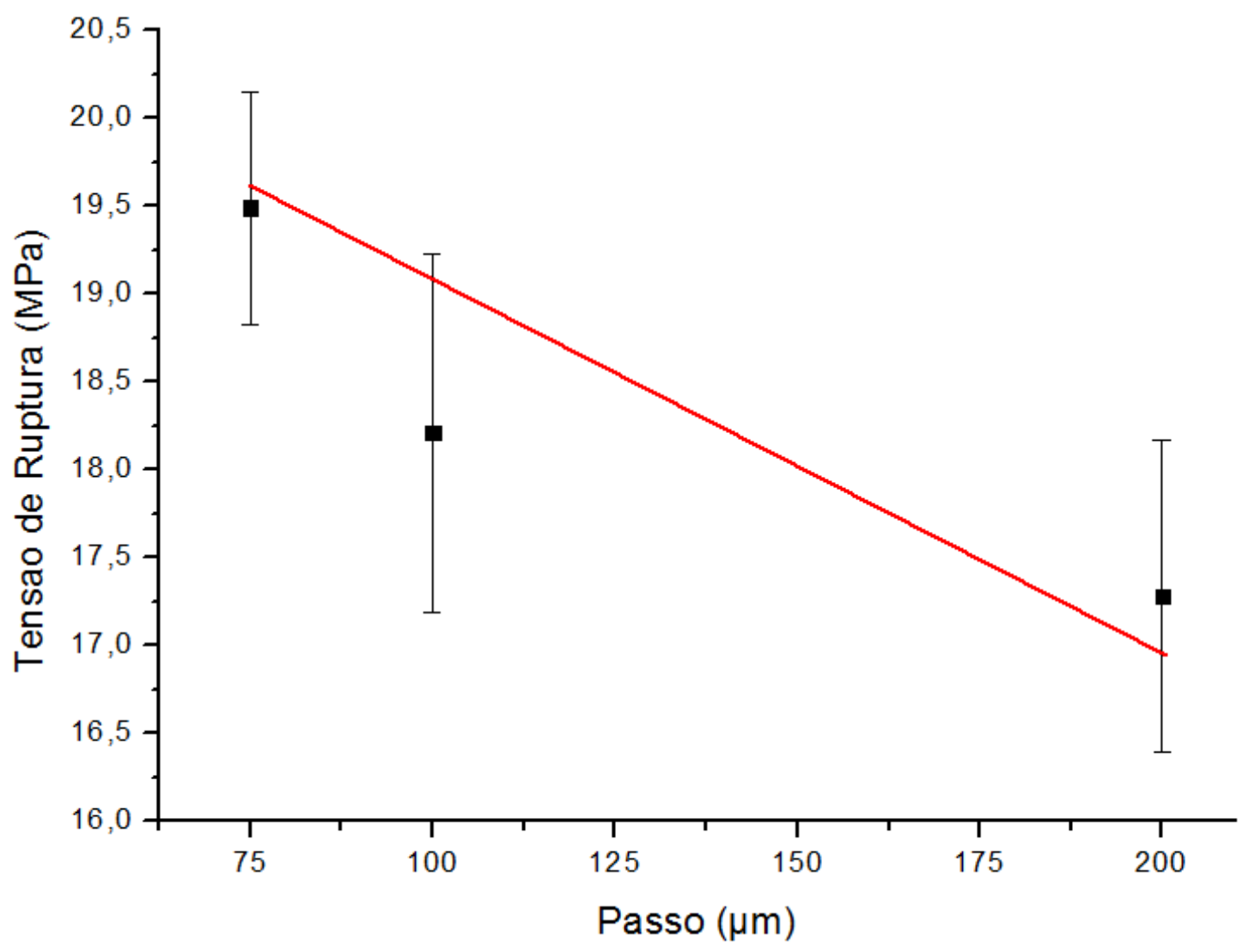

FIGURA 76 - Imagem de MEV após ruptura por cisalhamento da amostra 1 da texturização 03 no Ti Gr. 2 CP. Aumento de 200x.

Como pode ser visto nos resultados da TAB. 18 e no gráfico da FIG. 76, há o aumento da resistência ao cisalhamento com a diminuição do passo de texturização, ou seja, com a redução da distância entre as linhas texturizadas. Analisando somente sob o ponto de vista da molhabilidade, poderia ser esperado que a cola fluísse de forma mais fácil nas superfícies com menor ângulo de contato, isto é, mais hidrofílicas. No entanto, na texturização 01 que é onde há o maior número de células unitárias, o maior volume específico e total e ainda uma 
maior área de contato na junta adesiva, a cola preencheu todas as lacunas da texturização e com isto promoveu uma maior resistência à adesão. Nesta linha de análise, o comportamento mostrou-se coerente visto que a texturização 03 que possui o menor volume específico e total apresentou a menor resistência.

Além disto, um fator que influenciou a eficiência da junta adesiva é a irregularidade das superfícies. A texturização 01, conforme visto na FIG. 54, possui as superfícies no topo de cada célula unitária com um aspecto muito mais irregular, o que contribuiu para que a cola tivesse uma maior área de contato com o titânio. Na texturização 01 nota-se que a superfície texturizada apresenta uma irregularidade maior que na texturização 02 (FIG. 55), que por sua vez também é mais irregular que a texturização 03 (FIG. 56). Isto ocorre devido à distância entre as linhas de usinagem, ou seja, quanto menor o passo de texturização maior é o efeito do laser na célula unitária vizinha, pois há uma influência mais pronunciada do regime de baixa fluência. Assim, a superfície entre as linhas de usinagem sofre alterações em sua topologia, tornando-a mais irregular. Desta forma, a região onde ocorre o maior dano, que é o centro da linha, é onde se tem a usinagem no regime de alta fluência. A FIG. 77 apresenta imagem de MEV com linhas feitas na determinação do limiar de ablação pelo método D-Scan, onde é possível ver a região afetada pelo regime de baixa fluência, que é a região vizinha à linha usinada. Estas linhas foram executadas com fluência de energia por pulso e sobreposição similares às condições em que foram realizadas as texturizações.

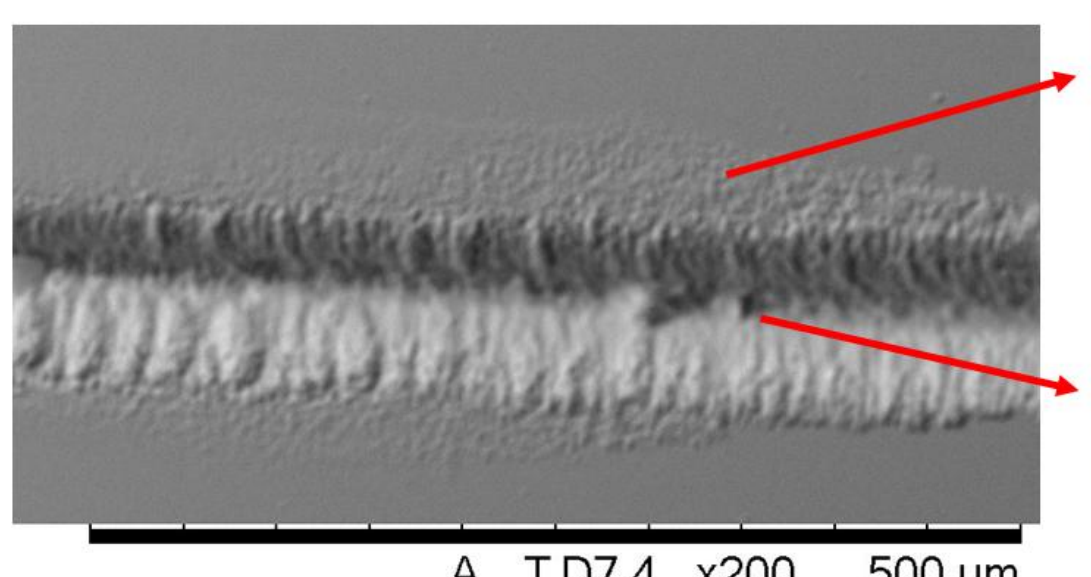

Região vizinha afetada pelo regime de baixa fluência

Linha texturizada - no centro da linha ocorre a máxima fluência

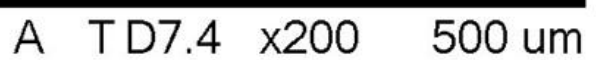

FIGURA 77 - Imagem de MEV de linha realizada no método D-Scan com fluência de energia por pulso e sobreposição similares às condições das texturizações. Aumento de 200x. 
Contudo, pela análise dos limites de erros da TAB. 18, os resultados podem ser considerados equivalentes para as texturizações 02 e 03, visto que os limites inferior e superior se sobrepõem. Mesmo com a proximidade dos resultados, a texturização 01 apresenta uma maior resistência ao cisalhamento da junta adesiva. 


\section{CONCLUSÕES}

As chapas de 0,1 mm de espessura de Ti Gr. 2 CP que foram texturizadas utilizando o laser chaveado com pulsos de nanossegundos, apresentaram excessivas distorções e empenamentos. Além disto, foi contatada a presença de grande quantidade de material ressolidificado na região texturizada, com uma topologia lisa e uma profundidade usinada baixa. Os resultados obtidos com este processo não são aceitáveis à aplicação final do titânio, que é a adesão ao CFRP.

Por meio da obtenção dos limiares de ablação para o Ti Gr. 2, pelo laser com pulsos ultracurtos de femtossegundos, através da realização dos experimentos pelos métodos do Dano Zero e D-Scan foi possível a determinação dos regimes de alta e baixa fluência. Foram obtidos valores diferentes para cada método, sendo que para o método do Dano Zero os valores são menores devido à distribuição espacial constante.

Foi utilizada a estratégia de se atuar no regime de alta fluência para produzir uma textura de "traços em malha", que mostrou-se eficiente. Através do conhecimento dos limiares de ablação, foram realizadas diversas microusinagens em chapas de 0,1 mm de espessura de Ti Gr. 2 CP, e como resultado foram definidos os parâmetros para a realização de texturizações em três condições. Tais texturizações foram realizadas atuando no regime de alta fluência, visto que mesmo nesta condição não acarretou em distorções e empenamento às chapas além de que o material fundido foi totalmente expelido para fora da região processada, deixando uma superfície livre de material ressolidificado. O tempo de aquecimento, e/ou a energia introduzida não foram suficientes para produzir uma ZTA suficientemente grande para ser detectada, além de ter promovido uma satisfatória profundidade.

A análise das texturizações realizadas permitiu a mensuração da molhabilidade e dos volumes específicos para cada célula unitária bem como o volume total disponível para o preenchimento com o adesivo estrutural. Desta forma, foi verificado que quanto maior o número de células unitárias, maior o volume total para a penetração da cola e maior a área de contato da junta adesiva. Não há uma relação entre a molhabilidade com a facilidade de fluidez da 
cola, visto que as condições mais favoráveis para se promover uma junta mais eficiente foram justamente para as superfícies mais hidrofóbicas.

A aderência do Ti Gr. 2 CP ao CFRP apresentou uma maior resistência ao cisalhamento nas texturizações com menor passo entre as linhas usinadas, ou seja, onde havia o maior o volume disponível para a penetração da cola e maior área de contato, a resistência ao cisalhamento da junta adesiva foi maior. Contudo, pode-se dizer que os valores foram relativamente próximos para as três texturizações realizadas. Concomitantemente, a adesão nas amostras de Ti Gr. 2 CP sem texturização não se mostrou eficiente, uma vez que a junta adesiva não apresentou tenacidade suficiente e simplesmente não se manteve colada.

Desta forma, a utilização de laser com pulsos ultracurtos mostrou-se extremamente satisfatória para a realização de texturizações em Ti Gr. 2 CP, com a possibilidade de realização de microusinagens com variações nas geometrias e que possibilitem diferentes resistências ao cisalhamento às juntas adesivas, mantendo a integridade do material e com ótima qualidade da região ablacionada. 


\section{REFERÊNCIAS BIBLIOGRÁFICAS}

1 SAMAD, R. E.; MACHADO, L. M.; VIEIRA Jr., N. D.; ROSSI, W. d. Ultrashort Laser Pulses Machining. In: I. Peshko (Ed.) Laser Pulses Theory, Technology, and Applications, InTech, p. 143-174, 2012.

2 LIMA, M. S. F.; SAKAMOTO, J. M. S.; SIMOES, J. G. A.; RIVA, R. Laser processing of carbon fiber reinforced polymer composite for optical fiber guidelines. Physics Procedia, v. 41, p. 572-580, 2013.

3 MOLITOR, P.; BARRON, V.; YOUNG, T. Surface treatment of titanium for adhesive bonding to polymer composites: a review. International Journal of Adhesion and Adhesives, v. 21, n. 2, p. 129-136, 2001.

4 MOLITOR, P.; YOUNG, T. Investigations into the use of excimer laser irradiation as a titanium alloy surface treatment in a metal to composite adhesive bond. International Journal of Adhesion and Adhesives, v. 24, n. 2, p. 127-134, 2004.

5 PRONKO, P. P.; DUTTA, S. K.; SQUIER, J.; RUDD, J. V.; DU, D.; MOUROU, G. Machining of sub-micron holes using a femtosecond laser at 800 nm. Optics Communications, v. 114, n. 1-2, p. 106-110, 1995.

6 JANDELEIT, J.; HORN, A.; WEICHENHAIN, R.; KREUTZ, E. W.; POPRAWE, R. Fundamental investigations of micromachining by nanoand picosecond laser radiation. Applied Surface Science, v. 127-129, p. 885-891, 1998.

7 STRICKLAND, D.; MOUROU, G. Compression of amplified chirped optical pulses. Optics Communications, v. 56, n. 3, p. 219-221, 1985.

8 KELLER, U. Ultrafast solid-state laser oscillators: a success story for the last 20 years with no end in sight. Applied Physics B- Lasers and Optics, v. 100 , p. 15-28, 2010.

9 MACHADO, L. M. Microusinagem de dielétricos com pulsos laser de femtossegundos. (Tese de Doutorado) - Instituto de Pesquisas Energéticas e Nucleares, São Paulo, 2012.

10 BULGAKOVA, N. M.; STOIAN, R.; ROSENFELD, A.; HERTEL I. V.; CAMPBELL, E. E. B. Electronic transport and consequences for material removal in ultrafast pulsed laser ablation of materials. Physical Review BCondensed Matter and Materials Physics, v. 69, n. 5, 054102, 2004.

11 ASHKENASI, D.; ROSENFELD, A.; STOIAN, R. Laser-induced incubation in transparent materials and possible consequences for surface and bulk micro-structuring with ultrashort pulses. Society of Photo-Optical Instrumentation Engineers (SPIE), v. 4633, 2002. 
12 LIU, J. M. Simple technique for measurements of pulsed Gaussian-beam spot sizes. Optics Letters, v. 7, n. 5, p. 196-198, 1982.

13 SAMAD, R. E.; VIEIRA, N. D. Geometrical method for determining the surface damage threshold for femtosecond laser pulses. Laser Physics, v. 16, n. 2, p. 336-339, 2006.

14 ARNOLD, D.; CARTIER, E. Theory of laser-induced free-electron heating and impact ionization in wide-band-gap solids. Physical Review B, v. 46, n. 23, p. 15102, 1992.

15 JONES, S. C. et al. Recent progress on laser-induced modifications and intrinsic bulk damage of wide-gap optical materials. Optical Engineering, v. 28 , p. $1039-1068,1989$.

16 PROKHOROV, A. M.; KONOV, V. I.; URSU, I.; MIHAILESCU, I. N. Laser heating of metals. Bristol, Philadelphia, PA: Adam Hilger, 1990.

17 DULEY, W. W. UV lasers: effects and applications in materials science, New York, N.Y.: Cambridge University Press, 2005.

18 NEDIALKOV, N. N.; IMAMOVA, S. E.; ATANASOV, P. A.; HEUSEL, G.; BREITLING, D.; RUF, A.; HÜGEL, H.; DAUSINGER, F.; BERGER, P. Laser ablation of iron by ultrashort laser pulses. Elsevier J. - Thin Solid Films, v. 453-454, p. 496-500, 2004.

19 NOLTE, S., MOMMA, C.; JACOBS, H.; TÜNNERMANN, A.; CHICHKOV, B.N.; WELLEGEHAUSEN, B.; WELLING, H. Ablation of metals by ultrashort laser pulses. Journal of the Optical society of America B, v. 14, n. 10, p. 2716-2722, 1997.

20 ANISIMOV, S.I.; KAPELIOVICH, B.L.; PEREL'MAN, T.L. Electron emission from metal surfaces exposed to ultrashort laser pulses, Soviet Physics Jept, v. 39, n. 2, p. 375-377, 1974.

21 NOLTE, S. Micromachining. In: Martin E. Fermann, Almantas Galvanauskas, and Gregg Sucha (Ed.) Ultrafast Lasers - Technology and Applications, CRC Press, chapter 7, 2002.

22 VON DER LINDE, D.; SOKOLOWSKI-TINTEN, K.; BIALKOWSKI, J. Lasersolid interaction in the femtosecond time regime. Elsevier J. - Applied Surface Science, v.109-110, p. 1-10, 1997.

23 DU, D.; LIU, X.; KORN, G.; SQUIER, J.; MOUROU, G. Laser-induced breakdown by impact ionization in Si02 with pulse widths from 7 ns to 150 fs. Applied Physics Letters, v. 64, p. 3071-3073, 1994.

24 STUART, B. C.; FEIT, M. D.; HERMAN, S.; RUBENCHIK, A. M.; SHORE, B. W.; PERRY, M. D.; Nanosecond-to-femtosecond laser-induced breakdown in dielectrics. Physical Review B, v. 53, p. 1749-1761, 1996. 
25 LORAZO, P.; LEWIS, L. J.; MEUNIER, M. Short-pulse laser ablation of solids: From phase explosion to fragmentation. Physical Review Letters, v. 91 , p. 225502-1-225502-4, 2003.

26 ZHIGILEI, L. V. Dynamics of the plume formation and parameters of the ejected clusters in short-pulse laser ablation. Applied Physics AMaterials Science and Processing, v. 76, p. 339-350, 2003.

27 STUART B. C.; FEIT, M.; RUBENCHIK, A.; SHORE, B.; PERRY, M. LaserInduced Damage in Dielectrics with Nanosecond to Subpicosecond Pulses. Physical Review Letters, v. 74, p. 2248-2251, 1995.

28 KAUTEK, W.; KRUGER, J.; LENZNER, M.; SARTANIA, S.; SPIELMANN, C.; KRAUSZ, F.; Laser ablation of dielectrics with pulse durations between 20 fs and 3 ps. Physical Review Letters, v. 69, p. 3146-3148, 1996.

29 KELDYSH, L. V. Ionization in the field of a strong electromagnetic wave. Soviet Physics Jept, v. 20, n. 5, p. 1307-1314, 1965.

30 JOGLEKAR, A. P.; LIU, H.; SPOONER, G. J.; MEYHOFER, E.; MOUROU, G.; HUNT, A. J. A study of the deterministic character of optical damage by femtosecond laser pulses and applications to nanomachining. Applied Physics B- Lasers and Optics, v. 77, p. 25-30, 2003.

31 GAMALY, E. G.; RODE, A. V.; LUTHER-DAVIES, B.; TIKHONCHUK, V. T. Ablation of solids by femtosecond lasers: ablation mechanism and ablation thresholds for metals and dielectrics. Physics of Plasmas, v. 9, n. 3, p. 949-957, 2002.

32 STOIAN, R.; ROSENFELD, A.; ASHKENASI, D.; HERTEL, I. V.; BULGAKOVA, N. M.; CAMPBELL, E. E. B. Surface charging and impulsive ion ejection during ultrashort pulsed laser ablation. Physical Review Letters, v. 88, 097603, 2002.

33 BORGHESI M.; ROMAGNANI, L.; SCHIAVI, A.; CAMPBELL, D. H.; HAINES, M. G.; WILLI, O.; MACKINNON, A. J.; GALIMBERTI, M.; GIZZI, L.; CLARKE, R. J.; HAWKES, S. Measurement of highly transient electrical charging following high-intensity laser-solid interaction. Applied Physics Letters, v. 82, p. 1529-1531, 2003.

34 KANAVIN, A. P.; SMETANIN, I. V.; ISAKOV, V. A.; AFANASIEV, Y. V.; CHICHKOV, B. N.; WELLEGEHAUSEN, B.; NOLTE, S.; MOMMA, C. TUNNERMANN, A. Heat transport in metals irradiated by ultrashort laser pulses. Physical Review B, v. 57, p. 14698-14703, 1998.

$35 \mathrm{SINGH}, \mathrm{N}$. Relaxation between electrons and surface phonons of a homogeneously photoexcited metal film. Pramana Journal Physics, v. 63, p. 1083-1087, 2004. 
36 HIRAYAMA, Y.; OBARA, M. Heat effects of metals ablated with femtosecond laser pulses. Applied Surface Science, v. 197-198, p. 741745, 2002.

37 REIF, J.; COSTACHE, F. Femtosecond laser interaction with solid surfaces: explosive ablation and self-assembly of ordered nanostructures. In: Rempe G, Scully M. (Ed.) Advances in Atomic, Molecular, and Optical Physics, v. 53. San Diego: Elsevier Academic Press Inc., p. 228-249, 2006.

38 BAUER, J. R. O. Propriedades mecânicas do titânio comercialmente puro e da liga Ti-6Al-4V fundidos em diferentes ambientes. (Tese de Doutorado) - Universidade de São Paulo, São Paulo, 2007.

39 SILVA, D. R. Análise da influência dos gases de proteção nas propriedades da solda a laser da liga Ti-6Al-4V. (Dissertação de Mestrado) - Instituto de Pesquisas Energéticas e Nucleares, São Paulo, 2008.

40 AMERICAN SOCIETY OF MATERIALS. Metals Handbook volume 2Properties and selection: nonferrous alloys and special-purpose materials. 10 ${ }^{a}$ ed., New York, NY.: ASM, 1992.

41 LU, J.; Society for Experimental Mechanics. Handbook of Measurements of Residual Stress. V. 2, 2 ed., Lilburn, GA: Fairmont Press, 2005.

42 MIRIM, D. C. Investigação da tensão residual na soldagem laser entre o aço carbono AISI 1010 e o aço inoxidável AISI 304. (Dissertação de Mestrado) - Instituto de Pesquisas Energéticas e Nucleares, São Paulo, 2011.

43 WALMSLEY, A.; WAXER, L.; DORRER, C. The role of dispersion in ultrafast optics, Review of Scientific Instruments, v. 72, n. 1, 2001.

44 DORRER, C. Chromatic dispersion characterization by direct instantaneous frequency measurement, Optlcs Letters, v. 29, n. 2, p. 204-206, 2004.

45 VIDAL, J. T. Desenvolvimento de um sistema opto-mecânico para microusinagem com laser de femtossegundo. (Dissertação de Mestrado) - Instituto de Pesquisas Energéticas e Nucleares, São Paulo, 2010.

46 AMERICAN SOCIETY FOR TESTING AND MATERIALS. Standard Specification for Unalloyed Titanium, for Surgical Implant Applications. West Conshohocken, PA.: ASTM, 2013 (ASTM F67-13 UNS R50400).

47 SIEGMAN, A.E.; Lasers. Salsalito, CA.: University Science Books, 1986.

48 AMERICAN SOCIETY FOR TESTING AND MATERIALS. Standard Test Method for Surface Wettability and Absorbency of Sheeted Materials 
Using an Automated Contact Angle Tester. West Conshohocken, PA.: ASTM, 2008 (ASTM D5725-99).

49 LUO, K. Y.; LU, J. Z.; WANG, Q. W.; LUO, M.; QI, H.; ZHOU, J. Z. Residual stress distribution of Ti-6Al-4 V alloy under different ns-LSP processing parameters. Applied Surface Science, v. 285, part B, p. 607-615, 2013.

50 AMERICAN SOCIETY FOR TESTING AND MATERIALS. Standard Test Method for Apparent Shear Strength of Single-Lap-Joint Adhesively Bonded Metal Specimens by Tension Loading (Metal-to-Metal). West Conshohocken, PA.: ASTM, 2010 (ASTM D1002-10).

51 AMERICAN SOCIETY FOR TESTING AND MATERIALS. Standard Test Method for Lap Shear Adhesion for Fiber Reinforced Plastic (FRP) Bonding. West Conshohocken, PA.: ASTM, 2014 (ASTM D5868-01).

52 IGAMI, M. P. Z.; ZARPELON, L. M. C. (Org). Guia para a elaboração de dissertações e teses: preparado para orientação dos alunos de Pósgraduação do IPEN. São Paulo: IPEN, Divisão de Informação e Documentação Científicas, 2002. Disponível em:

https://www.ipen.br/conteudo/upload/200609111605540.guia_teses.pdf. Acesso em: 01/12/2014. 